Luciana Nunes Silva Souza

\title{
Doença de Hodgkin: análise do protocolo $\mathrm{DH}-\mathrm{II}-90$
}

Dissertação apresentada à Faculdade de Medicina da Universidade de São Paulo para obtenção do título de Mestre em Ciências

Área de concentração: Pediatria Orientadora: Profa. Dra. Lílian Maria Cristófani 
Dados Internacionais de Catalogação na Publicação (CIP)

Preparada pela Biblioteca da

Faculdade de Medicina da Universidade de São Paulo

Creprodução autorizada pelo autor

Souza, Luciana Nunes Silva

Doença de Hodgkin : análise do protocolo DH-II-90 / Luciana Nunes Silva

Souza. -- São Paulo, 2010.

Dissertação(mestrado)--Faculdade de Medicina da Universidade de São Paulo.

Departamento de Pediatria.

Área de concentração: Pediatria.

Orientadora: Lílian Maria Cristófani.

Descritores: 1.Doença de Hodgkin/quimioterapia 2.Doença de Hodgkin/radioterapia 3.Prognóstico 4.Criança

USP/FM/SBD-044/10 
À minha princesinha Alice, minha inspiração para viver 


\section{AGRADECIMENTOS}

\section{"Suddenly, as I saw what I had to face in acceptance of injustice - I knew that I couldn't take it"}

Com esta frase Dorothy Reed abandonou a patologia e agarrou a carreira de saúde pública. Tudo ocorreu logo após a sua descrição histopatológica da doença de Hodgkin - pela qual é lembrada até hoje, quando William Welch negou a ela uma vaga de professor na Johns Hopkins Medical School pelo fato de ser uma mulher. Não saberia ela, naquele momento, que seu nome seria lembrado e comentado até hoje nas milhares escolas médicas existentes em todo o mundo. Teria ela, talvez, muito mais acrescentado, se tivesse persistido um pouco mais.

Também o próprio Thomas Hodgkin talvez tivesse acrescentado muito mais conhecimento ao nosso mundo caso não houvesse levado tão a sério um desentendimento com Benjamin Harrison. O número de cadeiras para professores do hospital que trabalhava, o Guy, era limitado, e na época era necessário a morte ou aposentadoria de alguém para que ele pudesse ser promovido. Ele estava empolgado com o surgimento de uma vaga para professor assistente, porém foi prejudicado pelas suas atividades não médicas relacionadas a campanha que fazia em prol dos nativos da américa e contra o imperialismo imposto pelos países europeus. Travou então uma briga com Harrison o que acabou resultando no seu abandono na posição que tinha no Guy e deixando seu brilhantismo falar apenas pelo que já havia sido construído até então. Também acabou seguindo com algumas atividades em saúde pública de menor importância até a sua morte em 1866.

Estas duas histórias me levam a pensar: qual será o meu limite? onde será que quero chegar? o que devo superar para atingir objetivos? Por isto, inicio meus agradecimentos a eles dois, Hodgkin e Reed, que me levaram não só a escrever esta dissertação, mas também a pensar o meu futuro. 
No meu percurso, para chegar até aqui, muita gente me impulsionou e sou eternamente grata por isto.

Agradeço à minha família: meu pai, minha mãe, minha irmã e minha filha que reuniram minhas forças para que eu pudesse terminar este trabalho. Ao meu irmão que mesmo longe sei que torce por mim. À minha irmã do coração, Teco, que tem me ajudado sem igual. Aos meus tios, tias, primas e primos, à minha avó, pela alegria que me fazem sentir no meu coração.

Aos meus pequenos pacientes que humildemente me ensinam qual é o sentido real da vida.

À Dra. Lilian Maria Cristófani, minha orientadora, agradeço por toda delicadeza e paciência que me dedicou durante este trabalho. Não deve ser fácil uma orientação à distância que dê a segurança que tenho hoje como aluna.

Ao Prof. Dr. Vicente Odone Filho, pelo brilhantismo e simplicidade, a sua estrela continua iluminando meus caminhos.

Aos meus assistentes do ITACI, Dra. Teti, Dr. Roberto, Dr. Paulo, Dra. Ana Lúcia, Dra. Márcia e Dra. Evelyn, aprendi muito mais com vocês do que possam algum dia imaginar.

Aos funcionários do ITACI e do Instituto da Criança, em especial aos colegas do SAME, que nunca negaram meus enormes pedidos de ajuda.

À Dra. Sheila do serviço de patologia do Hospital das Clínicas da Faculdade de Medicina de São Paulo que contribuiu para a investigação deste estudo, apesar dos eventos adversos que ocorreram no seu setor.

Aos colegas do serviço de Radioterapia do Hospital das Clínicas da 
Faculdade de Medicina de São Paulo, em especial Dr. Eduardo Weltman que, com pequenas dicas, me fez entender o funcionamento deste serviço.

À minha amiga Alessandra Prandini que além de tudo é de uma solicitude sem tamanho, muito obrigada amiga!

À Elisa Saito Novais, amiga do peito, que me ajudou no entendimento dos conceitos de radioterapia, mas também no entendimento dos meus conflitos internos.

À Ana Maria Marinho e Claudia Mei com quem também tenho aprendido muito e dividido as angústias do dia-a-dia.

A todos os outros amigos meus que direta ou indiretamente me ajudaram, torceram e participaram deste trabalho. 


\section{NORMALIZAÇÃO ADOTADA}

Esta dissertação está de acordo com as seguintes normas, em vigor no momento desta publicação:

- Referências: adaptado de International Committee of Medical Journals Editors (Vancouver)

- Universidade de São Paulo. Faculdade de Medicina. Serviço de Biblioteca e Documentação. Guia de apresentação de dissertações, teses e monografias. Elaborado por Anneliese Carneiro da Cunha, Maria Julia de A. L. Freddi, Maria F. Crestana, Marinalva de Souza Aragão, Suely Campos Cardoso, Valéria Vilhena. 2a ed. São Paulo: Serviço de Biblioteca e Documentação; 2005.

- Abreviaturas dos títulos dos periódicos de acordo com List of Journals Indexed in Index Medicus. 


\section{SUMÁRIO}

Lista de abreviaturas

Lista de Tabelas

Lista de Figuras

Resumo

Summary

1. INTRODUÇÃO -------------------------------------------------------------------------- 01

1.1. Hipótese --------------------------------------------------------------------------------- 05

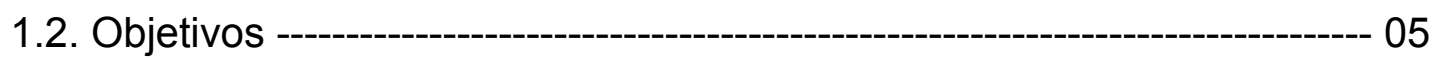

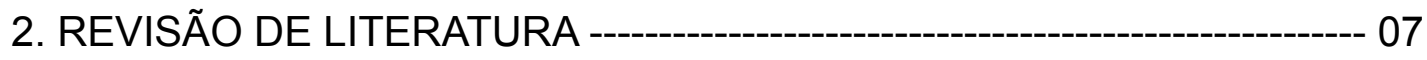

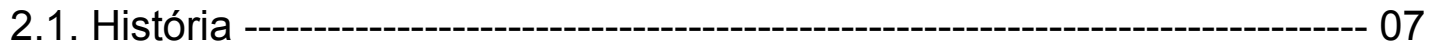

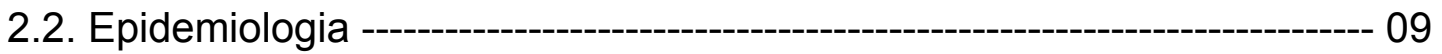

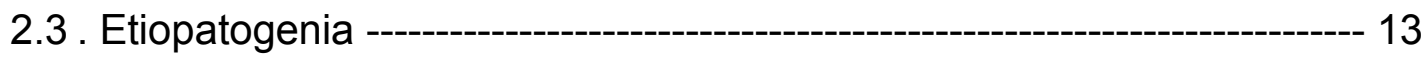

2.4 . Classificação --------------------------------------------------------------------------- 20

2.5 . Patologia --------------------------------------------------------------------------------- 25

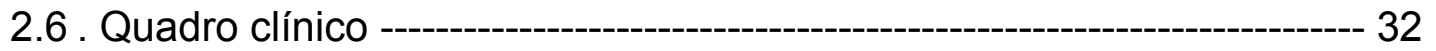

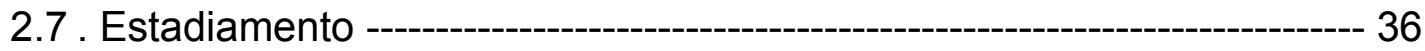

2.8 . Prognóstico -------------------------------------------------------------------------------- 40

2.9 . Tratamento ------------------------------------------------------------------------------ 43

3. PACIENTES E MÉTODOS ---------------------------------------------------------- 48

3.1. Critérios de inclusão ----_--- 49

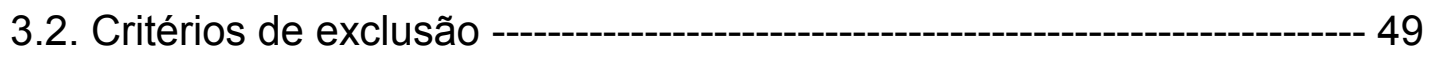


3.3. Análise dos dados -- 50

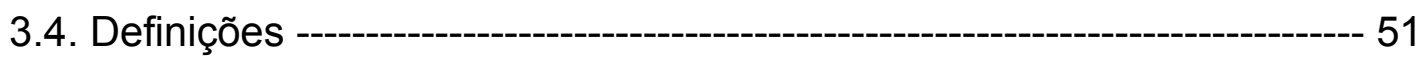

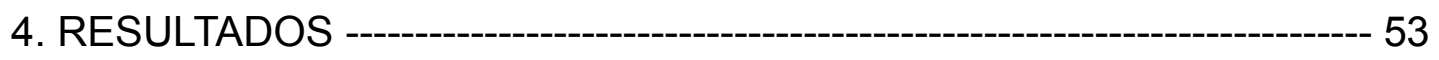

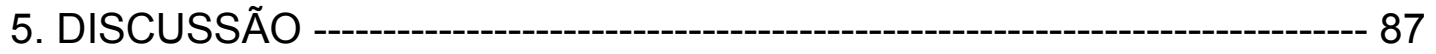

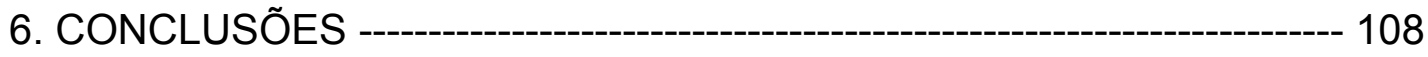

7. ANEXOS - 110

8. REFERÊNCIAS -----_-- 114 


\section{LISTA DE ABREVIATURAS}

ABVD

BEACOPP

COP

$\mathrm{DH}$

EBV

GHLSG

HRS

ICr-HC-FMUSP

L\&H

LP

MOPP

MOP

REAL

SG

SLE

SLD

VAMP

VEPA

WHO
Adriamicina, Bleomicina, Vinblastina, Dacarbazina

bleomicina, etoposido, adriamicina, ciclofosfamida, vincristina, procarbazina, prednisona

Ciclofosfamida, Vincristina, Prednisona

Doença de Hodgkin

Virus Epstein-Barr

"German Hodgkin Lymphoma Study Group"

Células de Hodgkin e Reed-Sternberg

Instituto da Criança do Hospital das Clínicas da Faculdade de Medicina da Universidade de São Paulo

Linfocíticas e Histiocíticas

Células de predominância linfocitária

Oncocloramin,Vincristina, Procarbazina, Prednisona

Oncocloramin, Vincristina, Prednisona

"Revised European-American Lymphoma"

Sobrevida global

Sobrevida livre de eventos

Sobrevida livre de doença

Vincristina, Doxorrubicina, Metotrexate, Prednisona

Vimblastina, etoposido, prednisona, doxorrubicina

"World Health Organization" 


\section{LISTA DE TABELA}

Tabela 1 - Equivalência entre as classificações histopatológicas de Rye (1966) e REAL (1994)

Tabela 2 - Diferenças histopatológicas e imunofenotípicas entre a Doença de Hodgkin de Predominância Linfocitária e a Doença de Hodgkin clássica 27

Tabela 3 - Sistema de estadiamento de Ann Arbor com as modificações

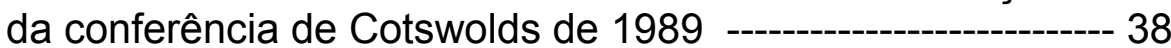

Tabela 4 - Características clínicas e laboratoriais dos pacientes tratados com o protocolo DH-II-90 56

Tabela 5 - Descrição de efeitos tardios descritos em prontuário por paciente 


\section{LISTA DE FIGURAS}

Figura 1 - Curva de estimativa de sobrevida livre de doença para todo o grupo de pacientes com doença de Hodgkin pelo método de Kaplan-Meier

Figura 2 - Curva de estimativa de sobrevida livre de doença para pacientes com doença de Hodgkin por estadiamento pelo método de Kaplan-Meier.

Figura 3 - Curva de estimativa sobrevida de livre de doença pela positividade (1) ou não (2) ao EBV em pacientes com doença de Hodgkin pelo método de Kaplan-Meier. --- 65

Figura 4 - Curva de estimativa de sobrevida livre de eventos para todo o grupo de pacientes com doença de Hodgkin pelo método de Kaplan-Meier

Figura 5 - Curva de estimativa de sobrevida livre de eventos para pacientes com doença de Hodgkin por estadiamento pelo método de Kaplan-Meier 68

Figura 6 - Curva de estimativa de sobrevida livre de eventos por faixa etária para pacientes com doença de Hodgkin pelo método de Kaplan-Meier 69

Figura 7 - Curva de estimativa de sobrevida livre de eventos pela ausência ou presença de doença "bulky" em pacientes com doença de Hodgkin pelo método de Kaplan-Meier 
Figura 8 - Curva de estimativa de sobrevida livre de eventos por tipo de radioterapia: campo envolvido versus campo estendido para pacientes com doença de Hodgkin pelo método de Kaplan-Meier

Figura 9 - Curva de estimativa de sobrevida livre de eventos para pacientes com doença de Hodgkin pela presença ou não de sintomas $B$ pelo método de Kaplan-Meier ----- 73

Figura 10 -Curva de estimativa de sobrevida livre de eventos para pacientes com doença de Hodgkin pela presença ou ausência de massa mediastinal pelo método de Kaplan-Meier

Figura 11 -Curva de estimativa de sobrevida livre de eventos por dose total de radioterapia ( 2100 cGy versus mais que 2100 cGy) para pacientes com doença de Hodgkin pelo método de Kaplan-Meier75

Figura 12 - Curva de estimativa de sobrevida livre de eventos para pacientes com doença de Hodgkin pela positividade ou não ao EBV pelo método de Kaplan-Meier 76

Figura 13 - Curva de estimativa de sobrevida global para todo o grupo de pacientes com doença de Hodgkin pelo método de Kaplan-Meier.

Figura 14 - Curva de estimativa de sobrevida global para pacientes com doença de Hodgkin por estadiamento pelo método de Kaplan-Meier

Figura 15 - Curva de estimativa de sobrevida global para pacientes com doença de Hodgkin pela positividade ou não ao EBV pelo método de Kaplan-Meier 
Figura 16 -Curva de estimativa de sobrevida livre de doença de pacientes com doença de Hodgkin pelo uso de MOP ou COP pelo método de Kaplan-Meier 85

Figura 17 - Curva de estimativa de sobrevida livre de eventos para pacientes com doença de Hodgkin pelo uso de MOP ou COP pelo método de Kaplan-Meier 86 


\section{RESUMO}

O tratamento da Doença de Hodgkin (DH) tem tido sucesso crescente nos últimos anos. Considerando que a taxa atual de cura situa-se ao redor de $85 \%$, o desafio dos protocolos da $\mathrm{DH}$ agora é reduzir a agressividade do tratamento e suas conseqüentes toxicidades agudas e crônicas, sem prejuízo dos resultados oncológicos. O protocolo $\mathrm{DH}-\mathrm{II}-90$ foi desenhado com estes propósitos para o tratamento de crianças e adolescentes com $\mathrm{DH}$. O protocolo consiste em três ciclos de ABVD (adriamicina, bleomicina, vinblastina e dacarbazina) e radioterapia em campo envolvido para pacientes de baixo risco, e acrescentando três ciclos de MOP (oncocloramin, vincristina e prednisona) ou COP (substituindo oncocloramin por ciclofosfamida) à quimioterapia e radioterapia em campo estendido para pacientes de alto risco. Objetivos: Este estudo visa: 1) avaliar as taxas de sobrevida global, livre de doença e livre de eventos do protocolo DH-II-90, 2) avaliar as taxas de sobrevida global e livre de eventos de acordo com o estádio, idade, presença de tumor "bulky", massa mediastinal, sintomas B, dose e tipo de radioterapia e 3) descrever os efeitos tardios relatados em prontuário. Casuística e Métodos:Trata-se de um estudo retrospectivo por análise de prontuário de pacientes entre 0 e 21 anos portadores de $\mathrm{DH}$, admitidos no serviço de Oncologia do Instituto da Criança do Hospital das Clínicas da Faculdade de Medicina da Universidade de São Paulo entre 1990 e 2005 e que foram tratados de acordo com o protocolo DH-II-90. Foram construídas curvas de sobrevida global, livre de doença e livre de eventos pelo método de Kaplan-Meier e realizada análise com a regressão 
de Cox. Foi utilizado um nível de significância de $5 \%(p<0,05)$. Foram analisadas as características clínicas e laboratoriais dos pacientes, completando um perfil desta neoplasia em 15 anos de experiência. Resultados: A taxa de remissão completa após a quimioterapia foi de $94,1 \%$ para todo o grupo, sendo $97,3 \%$ para baixo risco e $90 \%$ para alto risco. A sobrevida global em 10 anos foi de $96 \%$ para o grupo de baixo risco e $93 \%$ para o alto risco. A sobrevida livre de doença foi $90 \%$ após 5 anos, sendo o grupo de alto risco pior quando comparado com o baixo risco, $87 \%$ e $92 \%$ respectivamente, porém não estatisticamente significante $(p: 0,468)$. A sobrevida livre de eventos foi de $90 \%$ em 5 anos, sendo as curvas semelhantes para alto e baixo risco (p: 0,969). Foi observada diferença quando comparadas as curvas de sobrevida livre de eventos por presença ou ausência de massa mediastinal ( $p: 0,020)$ e dose de radioterapia utilizada (maior ou menor que $2100 \mathrm{cGy}$ ) (p: 0,014). Dentre os efeitos tardios, o mais freqüente foi disfunção da glândula tireóide, havendo 2 casos de carcinoma de tireóide como segunda neoplasia. Conclusão: O protocolo $\mathrm{DH}-\mathrm{II}-90$ é eficaz, sendo que a presença de massa mediastinal e doses de radioterapia maiores que 2100 cGy apresentam impacto negativo na sobrevida livre de eventos, e anormalidades da tireóide são seqüelas freqüentes neste grupo de pacientes.

Descritores: 1. Doença de Hodgkin/quimioterapia 2. Doença de Hodgkin/radioterapia 3. Prognóstico 4. Criança 


\section{SUMMARY}

The treatment of Hodgkin's disease (HD) has been increasingly successful lately. Since today cure rates are about $85 \%$, the challenge of new protocols for treatment of $\mathrm{HD}$ is to decrease its aggressiveness and consequent acute and late toxicity, without impairing results. The protocol DH-II-90 was designed to treat children and adolescents with HD. It consists of three cycles of ABVD (doxorubicin, bleomycin, vinblastine and dacarbazine) and involved-field radiotherapy for low risk patients, and incremented with three cycles of MOP (mechlorethamine, vincristine and prednisone) or COP (replacing mechlorethamine by cyclophosfamide) and extended field radiotherapy for high risk patients. Objectives: the purposes of this study are 1) to assess the overall, disease free and event free survival of the protocol $\mathrm{DH}-\mathrm{II}-90,2)$ to assess the overall and event free survival by stage, age, presence of bulky disease, mediastinal mass, B symptoms, dose and type of radiotherapy, and 3) to describe late effects data collected from the patients'charts. Methods: This is a retrospective study to assess archive of patients with HD, with 0 to 21 years old, admitted to the pediatric oncology service of the Instituto da Criança da FMUSP diagnosed between 1990 and 2005 and treated with the protocol DH-II-90. Overall, disease free and event free survival curves were developed by the Kaplan-Meier method and analyzed with the Cox regression. A significant level of $5 \%(p<0.05)$ was employed. The clinical and laboratorial data of these patients are described, completing a profile of 15 year of experience. Results: The complete 
response rate after chemotherapy was $94.1 \%$ for all the group, $97.3 \%$ for the low risk patients and $90 \%$ for the high risk patients. The overall survival in 10 years was $96 \%$ for the low risk group and $93 \%$ for the high risk group. The 5years disease free survival was $90 \%$. Disease free survival for high risk patients was worse than low risk group ( $87 \%$ and $92 \%$ respectively), but it was not statistically significant ( $p$ : 0.486). The 5-year event free survival was $90 \%$, with similar curves for low and high risk patients ( $p: 0.969)$. The presence of mediastinal mass and more than 2100 cGy radiation doses had negative impact on event free survival $(p=0.020$ and $p=0.014$ respectively). Thyroid gland dysfunction was the most frequent late effect described, with two cases of thyroid carcinoma as a secondary neoplasia. Conclusions: The $\mathrm{DH}-\mathrm{II}-90$ protocol is effective, while the presence of mediastinal mass and radiation dose over 2100 cGy have a negative impact on event free survival. Thyroid abnormalities are the most frequent late effects in this group of patients.

Descriptors: 1. Hodgkin's disease/chemotherapy 2. Hodgkin's disease/radiotherapy 3. Prognosis 4. Children 


\section{INTRODUÇÃO}

A Doença de Hodgkin (DH), hoje bem reconhecida como doença maligna originada do sistema linfático e reticuloendotelial, é uma neoplasia de bom prognóstico na população pediátrica. Descrita originalmente por Hodgkin em $1832{ }^{1}$, foram Sternberg em $1898^{*}$ e Reed em $1902^{* *}$ apud Hudson e Donaldson ${ }^{2}$ que descreveram a célula característica desta neoplasia, a célula de Reed-Sternberg, permitindo o seu diagnóstico.

A "World Health Organization" (WHO) define a doença de Hodgkin como aquela que compartilha das seguintes características: 1) origina-se em linfonodos, preferencialmente da região cervical; 2) a maioria manifesta-se clinicamente em adultos jovens; 3) os tecidos neoplásicos normalmente contem um pequeno número de células tumorais grandes mono ou multinucleadas (designadas células de Hodgkin e Reed-Sternberg, aqui chamadas de HRS), localizadas em um meio heterogêneo de células não-

\footnotetext{
* Stenberg C. Uber eine eigenartige unter dem bilde de pseudoleukemie verlaufende tuberculose des lymphatischen. Apparates Z Heikd 1898;19:21.

${ }^{* *}$ Reed DM. On the pathological changes in Hodgkin's disease, with special reference to its relation to tuberculosis. Johns Hopkins Hosp Rep 1902; 10: 133.
} 
neoplásicas, inflamatórias e acessórias; 4) as células tumorais são frequentemente circundadas por linfócitos $T$ dispostos em forma de uma roseta ${ }^{3}$. Estudos clínicos e biológicos das últimas três décadas evidenciaram que a $\mathrm{DH}$ abrange duas entidades distintas: a $\mathrm{DH}$ de predominância linfocitária e a DH clássica ${ }^{3,4,5}$. Elas diferem em suas características clínicas, de comportamento e prognóstico, assim como morfológica, imunofenotípica e geneticamente.

O manejo da $\mathrm{DH}$ mudou drasticamente nos últimos quarenta anos. Foram abandonadas condutas clássicas como o estadiamento cirúrgico e modificado tratamento, agora em busca de qualidade de vida nos sobreviventes desta doença, visto que a cura é bem provável ${ }^{2,6,7,8,9,10}$. Os trabalhos mais recentes vêm explorando estratégias terapêuticas com menor efeito adverso, porém com a intenção de manter a mesma sobrevida de protocolos anteriormente utilizados.

O Instituto da Criança da Faculdade de Medicina de São Paulo também vem no ímpeto de padronizar o tratamento da $\mathrm{DH}$, desenhando protocolos e modificando-os com o objetivo de manter a sobrevida e reduzir os efeitos tardios. Em fevereiro de 1985, elegeu-se o DH-I-86 como protocolo de tratamento de $\mathrm{DH}$ para os pacientes desta instituição. 
Este protocolo foi avaliado em 1991 por Eduardo Weltman ${ }^{11}$. No seu trabalho foram inclusos 32 pacientes, 26 avaliáveis. Destes, um apresentou recidiva tardia (mais de dois anos fora de terapia), um apresentou falha indutória e um apresentou escape fora de terapia. A sobrevida livre de eventos foi $88,4 \%$. O tempo de seguimento variou de 12 a 76 meses, sendo a mediana de 39 meses $^{11}$. Estes pacientes foram reavaliados em 1993, com tempo de seguimento maior entre 36 e 100 meses (mediana de 63 meses) mantendo os resultados ${ }^{12}$.

Em 1990 este protocolo foi modificado, sendo reduzido o tratamento radio e quimioterápico na tentativa de diminuir seus principais efeitos tóxicos. $\mathrm{O}$ protocolo atual, o DH-II-90, seguiu os preceitos do tratamento da doença de Hodgkin pediátrico vigente: terapia combinada e adaptada ao grupo de risco. Desta forma, os estádios I A e II A recebem três ciclos de ABVD (Adriamicina $25 \mathrm{mg} / \mathrm{m}^{2}$ dias 1 e 15, Bleomicina $10 \mathrm{mg} / \mathrm{m}^{2}$ dias 1 e 15 , Vinblastina $6 \mathrm{mg} / \mathrm{m}^{2}$ dias 1 e 15, Dacarbazina $250 \mathrm{mg} / \mathrm{m}^{2}$ dias 1 e 15) e radioterapia em campo envolvido nas doses 1800 a 2100 cGy. Em apresentações mediastinais irradiase o andar infra-diafragmático até a bifurcação da aorta e inclui-se o baço. Os estádios III, IV e B recebem três ciclos de ABVD, além de três ciclos de MOP 
(Oncocloramin $5 \mathrm{mg} / \mathrm{m}^{2}$ dias 1 e 8 , Vincristina $1,5 \mathrm{mg} / \mathrm{m}^{2}$ dias 1 e 8 e prednisona $40 \mathrm{mg} / \mathrm{m}^{2} /$ dia por 14 dias), posteriormente substituído por COP, no qual Oncocloramin é trocado por Ciclofosfamida $600 \mathrm{mg} / \mathrm{m}^{2}$ pela falta da primeira substância no mercado. A radioterapia no estádio III A é semelhante àquela aplicada aos estádios I e II A. Nos estádios IV e subgrupos B a radioterapia é estendida, envolvendo os campos supra e infra diafragmáticos, com proteção ovariana quando necessário.

Idealmente, a avaliação do protocolo $\mathrm{DH}-\mathrm{Il}-90$ deveria incluir uma avaliação criteriosa dos possíveis efeitos tardios relacionados ao tratamento. Esta avaliação, no entanto, necessitaria medidas antropométricas especiais, emprego de exames como ecocardiograma, expirometria, espermograma, dosagens hormonais, entre outros, de maneira rotineira pelo serviço, visto que este é um estudo retrospectivo. Portanto, este estudo visa avaliar as taxas de sobrevidas relacionadas a este protocolo, definindo a sua eficácia e apenas descrever os efeitos tardios relatados em prontuário. 


\subsection{HIPÓTESE}

O protocolo $\mathrm{DH}-\mathrm{II}-90$ apresenta taxas de sobrevida livre de doença e livre de eventos melhores que o protocolo anterior utilizado no mesmo serviço, o $\mathrm{DH}$ I-86, e equivalentes aos protocolos atuais utilizados em outros serviços.

\subsection{OBJETIVOS}

1. Descrever as características clínicas e laboratoriais dos pacientes com DH admitidos no serviço de Oncologia Pediátrica do Instituto da Criança/ HC- FMUSP entre janeiro de 1990 e dezembro de 2005, e que foram tratados de acordo com o protocolo $\mathrm{DH}-\mathrm{II}-90$, completando um perfil desta neoplasia em 15 anos de experiência.

2. Avaliar a eficácia do protocolo de tratamento utilizado no mesmo serviço neste período, o $\mathrm{DH}-\mathrm{II}-90$, descrevendo as taxas de resposta à terapia aplicada, com de curvas de sobrevida global, livre de eventos e livre de doença. 
3. Identificar fatores clínicos e terapêuticos que tenham impacto na sobrevida livre de eventos deste grupo de pacientes.

4. Avaliar a presença do vírus de Epstein-Barr em amostras de tumor e determinar sua influência na evolução destes pacientes.

5. Descrever efeitos tardios e, mais especificamente, a ocorrência de segundas neoplasias decorrentes do tratamento empregado. 


\section{REVISÃO DE LITERATURA}

\subsection{HISTÓRIA}

Em 1832, o Dr. Thomas Hodgkin, professor de anatomia mórbida do Hospital Guy em Londres, no qual foi chamado de "Inspetor da morte" e curador do museu, descreveu o artigo intitulado "On some Morbid Appearances of the Absorbent Glands and Spleen"1. Naquela época, sabia-se que câncer, inflamação, tuberculose e sífilis causavam aumento dos gânglios ${ }^{13}$. Ele descreveu clinica e anatomicamente seis casos que ele considerou diferentes e acrescentou um caso do Dr. Carswell, cujo relato serviu como ilustração original da doença ${ }^{14}$. O Dr. Hodgkin ratificou: "todos esses casos concordam no aumento considerável dos gânglios acompanhando artérias maiores (...) cervicais, axilares, inguinais e daqueles acompanhando a aorta no tórax e no abdome"1. Ele ainda chama atenção de que este aumento não pode ser causado por inflamação, visto que não há dor, calor ou outros sintomas associados à inflamação' ${ }^{1}$. Ele reconheceu que havia coexistência de 
tuberculose em alguns dos seus casos, mas o tamanho e a consistência endurecida dos gânglios o levaram a concluir tratar-se de outra doença ${ }^{15}$. Hodgkin observou ainda que a doença se espalha primariamente por contigüidade nos gânglios linfáticos e que o envolvimento do baço acontece só tardiamente no curso da doença ${ }^{13,15}$. Posteriormente, devido à qualidade do material de seus próprios casos, foi possível a avaliação histopatológica em 1926 por Hebert Fox, confirmando tratar-se de Linfoma de Hodgkin em alguns deles $^{13,15,16}$.

A descrição original de Hodgkin não ficou bem reconhecida até 1865 , quando Samuel Wilks descreveu maiores detalhes da doença e atribuiu o epônimo de "Doença de Hodgkin," imortalizando seu antecessor ${ }^{13,15,17,18}$. O Dr. Hodgkin, porém, mencionou que a primeira referência a esta doença foi feita por Malpighi em $1666^{13,15}$.

As características histopatológicas da doença começaram a ser descritas por vários pesquisadores após o advento do microscópio, reconhecendo-se as células gigantes característica da DH. Entre eles, estavam Tuckwell em 1870 ${ }^{15,16}$, Langerhans em $1872^{13,15,16}$, e Greenfield em $1878^{13,15,16}$. Porém, foram Carl Sternberg em 1898 e Dorothy Reed em 1902 que publicaram independentemente as características citológicas detalhadas das células 
gigantes e multinucleadas típicas desta doença e que receberam o nome de "célula de Reed-Sternberg"15,16,19. Sternberg acreditava que a DH era um processo inflamatório relacionado à tuberculose, porém Reed observou que os pacientes até pouco tempo do adoecimento eram pessoas de boa saúde, ocorria em crianças e adultos jovens e clinicamente havia crescimento progressivo e indolor dos gânglios normalmente cervicais ${ }^{20}$. Estas observações foram importantes no reconhecimento da etiologia da doença, mas esta discussão durou anos e só recentemente se definiu tratar-se de um câncer, como abordado adiante.

\subsection{EPIDEMIOLOGIA}

A doença de Hodgkin é responsável por cerca de $30 \%$ dos linfomas, e sua incidência não parece estar mudando³ . Estima-se que em 2009 ocorreram 8510 casos novos de linfoma de Hodgkin nos Estados Unidos ${ }^{21}$. No Brasil, segundo estimativas do INCA - Instituto Nacional do Câncer e de acordo com os registros de câncer de base populacional (RCBP), foram diagnosticados 
2870 casos novos da doença para este mesmo $a^{22}$. Porém, como a sobrevida é alta, a prevalência da doença é muito maior. Segundo estatísticas americanas $^{23}$, em 2006 nos Estados Unidos havia 160007 pessoas vivas com história de linfoma de Hodgkin em algum momento de sua vida. Ainda segundo SEER ("Surveillance, Epidemiology and End Results") entre 2002-2006, apenas $11,9 \%$ dos pacientes foram diagnosticados com idade inferior a 20 anos e entre aquelas que morreram por causa da doença, apenas 1,9\% tinham menos de 20 $\operatorname{anos}^{23}$. Portanto, a prevalência da $\mathrm{DH}$ é, proporcionalmente, maior para aqueles pacientes que tiveram um diagnóstico ainda na faixa etária pediátrica, visto que, apesar da menor incidência, é a faixa etária com menor mortalidade.

Quanto à subclassificação, cerca de 95\% dos linfomas de Hodgkin são DH clássicos, apenas 5\% são DH de predominância linfocitária (vide explanação adiante). Entre os tipos histológicos, a celularidade mista é mais comum em idades mais jovens e a esclerose nodular tem maior incidência em sociedades mais ricas ${ }^{2}$.

A DH tem uma distribuição de idade bimodal, com um pico na terceira e outro na sexta década de vida, caracteristicamente descrita em populações economicamente avançadas ${ }^{2,24,25}$, com a maioria dos casos ocorrendo em adultos jovens. Esta bimodalidade, porém, parece ser menos evidente em 
países em desenvolvimento, onde o primeiro pico acontece antes da adolescência. Isto foi inicialmente descrito em 1966 por Solidoro et $\mathrm{al}^{26}$, mas vista também por outros autores ${ }^{27,28,29,30}$.

Pouco se sabe sobre possíveis fatores de risco ambientais associados à doença de Hodgkin em pacientes pediátricos ${ }^{24}$, até mesmo por conta da menor incidência nesta população. Alguns estudos, entretanto, evidenciam uma maior proporção de pacientes com menos de 15 anos de idade em países em desenvolvimento ${ }^{26,30}$. A forma pediátrica tende a ser mais freqüente quanto maior a família ${ }^{31}$ e pacientes com menos de 10 anos de idade parecem pertencer a uma menor classe socioeconômica ${ }^{24}$, contudo, isto parece ter menor relevância em adolescentes. Num estudo realizado na Dinamarca, observou-se que o risco relativo de desenvolver um linfoma de Hodgkin era maior quanto maior o número de irmãos, porém apenas para a faixa etária menor que 15 anos de idade ${ }^{31}$. Os dados são limitados, porém levam a crer que estas crianças, que desenvolvem linfoma de Hodgkin em uma idade tão jovem, são aquelas sob risco de infecções precoces. Dworsky e Henderson relataram grupos de pessoas com $\mathrm{DH}$ incluindo casais e estudantes de uma mesma classe, sugerindo uma transmissão horizontal por um agente infeccioso ${ }^{32}$. 
Vários estudos epidemiológicos sugerem uma associação com o vírus Epstein-Barr (EBV) e isto parece ocorrer predominantemente com a $\mathrm{DH}$ clássica ${ }^{4,33,34}$. A relação entre EBV e DH foi confirmada em estudo que demonstrou sorologicamente um aumento do risco de $\mathrm{DH}$ após episódio de mononucleose $^{33}$. O risco aumentado de $\mathrm{DH}$ na faixa etária pediátrica pode estar relacionado à exposição precoce e intensa a este agente ${ }^{24}$. Uma grande parcela de pacientes com $\mathrm{DH}$ tem altos títulos de anticorpos contra o EBV, o que sugere que uma ativação contra o vírus pode preceder a doença. Além disto, técnicas de hibridização in situ encontram evidências do seu genoma nas células de Reed-Sternberg ${ }^{34}$. Entre as características da DH mais associadas ao EBV estão: subtipo celularidade mista ou depleção linfocitária, crianças procedentes de países em desenvolvimento, sexo masculino e pacientes com imunodeficiência ${ }^{35}$.

Há também descrições de grupos de famílias com $\mathrm{DH}^{2,24,36}$. Estudos envolvendo estas famílias sugerem uma maior associação da doença com antígenos HLA específicos ${ }^{36}$. O maior argumento para uma possível etiologia genética para a doença de Hodgkin veio, porém, de um estudo de Mack et al ${ }^{37}$. Eles analisaram uma grande coorte de gêmeos com doenças crônicas e relataram, no grupo de pacientes gêmeos monozigóticos, um risco aumentado 
em quase 100 vezes para o desenvolvimento do linfoma de Hodgkin. Não foi observado aumento do risco para os gêmeos dizigóticos. Esta evidência indica que há um componente genético, além da exposição a fatores ambientais implicados na etiologia desta doença.

\subsection{ETIOPATOGENIA}

A discussão se o linfoma de Hodgkin é uma doença malígna ou infecciosa foi motivo de longos debates por mais de um século, e só há mais ou menos uma década ficou clara sua etiologia. Todo este esforço para entender a origem da $\mathrm{DH}$ deve-se ao fato de apenas $1 \%$ do total das células do tumor serem neoplásicas ${ }^{38,39}$, havendo um infiltrado inflamatório variável ao redor. Isto acabou sendo um grande obstáculo para obter uma população de células que era considerada patognomônica da doença e sua análise molecular ${ }^{19,38,39,40,41}$.

Inicialmente para definir os precursores da célula de Hodgkin e ReedSternberg (HRS), foram utilizados estudos imunohistoquímicos para detectar expressão de marcadores de linhagens típicas para células do sistema linfo- 
hematopoiético ${ }^{40}$. No início da década de 80 , Stein et al descreveram a expressão do antígeno CD30 pelas células $\mathrm{HRS}^{42}$ e posteriormente observaram que a sua expressão pode ser induzida por célula B ou T ou ainda pela infecção pelo vírus $\mathrm{EBV}^{43}$, sugerindo a associação da doença com células linfóides. Foi reconhecido, a partir de então, que as células de HRS expressam marcadores de diferentes tipos de células, como TARC ("thymus and activation-regulated chemokine"), expressada por células dendríticas; CD15 vista em granulócitos e monócitos, Pax-5 de células B, CD138 de plasmócitos e CD30 de linfócitos ativados $^{41}$. Porém alguns dos marcadores típicos da linhagem B, como o CD20, e de células $T$, como o $C D 3$, apenas raramente são encontrados nestas células $^{41}$. Por isto, a imunohistoquímica não foi suficiente para determinar a origem da doença, mas foram importantes para classificá-la em duas categorias: Linfoma de Hodgkin clássico e Linfoma de Hodgkin nodular de predominância linfocitária. A primeira apresenta positividade para CD15 e CD30, enquanto que a última é positiva para antígenos associados à célula $B$ como CD20, CD79a, CD19 e normalmente negativos para CD15 e CD3044.

Na década de 90, a origem das células de Hodgkin e Reed-Sternberg foi finalmente determinada quando Küppers et $a^{39}$ amplificaram rearranjos dos genes de imunoglobulinas provenientes de uma única célula de Hodgkin e 
Reed-Sternberg micromanipulada ${ }^{39,40,41}$. Estes rearranjos ocorrem apenas em células da linhagem B e conseqüentemente representam um marcador molecular desta célula ${ }^{41,45}$. Em estudos subseqüentes, com o aperfeiçoamento da técnica para isolamento destas células, estes rearranjos foram encontrados em quase todos os casos de DH clássica ${ }^{38,46}$, o que definiu a origem de células B e sua clonalidade, como descrito a seguir.

Em 1994, Küppers et al ${ }^{39}$ detectaram mutações somáticas nos genes de imunoglobulinas e diversidade intraclonal em pacientes com $\mathrm{DH}$, o que levava a crer que a célula B era o progenitor do tumor, e mais especificamente, tratavase de uma célula B do centro germinativo. Enquanto as células B virgens expressam genes sem mutação da região variante $(V)$, as células $B$ ativadas por antígenos adquirem mutações somáticas nesta região do gene durante a sua passagem pelo centro germinativo ${ }^{40,45}$, na tentativa de produzir imunoglobulinas altamente específicas aos antígenos apresentados. Por isto, a presença de mutação somática na região $\mathrm{V}$ dos genes de imunoglobulinas é característica de células B do centro germinativo e seus descendentes. Desta forma, em reações imunes fisiológicas, as células B que apresentam 
características desfavoráveis são eliminadas através de apoptose mediada por $\mathrm{FAS}^{40}$.

Apesar de hoje a $\mathrm{DH}$ ser claramente reconhecida como uma doença derivada de células $B$, também é bem descrito a ausência da expressão de imunoglobulinas pelas células de HRS, importantes moléculas associadas à linhagem $B^{47}$. Stein et al demonstraram que as células de HRS carecem de fatores de transcrição associados à célula B que regulam a expressão de imunoglobulinas ${ }^{48}$. Também Schewring et al, em 2003, observaram uma redução dos níveis de RNA mensageiro para quase todos os genes estabelecidos para linhagem B nas células de $\mathrm{HRS}^{49}$. As células malignas da DH originam-se, então, no centro germinativo, através de mutações na região $V$ dos genes de imunoglobulinas das células B que parecem não expressar antígenos específicos e acabam escapando da seleção negativa e conseqüentemente do processo de apoptose, gerando então o linfoma ${ }^{40}$. Outra hipótese é que essas mutações causam uma alteração do mecanismo de transcrição o que leva à ausência de expressão de imunoglobulinas pelas células de $\mathrm{HRS}^{46}$. O evento final desencadeante da $\mathrm{DH}$ pode estar ainda associado a uma mudança completa da morfologia, imunofenotipagem e comportamento clínico da célula $\mathrm{B}^{46}$. 
A origem da célula de HRS clássica do centro germinativo é ainda respaldada pela descrição de um paciente com $\mathrm{DH}$ que desenvolveu um linfoma folicular dois anos após ter sido tratado para DH com sucesso ${ }^{50}$. A análise genética evidenciou o mesmo rearranjo dos genes de Imunoglobulina, todavia com números diferentes de mutações somáticas, sendo sete nas células de Reed-Sternberg e vinte e duas nas células tumorais do linfoma folicular. Entre elas seis eram idênticas, o que identifica a célula B do centro germinativo como o progenitor dos dois linfomas. Interessante é que a expressão de imunoglobulinas só ocorreu nas células do linfoma folicular.

Em torno de $5 \%$ das células de HRS expressam antígenos de células $\mathrm{T}^{51}$. A expressão de marcadores T pelas células de HRS estimulou a análise de alguns casos por uma derivação T potencial. Inclusive, dois estudos relataram casos raros de ocorrência de $\mathrm{DH}$ com rearranjos clonais dos genes do receptor de célula $T$, indicando que excepcionalmente a célula $T$ pode ser a progenitora da doença ${ }^{52,53}$. Porém, muitos dos casos que expressavam moléculas $T$ específicas, na verdade, tratavam-se de tumores derivados de células B, evidenciando que a presença de marcadores imunohistoquímicos não definiam 
a origem celular $^{41}$. Hoje, menos de $1 \%$ dos casos de $\mathrm{DH}$ clássica são consideradas de possível origem de células $T^{51}$.

Como discutido anteriormente, estudos epidemiológicos têm sugerido que o EBV está implicado na oncogênese da DH. Nos casos de DH EBV positivos, três proteínas virais são expressas: o antígeno nuclear do EBV 1 (EBNA-1) e as proteínas de membrana latente LMP1 e LMP2 ${ }^{19}$. Tendo em vista que EBV pode transformar a célula B in vitro e que a LMP1 é oncogênica, é provável que o EBV possa realmente contribuir para a patogênese da $\mathrm{DH}$ clássica ${ }^{41}$.

A infecção de células epiteliais pelo EBV in vitro resulta em produção viral e lise celular, porém infecções de linfócitos B resultam em infecção latente $^{35}$. Durante uma infecção latente, a programação genética do vírus o permite permanecer nas células hospedeiras e escapar da vigilância imune ${ }^{54}$. Enquanto a EBNA-1 é essencial para a replicação do genoma viral, a LMP1 e LMP2 ativa fatores de transcrição e quinases citoplasmáticas que são importantes sinais de sobrevivência no centro germinativo, escapando a seleção negativa ${ }^{19,40,41,55}$. Entretanto, existem pacientes com $\mathrm{DH}$ sem evidência de EBV. Alguns autores têm proposto que mesmo nestes casos o EBV teria um papel, por exemplo, através da hipótese de "hit and run"54, mas estudos ainda 
continuam sendo necessários para melhor esclarecimento da patogênese da DH clássica.

Ao contrário das células de HRS, as células da DH de predominância linfocitária frequentemente apresentam marcadores típicos da linhagem B. Isto, juntamente com o fato de expressarem o gene BCL6 que são típicos nas células B do centro germinativo, colocaram a este subtipo de $\mathrm{DH}$ como uma doença de estádio distinto de célula $\mathrm{B}$ madura ${ }^{40}$. As diferenças entre a $\mathrm{DH}$ clássica e de a predominância linfocitária não param por aí. Várias moléculas sinalizadoras estão ausentes ou diminuídas nas células de HRS, enquanto que estão preservadas nas células LP, assim como nas células do Linfoma não$\operatorname{Hodgkin}^{47}$. Isto pode confirmar a hipótese, de que existem mecanismos ontogênicos distintos para as duas formas de $\mathrm{DH}^{44}$.

Assim, ficou provado o caráter maligno da $\mathrm{DH}$ através da transformação neoplásica de uma única célula $B$ em vários estágios de desenvolvimento com subseqüente expansão monoclonal. As células tumorais de ambas a $\mathrm{DH}$ clássica e de predominância linfocitária são derivadas de células B que permaneceram por um período anormalmente longo no centro germinativo, predispondo a mutações e expansão clonal ${ }^{46}$. A extinção de antígenos B pelas 
células de HRS parece ser um processo complexo e sua elucidação provavelmente contribuirá com o entendimento completo da etiopatogenia desta doença.

\subsection{CLASSIFICAÇÃO}

Jackson e Parker, em 1944, descreveram uma das primeiras classificações histológicas para $\mathrm{DH}^{56}$. Eles dividiram em: paragranuloma, sarcoma e granuloma ${ }^{57,58}$. O paragranuloma era caracterizado pela presença das células de HRS na ausência de fibrose ou necrose, e parecia ser uma doença exclusiva de linfonodos e apenas com o tempo transformava-se em uma DH granulomatosa. Esta, por sua vez, apresentava as células de HRS com pleomorfismos, eosinófilos, necrose e fibrose e podia envolver qualquer órgão do corpo, exceto o sistema nervoso central. Já o subtipo sarcomatoso caracterizava-se por células de HRS, dispersas entre outras células anaplásicas e comportava-se como um tumor agressivo, altamente invasivo podendo acometer qualquer órgão incluindo o próprio sistema nervoso central ${ }^{56}$. Porém, a grande maioria dos casos era do subtipo granulomatoso, e este era um grupo 
extremamente heterogêneo o que tornava a classificação muito confusa e inútil ${ }^{59}$.

Em 1966, Lukes e Butler ${ }^{57}$, publicaram uma nova classificação para DH, baseada na variação de características e freqüência das células de HRS, alterações anatômicas, termos histológicos encontrados na literatura, estadiamento clinico, rapidez da progressão da doença e nos defeitos imunológicos relacionados à $\mathrm{DH}$. Foi reconhecido nesta publicação as novas categorias esclerose nodular e celularidade mista $^{57}$. Ainda, na definição do subtipo Linfoma de Hodgkin nodular de predominância linfocitária, Lukes e Butler descreveram duas formas ricas em linfócitos e histiócitos: uma com um padrão de crescimento nodular e outra com um padrão predominantemente difuso $^{16,57}$. Foi este o subtipo que apresentava as células Linfocíticas e Histiocíticas (L\&H), sendo descritas pela primeira vez, aqui chamadas de células LP (vide adiante).

Ainda em 1966, durante a conferência de $\mathrm{Rye}^{59}$, o comitê de nomenclatura, observando o fato de que uma terminologia para ser bem aceita precisava ser simples e atrativa, baseou a nova classificação histopatológica nos seis subtipos descritos por Lukes e Butler, alojando-os em quatro grupos: 1) 
predominância linfocitária (que inclui subtipos nodular e difuso das formas linfocíticas e histiocíticas de Lukes e Butler e subtipo paraglanunomatoso de Jackson e Parker), 2) celularidade mista, 3) esclerose nodular e 4) depleção linfocitária (que inclui os subtipos reticular e fibrose difusa de Lukes e Butler e subtipo sarcomatoso de Jackson e Parker).

Nos anos que se sucederam, poucas modificações foram feitas em relação à classificação estabelecida durante a conferência de Rye. Contudo, com o crescente reconhecimento da importância da genética como um dos principais fatores etiológicos do câncer, iniciou-se um processo para inserção de novas ferramentas diagnósticas como os anticorpos monoclonais, o que levou a uma nova discussão ao redor da classificação dos linfomas ${ }^{16}$.

Durante a década de 90 o "International Lymphoma Study Group" passou a promover reuniões para que houvesse um melhor entendimento entre os hematopatologistas e para melhor definir as entidades descritas até então. E em 1994, ao acrescentar dados imunológicos e moleculares à classificação anterior, criou-se a chamada "Revised European-American Lymphoma" $(\mathrm{REAL})^{4}$, representando um novo paradigma na classificação dos linfomas. O foco foi a identificação de doenças reais, baseado em um consenso entre os diversos especialistas e reconhecendo que um sistema de classificação deveria 
ir além da experiência individual de cada um. Para tanto, as decisões foram tomadas a partir de dados publicados e validados em mais de uma publicação ${ }^{4}$. Para definição das entidades foi utilizada uma constelação de características: morfológicas, imunofenotípicas, genéticas, apresentação clínica e curso da doença. Tentou-se ainda referenciar cada neoplasia à célula de origem, ficando reconhecida a origem linfóide da $\mathrm{DH}^{4}$. $\mathrm{A} \mathrm{DH}$ foi dividida em: 1) $\mathrm{DH}$ predominância linfocitária; 2) Esclerose Nodular; 3) Celularidade mista; 4) Depleção linfocitária; 5) DH clássica rica em linfócitos (entidade provisória) e 6) casos não classificáveis ${ }^{4}$. A Tabela 1 mostra a equivalência entre as classificações histopatológicas de Rye (1966) e REAL (1994).

Logo após a publicação da classificação REAL, a "World Health Organization" - WHO decidiu fazer uma atualização da classificação das neoplasias hematopoéticas e linfáticas para sua série de Classificação de Tumores ${ }^{16}$. Esta classificação levou sete anos para ficar pronta, novamente devido à discussão extensa em vários simpósios e encontros internacionais ${ }^{60}$. O grupo de patologistas e oncologistas clínicos concluiu que não seria viável o agrupamento de condições clínicas para protocolo de tratamento ou rotina clínica prática. Até porque o tratamento de um linfoma específico não é aplicado 
para outra doença, mesmo quando da mesma linhagem celular. Passou-se a reconhecer o papel crescente da genética na definição das doenças. Em 2001, foi então publicada a primeira classificação do WHO e mais recentemente em 2008 ela foi atualizada ${ }^{3}$. Uma das mudanças foi a inclusão das categorias provisórias da classificação REAL como o reconhecimento de maneira permanente da divisão da $\mathrm{DH}$ em clássica e de predomínio linfocitário nodular ${ }^{5,16}$. Outra foi o reconhecimento da origem $\mathrm{B}$ da $\mathrm{DH}$ clássica na classificação de $2008^{3}$. Hoje muito bem aceita, é a classificação WHO 2008, detalhadamente descrita a seguir, que será utilizada neste estudo.

Tabela 1 - Equivalência entre as classificações histopatológicas de Rye (1966) e REAL (1994) para a doença de Hodgkin

\begin{tabular}{|l|l|}
\hline RYE (1966) & REAL (1994) \\
\hline $\begin{array}{l}\text { Celularidade mista } \\
\text { Depleção linfocitária }\end{array}$ & $\begin{array}{l}\text { DH Clássica } \\
\text { Celularidade mista } \\
\text { Depleção linfocitária }\end{array}$ \\
$\begin{array}{l}\text { Predominância linfocitária nodular } \\
\text { (alguns casos) }\end{array}$ & $\begin{array}{l}\text { Esclerose nodular } \\
\begin{array}{l}\text { Predominância linfocitária difuso } \\
\text { (maioria dos casos) }\end{array}\end{array}$ \\
\hline $\begin{array}{l}\text { Predominância linfocitária nodular } \\
\text { (maioria dos casos) }\end{array}$ & $\begin{array}{l}\text { Predominância linfocitária } \\
\text { nodular }\end{array}$ \\
\hline
\end{tabular}

FONTE: Lukes RJ, et al. Cancer Res 1966;26:1311 (59) e Harris NL,et al. Blood 1994;84(5):1361-92 (4) 


\subsection{PATOLOGIA}

A doença de Hodgkin é diferente dos outros tipos de câncer, visto que apenas $1 \%$ do total de células do tumor são neoplásicas ${ }^{39}$, sendo a maior parte do tumor constituída de fibrose e infiltrado inflamatório constituído por células $\mathrm{T}$, histiócitos, eosinófilos e plasmócitos ${ }^{3,4,38,39,59}$. Idealmente, é necessária uma biópsia excisional, a fresco e estéril, para permitir ao patologista, além de uma melhor avaliação da arquitetura do gânglio, também um maior número de possibilidades de realização de estudos especiais. Teoricamente, a $\mathrm{DH}$ pode ser diagnosticada em pequenos materiais de biópsia, porém estudos imunohistoquímicos acabam sendo necessários para sua confirmação ${ }^{5}$ A biópsia por agulha fina muitas vezes acaba por protelar o diagnóstico, e deve ser usada com maior segurança nos casos de recidiva de $\mathrm{DH}^{5}$.

Por muitos anos, para a confirmação do diagnóstico de DH eram necessários a presença da célula de Reed-Sternberg e o infiltrado inflamatório reativo ${ }^{57}$. Porém, esta medida, provavelmente, levou a falhas na identificação da doença, principalmente quando a amostra não era adequada. Hoje, o diagnóstico definitivo de $\mathrm{DH}$ pode ser feito tanto pela avaliação morfológica, 
quanto com a associação com estudos imunohistoquímicos, o que reduziu a relevância da identificação das células de HRS 5 .

As células de Reed-Sternberg são células grandes multinucleada ou com um núcleo poliplóide ${ }^{5}$. Em cada lobo do núcleo há um nucléolo típico eosinofílico semelhante a uma inclusão, com cromatina condensada na periferia dando um aspecto espessado da membrana nuclear e formando uma zona clara ao redor do nucléolo ${ }^{5,57}$. As células de Reed-Sternberg patognomônicas precisam ter pelo menos dois nucléolos em dois lobos nucleares separados ${ }^{5}$. 0 citoplasma é variável, mais abundante e eosinofílico ou anfofílico ${ }^{57}$. As células Reed-Sternberg mononucleares, as chamadas células de Hodgkin ${ }^{5}$, são similares quanto às características nucleares e citoplasmáticas, porém não são consideradas patognomônicas por poderem ser simuladas em quadros de infecções virais e por isto não são suficientes para o diagnóstico ${ }^{5,57}$.

A descrição do subtipo Linfoma de Hodgkin nodular de predominância linfocitária de Lukes e Butler em 1966 continha uma célula variante àquela clássica de Reed-Sternberg, que eles chamaram de célula L\&H, também muito chamada de "pipoca"16. Segundo a última classificação da WHO 2008, estas células são chamadas hoje de células de predominância linfocitária (células LP) $)^{3}$. Caracteristicamente, as células LP lembram centroblastos dos centros 
germinativos, mas são maiores e têm núcleos lobulados com nucléolo basofílico pequeno a moderado, adjacente à membrana nuclear ${ }^{5}$. O citoplasma é abundante e discretamente basofílico ${ }^{5}$.

As células gigantes características são então chamadas de HRS para a DH clássica e células LP para a DH de predominância linfocitária nodular ${ }^{40}$. As diferenças histopatológicas e imunofenotípicas entre a DH de Predominância Linfocitária e a DH clássica estão demonstradas na Tabela 2.

Tabela 2 - Diferenças histopatológicas e imunofenotípicas entre a Doença de Hodgkin de Predominância Linfocitária e a Doença de Hodgkin clássica

\begin{tabular}{|l|c|c|}
\hline & $\begin{array}{c}\text { Doença de Hodgkin de } \\
\text { Predominância Linfocitária }\end{array}$ & $\begin{array}{c}\text { Doença de Hodgkin } \\
\text { Clássica }\end{array}$ \\
\hline Células atípicas & Célula LP (tipo "pipoca") & $\begin{array}{c}\text { Célula de HRS mononuclear } \\
\text { ou lacunar }\end{array}$ \\
\hline $\begin{array}{l}\text { Célula de HRS } \\
\text { diagnóstica }\end{array}$ & Rara ou ausente & Sempre presente \\
\hline CD15 & Negativo & Normalmente positivo \\
\hline CD30 & Frequentemente negativo & Normalmente positivo \\
\hline CD20 & Normalmente positivo & Normalmente negativo \\
\hline CD45 & Positivo & Normalmente negativo \\
\hline EMA & Frequentemente positivo & Negativo \\
\hline EBV & Normalmente negativo & $\begin{array}{c}\text { Frequentemente positivo (20 } \\
-70 \%)\end{array}$ \\
\hline
\end{tabular}

FONTE: Harris NL,et al. Blood 1994;84(5):1361-92 (4) 
A DH clássica é uma neoplasia monoclonal linfóide, na grande maioria dos casos derivadas de células $B$, composta pelas células de Hodgkin mononucleadas e Reed-Sternberg multinucleadas embebidas por infiltrado inflamatório variável com pequenos linfócitos, eosinófilos, neutrófilos, histiócitos, plasmócitos, fibroblastos e colágeno ${ }^{3}$. Mesmo a classificação atual - WHO 2008 foi baseada no esquema de Lukes e $B u t l e r^{57}$ e a subdivisão da DH clássica depende das características do infiltrado inflamatório e também da morfologia das células de HRS. Distinguem-se quatro subtipos: DH clássica rica em linfócitos, esclerose nodular, celularidade mista e depleção linfocitária ${ }^{3,4,5,59}$. A imunofenotipagem e alterações genéticas são idênticas entre estes subtipos histológicos (vide Tabela 2), porém diferem em suas características clínicas e sua associação com o vírus EBV³.

A DH do subtipo esclerose nodular é caracterizada pela presença de bandas de colágeno que circunda os nódulos de tecido linfóide anormal e células de HRS variante lacunares ${ }^{3,4,5,57}$. A presença de uma ou mais bandas escleróticas é a característica definitiva ${ }^{5,57}$. Este processo fibroso associa-se a um espessamento da cápsula do linfonodo ${ }^{3}$. As células de HRS são variáveis em número e tem característica lacunar - são mono ou multinucleadas com citoplasma anfofílico abundante e a membrana citoplasmática tende a retrair 
quando fixadas em formalina, formando lacunas ${ }^{3,5}$. O infiltrado inflamatório contém linfócitos, eosinófilos e neutrófilos ${ }^{5}$, mas também podem estar presentes histiócitos e plasmócitos ${ }^{4}$. A imunofenotipagem é aquela da DH clássica, contudo associação com o vírus EBV é menos freqüente que na $\mathrm{DH}$ de celularidade mista ${ }^{3}$.

O subtipo celularidade mista, como o próprio nome já diz, é intermediário entre o rico em linfócitos e depleção linfocitária ${ }^{59}$. As células de HRS são típicas e estão dispersas em um infiltrado inflamatório misto difuso ou discretamente nodular ${ }^{3,4,5}$. De um modo geral, casos que não se encaixam em outro subtipo, são colocados nesta categoria ${ }^{3}$. Pode haver fibrose intersticial, mas a cápsula do linfonodo não é espessada e não há bandas escleróticas como vistas na esclerose nodular ${ }^{3,4,59}$. O infiltrado inflamatório consiste de uma mistura de células, normalmente eosinófilos, neutrófilos, histiócitos e plasmócitos, podendo haver predominância de alguma delas ${ }^{3}$. Aqui também a imunofenotipagem corresponde àquela descrita para $\mathrm{DH}$ clássica com positividade para CD30 e CD15, porém a presença do EBV é muito mais prevalente ${ }^{3}$. 
A doença de Hodgkin clássica rica em linfócitos foi no passado frequentemente confundida com a $\mathrm{DH}$ de predomínio linfocitário. Segundo a WHO cerca de um terço dos casos diagnosticados no passado como DH nodular de predomínio linfocitário na verdade tratava-se de DH clássica rica em linfócitos. Este subtipo é caracterizado pela presença de células de HRS esparsas em um infiltrado nodular ou difuso consistindo de pequenos linfócitos e ausência de neutrófilos e eosinófilos ${ }^{3}$. Na variante nodular, os nódulos são compostos por pequenos linfócitos que com freqüência contem centros germinativos que são localizados excentricamente ${ }^{3,5}$. As células de HRS são localizadas nestes nódulos, inclusive algumas delas lembram as células LP ou lacunares $^{3}$. A distinção entre a $\mathrm{DH}$ clássica rica em linfócitos e a $\mathrm{DH}$ de predominância linfocitária foi possível através da imunofenotipagem, apresentando a primeira a marcação típica dos outros subtipos de DH clássica ${ }^{3}$. São positivas para CD30 e CD15, apenas eventualmente positivas para CD20 e negativas para CD75.

A DH de depleção linfocitária é um dos subtipos mais raros, mais comum em países em desenvolvimento e frequentemente associado à infecção pelo vírus $\mathrm{HIV}^{3}$. Tem aspecto variável, com infiltrado difuso e de aparência hipocelular, podendo haver fibrose ou necrose difusas ${ }^{4}$, mas é a predominância 
de células de HRS ${ }^{3,5}$ que é característica deste subtipo. É positivo para CD30 e CD15 e negativo para antígenos associados a linfócitos $\mathrm{B}$ e $\mathrm{T}^{4}$. A maioria dos casos HIV positivos também apresentam infecção pelo EBV 5 .

O subtipo Linfoma de Hodgkin nodular de predominância linfocitária é uma neoplasia monoclonal de células B caracterizada por uma proliferação nodular das células neoplásicas, chamadas células LP, habitualmente encontradas nos nódulos ou ao redor deles ${ }^{3,5}$. Já existem dados da literatura suficientes para definir este subtipo como uma entidade distinta ${ }^{4}$. Diferindo tanto em termos morfológicos, imunofenotípicos, como clínicos. A arquitetura dos linfonodos é totalmente ou parcialmente substituída por infiltrado nodular ou nodular e difuso consistindo predominantemente de pequenos linfócitos, histiócitos, e células LP. Estas últimas são grandes mononucleadas e com citoplasma escasso. O núcleo é frequentemente multilobulado ou pregueado dando um aspecto característico que originou o seu nome inicial - "células em pipoca",3.4. Células B foliculares são achadas adjacentes às células LP, enquanto que as células de HRS clássicas são ausentes ou escassas ${ }^{5}$. Inclusive, na presença desta última facilmente reconhecida, deve-se suspeitar de $\mathrm{DH}$ clássica rica em linfócitos ${ }^{5}$. A imunofenotipagem é típica e já bem 
reconhecida há alguns anos, com positividade para CD20, CD79a, CD75, BCL6 ${ }^{3}$. Normalmente, o CD15 e CD30 são negativos, assim como os marcadores do vírus EBV ${ }^{4}$.

\subsection{QUADRO CLÍNICO}

Como o próprio Hodgkin já havia sinalizado, a DH parece originar-se em um único sítio linfático e progride através de linfonodos adjacentes até disseminar para órgãos à distância e não adjacentes ${ }^{1,58,61}$. Por isto, é importante uma rotina que envolve uma anamnese detalhada buscando sinais e sintomas da doença para estadiamento e avaliar o prognóstico, além de comorbidades associadas que podem influenciar na escolha da terapêutica ${ }^{62}$. 0 exame físico deve ser minucioso com atenção especial a todas as cadeias ganglionares incluindo anel de Waldeyer. É crucial documentar a localização, quantidade e tamanho dos linfonodos acometidos e também presença de hepatoesplenomegalia, tanto para determinar o estadiamento, como para avaliação de resposta à terapia aplicada ${ }^{62}$. 
A doença pode se apresentar como adenomegalia isolada ou conglomerado de linfonodos endurecidos. As cadeias mais acometidas são cervicais ou supraclaviculares $(60-80 \%)^{61,62,63}$. Outra forma de apresentação bastante comum é o envolvimento de gânglios mediastinais ${ }^{61}$, raramente causando sintomas respiratórios mesmo quando em grandes volumes ${ }^{62}$. Linfonodos axilares aumentados ocorrem em torno de $10-20 \%$ dos casos e os gânglios inguinais estão alterados em $5-15 \%$ dos pacientes ${ }^{61,62,63}$. Doença primária subdiafragmática é rara e acontece em apenas $3 \%$ dos $\operatorname{casos}^{61}$.

Sintomas sistêmicos inespecíficos como febre, fadiga, anorexia, prurido, perda de peso e fraqueza, são reconhecidos desde a primeira descrição da doença por Thomas Hodgkin ${ }^{1}$. Hoje pouco freqüente, a febre de Pel-Ebstein consiste de episódios cíclicos de febre alta que duram cerca de uma a duas semanas e que pode recorrer a intervalos variáveis de dias ou semanas ${ }^{62,64}$. O prurido teve seu valor prognóstico questionado durante a conferência de Ann Arbor ${ }^{65}$, porém, alguns autores relatam que se for intenso, pode estar relacionado à doença ${ }^{66}$. Dor à ingestão de álcool é rara, mas é um sintoma já bem descrito como associado à $\mathrm{DH}$, podendo inclusive preceder o seu diagnóstico ${ }^{62,64}$. Três sintomas constitucionais, os chamados sintomas $B$, 
correlacionam-se com prognóstico desfavorável e são eles: febre maior que $38^{\circ} \mathrm{C}$ por três dias consecutivos, sudorese noturna intensa e perda inexplicada de mais que $10 \%$ do peso corpóreo nos últimos 6 meses $^{61,62,65}$. Cerca de 25 a $30 \%$ dos pacientes apresentam sintomas B ao diagnóstico ${ }^{61,63}$.

Existem outras manifestações clínicas mais raras da $\mathrm{DH}$. Algumas lesões de pele que podem estar associadas são ictiose, urticária, eritema multiforme, eritema nodoso, lesões necrotizantes ou hiperpigmentação ${ }^{62}$. O acometimento dos rins pela $\mathrm{DH}$ é pouco freqüente, mas pode ocorrer uni ou bilateralmente com nódulos infiltrativos ou envolvimento difuso. Normalmente é oligossintomático, mas pode causar perda de função $0^{64}$. A DH pode ainda estar associada à glomerulonefrite ou síndrome nefrótica por efeitos diretos ou indiretos ${ }^{64}$. Entre as anormalidades endocrinológicas a mais observada em associação à DH é a hipercalcemia, podendo ocorrer em 1-5\% dos casos, está normalmente associada à doença avançada e de pior prognóstico ${ }^{64}$. Síndromes neurológicas paraneoplásicas são incomuns, mas incluem degeneração cerebelar subaguda, encefalite límbica, mielopatia necrótica subaguda, neuropatia motora subaguda ${ }^{67}$.

Várias alterações laboratoriais podem ocorrer ao diagnóstico da $\mathrm{DH}$. Alterações hematológicas que incluem anemia e plaquetopenia podem ser 
causadas por hiperesplenismo ou infiltração medular ${ }^{64}$. No entanto, outras manifestações como anemia, leucocitose e linfopenia são imuno-mediadas e parecem estar relacionadas a um prognóstico desfavorável ${ }^{68}$. A anemia hemolítica, há muito tempo descrita como associada à $\mathrm{DH}$, é rara e relaciona-se à atividade da doença, com desaparecimento durante a remissão e recrudescência na recidiva da $\mathrm{DH}^{69}$. Há descrição ainda de púrpura trombocitopênica idiopática e neutropenia autoimune ${ }^{64}$. A eosinofilia é freqüente, e na ausência de leucocitose, ela está associada a uma melhor sobrevida ${ }^{64}$. Há ainda aumento da velocidade de hemossedimentação, ferritina e cobre, evidenciando uma ativação do sistema reticuloendotelial ${ }^{2}$.

Alguns estudos relataram quadros clínicos específicos para os subtipos da $\mathrm{DH}$. Mauch et $\mathrm{al}^{61}$ observaram três padrões diferentes de quadro clínico: 1) pacientes com esclerose nodular eram mais freqüentemente do sexo feminino, jovens, e tinham doença supradiafragmática com envolvimento do mediastino; 2) pacientes com celularidade mista ou depleção linfocitária apresentaram mais comumente doença avançada, envolvendo o abdome e com sintomas B; e 3) casos de predominância linfocitária foram menos freqüentes e tinham doença mais localizada, periférica, cervical alta e sem sintomas B. O estudo conclui que 
as diferenças maiores são entre DH nodular de predomínio linfocitário e outros subtipos de DH. Outros estudos registram dados semelhantes ${ }^{62,63}$, sendo a DH de predomínio linfocitário uma doença insidiosa tendendo a apresentar-se em estádios de baixo risco e com melhor prognóstico.

\subsection{ESTADIAMENTO}

O primeiro sistema de estadiamento para $\mathrm{DH}$ que se tem conhecimento foi proposto em 1865 sendo dividida a doença em 3 estágios: latente, progressivo e caquético ${ }^{62}$. Várias outras classificações foram elaboradas ao longo dos anos, até que em 1966, durante a conferência de Rye, foi padronizado um sistema de estadiamento, no qual foram estabelecidos 4 estadiamentos e subdivididos em A (assintomáticos) e B (sintomas B: febre, sudorese noturna e prurido $)^{70}$. Até então perda de peso não era considerada suficiente para definir um paciente no subgrupo "B".

Após a conferência de Rye, alguns conhecimentos foram adquiridos: 1) doença extra linfática quando localizada e relacionada a linfonodo adjacente não afeta a sobrevida dos pacientes e 2) laparotomia com esplenectomia foi 
introduzido como método de melhor avaliação de doença intra-abdominal ${ }^{65}$. Isto fez com que esta classificação fosse reconsiderada e modificada para o sistema de estadiamento de Ann Arbor, adotado em 197165. Esta classificação considerava ainda um estadiamento clínico baseado em história, exame físico, estudos radiológicos e laboratoriais e outro estadiamento anátomo-patológico no qual havia estudo patológico dos tecidos removidos cirurgicamente, através da laparotomia e esplenectomia. Introduziu-se ainda a designação "E" para distinguir extensão extranodal contígua (estadio II e não mais IV como no sistema anterior). Os pacientes continuaram a ser subclassificados em A ou B para indicar a ausência ou presença dos sintomas constitucionais (febre inexplicada maior que $38,0^{\circ} \mathrm{C}$ por três dias consecutivos, sudorese noturna intensa e perda inexplicada de mais que $10 \%$ peso corpóreo nos últimos 6 meses), sendo o prurido substituído pela perda de peso ${ }^{62}$.

Uma pequena modificação do sistema de estadiamento de Ann Arbor foi feita em 1989 na conferência de Cotswolds ${ }^{71}$ com o intuito de reconhecer o uso da tomografia computadorizada para detecção de doença intra-abdominal, para definir a doença "bulky" e para fornecer uma diretriz para avaliação de resposta $^{62}$. Este é o sistema de estadiamento que hoje é aceito 
internacionalmente e está detalhado na Tabela 3. A doença "bulky" foi definida como aquela que ocupa mais que $1 / 3$ do diâmetro torácico ao nível das vértebras torácicas T5 e T6 nos casos das massas mediastinais ou massas com diâmetro máximo maior que $10 \mathrm{~cm}^{71}$.

Tabela 3 - Sistema de estadiamento de Ann Arbor para a doença de Hodgkin com as modificações da conferência de Cotswolds de 1989

\begin{tabular}{|c|c|}
\hline Estádio & Definição \\
\hline $\mathrm{I}$ & $\begin{array}{l}\text { Envolve uma única cadeia linfonodal ou estrutura linfática (I) ou } \\
\text { único órgão extralinfático }\left(\mathrm{I}_{E}\right)\end{array}$ \\
\hline II & $\begin{array}{l}\text { Envolve duas ou mais cadeias linfonodais (II) ou envolvimento } \\
\text { localizado de um órgão extralinfático e uma ou mais cadeias } \\
\text { linfonodais ( }\left(I_{\mathrm{E}}\right)\end{array}$ \\
\hline III & $\begin{array}{l}\text { Envolve linfonodos dos dois lados do diafragma (III) podendo } \\
\text { ser acompanhado do envolvimento localizado de órgão } \\
\left.\text { extralinfático (III }) \text { ou baço (IIIS) ou ambos (III } I_{S E}\right)\end{array}$ \\
\hline IV & $\begin{array}{l}\text { Apresenta doença disseminada envolvendo um ou mais órgãos } \\
\text { ou tecidos extralinfático }\end{array}$ \\
\hline Observações & $\begin{array}{l}\text { A - assintomático } \\
\text { B - febre, sudorese noturna e perda de peso } \\
\text { X - Doença "bulky" } \\
\text { E - Envolvimento de sítios extralinfático contíguo ou próximo ao } \\
\text { linfonodo acometido } \\
\text { CS - Estadiamento clínico } \\
\text { PS - Estadiamento patológico }\end{array}$ \\
\hline
\end{tabular}

FONTE: Lister TA, et al. J Clin Oncol 1989; 7(11): 1630-6 (71)

O conceito de estadiamento cirúrgico passou a não ter mais uma relevância, inclusive porque a laparotomia e esplenectomia apresentavam 
problemas sérios principalmente na população pediátrica. $O$ risco aumentado de infecções graves por bactérias encapsuladas em crianças asplênicas, com necessidade de uso prolongado de antibióticos profiláticos e ainda a ocorrência de complicações pós cirúrgicas como obstrução intestinal foram argumentos importantes para o abandono desta prática ${ }^{10}$. Contribuíram também o uso de terapia sistêmica neste pacientes e o avanço na tecnologia de diagnóstico por imagem que permitiu a avaliação fidedigna de nódulos retroperitoneais ${ }^{10}$. A confirmação histopatológica de doença abdominal microscópica passou a ter menor importância com o abandono do uso de radioterapia isolada para tratamento deste grupo de doentes e hoje o estadiamento cirúrgico é limitado a casos isolados de achados duvidosos por estadiamento clínico ${ }^{10}$. Apesar de o estadiamento cirúrgico não ser mais utilizado, os resultados dos estudos com laparotomia forneceram informações relevantes ao manejo contemporâneo, pois o conhecimento da distribuição provável da doença facilita a interpretação dos exames de imagem ${ }^{62}$, principalmente quando há nódulos isolados com características duvidosas. É importante avaliar a extensão da doença porque há implicações terapêuticas como a intensidade da quimioterapia ou o campo da radioterapia a ser utilizado. 


\subsection{PROGNÓSTICO}

As descrições iniciais da história natural de pacientes não tratados com DH indicavam uma grande variedade de quadros clínicos, porém acabava sendo fatal em virtualmente todos os casos $^{72}$. Hoje, o prognóstico do Linfoma de Hodgkin é excelente, com uma expectativa de sobrevida a longo prazo de $85 \%$ ou mais ${ }^{6,7,73,74,75}$, mesmo para pacientes com doença avançada. Porém, ainda há pacientes de difícil controle e predispostos a eventos não só relacionados à doença, mas também aos efeitos do tratamento. Por isto, os fatores de prognóstico são relativos e podem ser divididos em: relacionados ao tumor, relacionados ao paciente e relacionados ao ambiente ${ }^{72}$.

Os fatores de risco relacionados ao tumor ou ao seu efeito sobre o paciente envolvem a patologia (subtipo de $\mathrm{DH}$ ), extensão anatômica (estadiamento propriamente dito) e biologia tumoral (envolvimento com vírus, genética tumoral). Os fatores associados ao paciente incluem características demográficas como idade e sexo, além de condição clínica, presença de comorbidades e estado imunitário. E, finalmente, aqueles ligados aos fatores ambientais são aqueles fora do paciente, como fator sócio-econômico e sistema de saúde em que o paciente está inserido ${ }^{72}$. Este último tem relação direta com 
o tipo de tratamento a ser instituído, o que por sua vez torna-se um fator de risco importante para eventos.

Por conta desta subjetividade, hoje, pacientes com $\mathrm{DH}$ de um mesmo estadiamento e subtipo histológico podem apresentar sobrevidas bem distintas a depender do seu estado clínico, idade, relação com EBV, tratamento, entre outros fatores. Além disto, a análise de fatores de risco deve levar em conta diferentes desfechos que possam ser de interesse: sobrevida global, sobrevida livre de doença e sobrevida livre de eventos ${ }^{72}$. Tendo em vista que a cura é provável, nos dias de hoje, há um interesse maior em sobrevida livre de eventos ao mesmo tempo em que se mantém a sobrevida global e livre de doença quando se trata de $\mathrm{DH}^{7}$. Portanto, a avaliação dos fatores prognósticos precisa ser ampla, focando também fatores que possam ser modificados.

Um consenso sobre quais características do paciente pediátrico com DH que se beneficiariam de uma terapia intensiva é importante por causa do alto risco de falha indutória ou ainda para identificar aqueles pacientes que não teriam sua sobrevida alterada por redução do tratamento ${ }^{7}$. Estadiamento e sintomas B continuam sendo os dois maiores determinantes para estratificação de risco em pacientes com $\mathrm{DH}^{76}$. Massa mediastinal volumosas, tipo "bulky", 
também há muito é sabidamente reconhecida como fator de risco desfavorável ${ }^{77}$. Alguns estudos consideram ainda 0 número de sítios envolvidos ${ }^{78}$ ou mesmo o volume total do tumor, calculado através da soma dos volumes de todas as lesões através de imagens radiológicas ${ }^{79}$. A relação entre os subtipos histológicos e prognóstico tem sido descrita desde a década de 60 , quando Lukes e Butler associaram a predominância linfocitária com estadiamento baixo e sobrevida média prolongada e a depleção linfocitária a pior prognóstico ${ }^{57}$.

Índices de fatores prognósticos têm sido desenvolvidos em pacientes adultos para guiar o tratamento. O escore de prognóstico internacional (IPS) utiliza os seguintes dados para definir pior evolução: albumina sérica menor que $4 \mathrm{~g} / \mathrm{dl}$, hemoglobina menor que $10,5 \mathrm{~g} / \mathrm{dl}$, sexo masculino, estadiamento IV, idade maior que 45 anos, leucocitose maior que $15000 / \mathrm{mm}^{3}$, e número de linfócitos menor que $600 / \mathrm{mm}^{3}$ ou menor que $8 \%$ dos leucócitos totais ${ }^{68}$. Porém, índices específicos para pacientes pediátricos têm sido propostos. Num estudo, Smith et al sugerem os seguintes fatores de prognóstico afetando sobrevida após análise multivariada: sexo masculino, estadiamento IIB, IIIB e IV, doença mediastinal "bulky", leucócitos totais maior que 13000/mm e hemoglobina abaixo de $11 \mathrm{~g} / \mathrm{dl}^{80}$. 
Um grande número de variáveis podem apresentar valor prognóstico em pacientes com $\mathrm{DH}$, tanto à apresentação quanto no curso da doença. Estes fatores têm sido utilizados para adaptar o tratamento, reduzindo sua toxicidade em pacientes de melhor prognóstico e intensificando-o naqueles com fatores de risco desfavoráveis com o intuito de manter altas chances de cura ${ }^{72}$.

\subsection{TRATAMENTO}

O tratamento da DH por muitos anos consistia de irradiação como modalidade única de tratamento. A descoberta do raio-X por Roentgen, radioatividade por Becquerel e do radio por Curie no final do século 19 levaram ao tratamento inicial da $\mathrm{DH}$ no início do século $20^{81,82}$. Inicialmente as técnicas de irradiação eram rudes e causavam queimaduras na pele com ulcerações e com resultados muito frustrantes com relação ao controle da doença. Gilbert, um radioterapêuta suíço, estabeleceu na década de 30 os princípios para tratamento da DH através da radioterapia* apud Yahalom ${ }^{82}$. Na década de 60, irradiação em altas doses e campo estendido era o tratamento padrão da $\mathrm{DH}$

\footnotetext{
* Gilbert R. La roentgentherapie de la granulomatose maligne. J Radiol Electrol 1925;9:509-14.
} 
para adultos e crianças ${ }^{83}$. Apesar de curativa, era associada a anormalidades do crescimento em crianças $^{84,85,86}$. A biologia e história natural da $\mathrm{DH}$ em crianças são semelhantes da $\mathrm{DH}$ do adulto, entretanto, quando técnicas e doses de irradiação apropriadas para o tratamento de adultos eram empregadas para pacientes pediátricos, morbidades significativas eram observadas $^{81}$.

Durante a primeira e a segunda guerra mundial, reconheceu-se o efeito da mostarda nitrogenada sob os tecidos $\operatorname{linfóides}^{87}$. Nas décadas que se seguiram, foi elaborada uma combinação de agentes quimioterápicos incluindo a mostarda nitrogenada para o tratamento desta doença. Foi então que, em 1972, Vicent De Vita Jr. descreveu a famosa combinação conhecida como MOPP - mostarda nitrogenada, vincristina (oncovin $®$ ), procarbazina e prednisona, para tratamento dos casos avançados ${ }^{88}$, com taxas de remissão completa em $84 \%$ e sobrevida livre de doença em $66 \%$. Apesar deste sucesso, alguns pacientes ainda recidivavam ou mantinham doença refratária. Logo em seguida, em 1975, Gianni Bonadonna descreveu a combinação ABVD adriamicina, bleomicina, vinblastina e dacarbazina, justamente com o intuito de resgatar os pacientes que falhavam após o uso de MOPP ou ainda intercalando 
os dois esquemas para obter maior percentagem de respondedores completos $^{89}$.

A partir destes relatos, passou-se a avaliar terapia combinada com quimioterapia e radioterapia para o tratamento da $\mathrm{DH}$, principalmente para aqueles pacientes com doença avançada. Inicialmente foi desenhado para controlar doença oculta, mas também para evitar o estadiamento cirúrgico ${ }^{90}$,

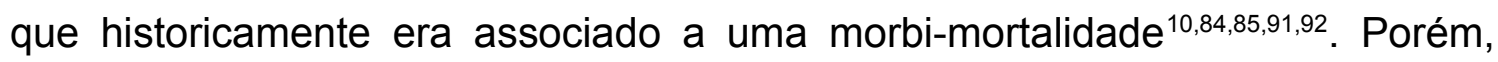
durante alguns anos, ainda houve resistência à aceitação da combinação de quimioterapia e radioterapia para os pacientes com doença localizada, e muitos serviços preconizavam o uso de radioterapia isolada. Neste mesmo momento, várias instituições pediátricas passaram também a avaliar o tratamento com a modalidade combinada para pacientes com $\mathrm{DH}^{10}$. $\mathrm{E}$ foi justamente o desejo de diminuir as seqüelas a longo prazo que guiaram o desenvolvimento dos protocolos e determinaram as mudanças no tratamento de pacientes pediátricos ${ }^{10,83,86}$.

O maior argumento contra o uso da modalidade combinada como primeira linha para o tratamento de $\mathrm{DH}$, principalmente para pacientes de baixo risco, é a possível morbidade iatrogênica relativa ao uso de quimioterápicos, 
especialmente com o uso de agentes alquilantes em associação com radioterapia $^{74}$. Em contrapartida, o seu uso permite a redução da dose e do campo de irradiação, utiliza doses menores de quimioterapia e evita esplenectomia e laparotomia diagnóstica, melhorando, assim, as taxas de curas e minimizando os efeitos adversos ${ }^{9,10,71,73}$.

Já se sabe que a terapia combinada tem excelentes resultados para linfoma de Hodgkin há mais de $30 \operatorname{anos}^{93}$. A cura da $\mathrm{DH}$ pediátrica e a complexidade do tratamento atual associadas à vulnerabilidade à radiação de uma criança em desenvolvimento requerem atenção especial da equipe que a atende ${ }^{81}$. O tratamento preconizado hoje é, portanto, a combinação de radioterapia e quimioterapia ${ }^{2,10,81,83,86}$.

Considerando-se que a maioria das crianças e adolescentes com $\mathrm{DH}$ tem excelente prognóstico com o tratamento disponível atualmente, o desafio dos protocolos da Doença de Hodgkin agora é reduzir a agressividade do tratamento, sem alterar a taxa de sobrevida. Os protocolos são adaptados ao risco, assim pacientes com prognóstico favorável recebem terapia reduzida em relação àqueles de pior prognóstico, restringindo doses de antraciclínicos, bleomicina e agentes alquilantes, além da radioterapia ${ }^{10,81,83}$. 
A radioterapia em campo envolvido tem sido cada vez mais utilizada, com bons resultados ${ }^{2,10}$. Neste caso, é importante uma definição meticulosa do campo a ser irradiado. A definição dos campos depende da anatomia da região em termos de distribuição dos linfonodos e da extensão da doença naquela cadeia ganglionar, e ainda, nos casos de recidiva, é preciso considerar a linha de intersecção ${ }^{81}$. O campo envolvido não inclui apenas os gânglios acometidos, mas toda a região linfonodal que os contém ${ }^{81}$. É preciso um esforço para evitar irradiar tecidos normais, principalmente na região supradiafragmática onde há proximidade entre os linfonodos e tecidos normais críticos como coração e pulmão ${ }^{81}$.

Com o tratamento combinado, a maioria das recaídas ocorre até três anos após o fim do tratamento ${ }^{6}$, porém alguns pacientes podem apresentar recidivas tardias, até dez anos após o diagnóstico inicial. Justamente porque a cura é bem provável em crianças e adolescentes, é preciso dar atenção às complicações a longo prazo. Podem ocorrer alterações de crescimento, cardiotoxicidade, infertilidade, neoplasias secundárias, fibrose pulmonar e hipotireoidismo ${ }^{84,85,94,95,96}$. Desta forma, é importante um seguimento longo dos pacientes fora de terapia. 


\section{PACIENTES E MÉTODOS}

Trata-se de um estudo retrospectivo, por revisão de prontuário, realizado no Serviço de Oncologia Pediátrica do Instituto da Criança / HC- FMUSP, com indivíduos de ambos os sexos, na faixa etária até 21 anos de idade e que apresentem os critérios de inclusão do estudo. A definição da idade pediátrica no tratamento de $\mathrm{DH}$ é dependente da toxicidade relacionada ao tratamento, sendo importante considerar um limite de 16 anos se há pretensão de reduzir a toxicidade músculo-esquelética. Porém, o limite entre 18 e 21 anos é apropriado quando se objetiva minimizar o tratamento visando reduzir toxicidade tardia de um modo geral ${ }^{10}$. Portanto, a faixa etária utilizada neste estudo foi de pacientes até 21 anos de idade.

Este projeto foi avaliado pela Comissão de Ética para Análise de Projetos de Pesquisa - CAPPesq da Diretoria Clínica do Hospital das Clínicas e da Faculdade de Medicina da Universidade de São Paulo, em sessão de 14 de junho de 2006 e aprovado protocolo de pesquisa sob número 470/06. 


\subsection{CRITÉRIOS DE INCLUSÃO}

Foram incluídos no estudo todos os pacientes com idade de 0 a 21 anos com diagnóstico histopatológico de Doença de Hodgkin que deram entrada no serviço de Oncologia Pediátrica do Instituto da Criança/ HC- FMUSP de 01 de Janeiro de 1990 a 31 de dezembro de 2005 e que foram tratados de acordo com o protocolo $\mathrm{DH}-\mathrm{II}-90$.

\subsection{CRITÉRIOS DE EXCLUSÃO}

Foram excluídos da análise pacientes tratados com outro protocolo que não o DH-II-90, aqueles que não completaram o protocolo e também as crianças tratadas em outro serviço e encaminhadas ao HC-FMUSP durante uma recaída ou para uma segunda opinião. 


\subsection{ANÁLISE DE DADOS}

Os dados foram analisados através de uma revisão de prontuário com o preenchimento de uma ficha para cadastramento de dados relacionados às características clínicas, laboratoriais, dados do tratamento e da evolução do paciente (vide anexo). Quanto à avaliação de toxicidade tardia, apenas foi registrado o que havia sido descrito no prontuário, não sendo feita uma busca ativa, visto o desenho do estudo. A pesquisa da presença do EBV nas células de HRS foi realizada através da técnica de hibridização in situ nos materiais recuperados dos pacientes tratados com o $\mathrm{DH}-\mathrm{II}-90$.

Os dados coletados foram colocados em um banco de dados utilizando o programa Microsoft Excel. Para a análise descritiva foram calculados média, desvio padrão, mínimo, mediana e máximo para as variáveis contínuas (idade, HB, VHS, DHL e dose radioterapia). Para as variáveis não contínuas (sexo, doença bulky, massa mediastinal, sintomas B, histologia, estadiamento, dose radioterapia maior ou menor ou igual a 2100 cGy, falha indutória, recaída, óbito, segunda neoplasia e TAMO) foram calculadas freqüências e percentuais.

As curvas de sobrevida foram construídas a partir do método de KaplanMeier e separadas por estadiamento (alto risco e baixo risco). As curvas foram 
comparadas de acordo com estadiamento, faixa etária, pesquisa para EBV positiva ou negativa, presença de doença "bulky", massa mediastinal, radioterapia (campo envolvido e campo estendido), dosagem radioterapia ( $\leq 2100$ e >2100 cGy) e Sintomas B (sim e não). Para verificar a relação de histologia, idade, presença de doença "bulky", massa mediastinal, radioterapia (campo envolvido e campo estendido), dosagem radioterapia ( $\leq 2100$ e $>2100$ cGy), presença de sintomas B (sim e não) e positividade ou não ao EBV no tempo de sobrevida livre de eventos foi utilizada a regressão de Cox. Foi utilizado um nível de significância de 5\% (p-valor < 0,05).

\subsection{DEFINIÇÕES:}

Sobrevida livre de eventos (SLE): calculada da data do diagnóstico até a data do evento ou da última consulta ou até 30 de junho de 2008.

Sobrevida livre de doença (SLD): foi definida como o intervalo entre o diagnóstico e o evento, sendo aqui considerado falha indutória ou recaída.

Sobrevida global (SG): foi considerado o intervalo entre o diagnóstico e a data do óbito. 
Eventos: óbito por qualquer causa, falha indutória, recaídas e segunda neoplasia.

Remissão completa: aquele paciente sem evidencia clínica ou radiológica de $\mathrm{DH}$. Alterações consistentes com efeitos por tratamento prévio podem estar presentes ${ }^{71}$.

Resposta parcial: redução de pelo menos $50 \%$ da soma do produto de todas as lesões no maior diâmetro perpendicular, com melhora clínica objetiva e ausência de sintomas $\mathrm{B}^{71}$.

Doença progressiva: aumento de $25 \%$ ou mais no tamanho de pelo menos uma lesão mensurável ou aparecimento de nova lesão ou recorrência dos sintomas $\mathrm{B}^{71}$.

Falha indutória: resposta parcial ou doença progressiva ao final do tratamento quimioterápico ou radioterápico.

Doença "bulky": linfonodo ou conglomerado de linfonodo com diâmetro maior que $10 \mathrm{~cm}^{71}$ ou massas mediastinais com tamanhos maiores que $1 / 3$ do diâmetro torácico ao nível das vértebras torácicas 5-6 ${ }^{77}$.

Baixo risco: pacientes com estadiamento clínico IA ou II A Alto risco: pacientes com estadiamento clínico IIB, III A/B e IV A/B 


\section{RESULTADOS}

No período de análise deste estudo, 89 pacientes deram entrada no serviço de Oncologia Pediátrica do Instituto da Criança/ HC- FMUSP com diagnóstico de Linfoma de Hodgkin, sendo 68 (71,5\%) elegíveis ao estudo. Dentre os pacientes excluídos três abandonaram o tratamento, onze receberam outro protocolo e sete chegaram ao serviço recaídos ou para uma segunda opinião.

As características clínicas e laboratoriais destes pacientes estão descritas na Tabela 4. Entre os casos, $20(29,4 \%)$ eram do sexo feminino e 48 $(70,6 \%)$ do sexo masculino, com uma relação $F: M$ de 1: 2,4 . A mediana de idade foi de 9 anos, com $16(23,5 \%)$ casos com 5 anos ou menos, $26(38,2 \%)$ entre 6 e 10 anos e $26(38,2 \%)$ com mais que 10 anos.

O tempo de doença decorrido até o diagnóstico apresentou uma média de 6,4 meses, sendo que $15,4 \%$ dos pacientes iniciaram os sinais e sintomas da doença até um mês antes do diagnóstico, $27,7 \%$ entre um e três meses, $30,8 \%$ entre quatro e seis meses e $26,2 \%$ com mais de seis meses. Dentre 
eles, dois casos apresentavam mais de três anos de história prévia. Em 4,4\% dos pacientes, este dado não estava disponível no prontuário.

A cadeia ganglionar mais acometida foi a cervical $(86,8 \%)$, seguida das cadeias supraclavicular $(48,5 \%)$, mediastinal $(39,7 \%)$, infra-diafragmáticas $(33,8 \%)$, e as menos comprometidas foram as axilares $(14,7 \%)$ e inguinais $(10,3 \%)$. O número de cadeias linfonodais acometidas foi menor que três em $63,2 \%$ e acima de seis em $11,7 \%$ dos casos.

Vinte e sete $(41,5 \%)$ pacientes apresentavam tumores volumosos, classificados como doença "bulky" e 12 (17,6\%) tinham massa mediastinal "bulky", destes, dois (2,9\%) abriram o quadro com síndrome da veia cava superior. Nove pacientes $(13,2 \%)$ apresentaram comprometimento do fígado e do baço ao diagnóstico. Quatro pacientes $(5,9 \%)$ tiveram acometimento de pulmão e dois $(2,9 \%)$ da medula óssea.

Dezenove $(27,9 \%)$ casos apresentaram sintomas B, sendo febre o sintoma mais comum ocorrendo em 17 casos (25\%). Nove pacientes $(13,2 \%)$ apresentaram emagrecimento, três $(4,4 \%)$ sudorese e quatro $(5,9 \%)$ prurido. $\mathrm{O}$ estadiamento foi distribuído desta forma nesta população: 13,2\% estádio I A, $42,6 \%$ II $A, 7,4 \%$ II $B, 13,2 \%$ III $A, 14,7 \%$ III $B, 2,9 \%$ IV A e $5,9 \%$ IV $B$, sendo 38 pacientes $(55,9 \%)$ de baixo risco - estadiamentos I e II A e $30(44,1 \%)$ de alto 
risco - demais casos. Entre os pacientes menores que cinco anos de idade, $11 / 16(68,7 \%)$ eram de baixo risco e $5 / 16(31,25 \%)$ eram de alto risco.

Quanto a dados laboratoriais, a hemoglobina variou de 7,3 a 15,3 g/dl, com uma média de 11,53 e mediana de $11,8 \mathrm{~g} / \mathrm{dl}$. A velocidade de hemossedimentação variou entre 5 e $116 \mathrm{~mm} / \mathrm{hora}$, sendo a média de $37,8 \mathrm{~mm} /$ hora e a desidrogenase lática variou entre 145 e 1556, com uma média de 409,4 U/L.

A avaliação histológica revelou 62 pacientes $(91,2 \%)$ com DH clássica e $4(5,9 \%)$ com DH nodular de predominância linfocitária. Dois pacientes apresentavam diagnóstico de DH com a presença das células de HRS, porém não foi possível sua classificação. Entre os casos de DH clássica, 39 (57,4\%) foram classificados como celularidade mista, 18 (26,5\%) como esclerose nodular e $5(7,4 \%)$ como depleção linfocitária. Não foram registrados casos de DH clássica rica em linfócitos. 
Tabela 4 - Características clínicas e laboratoriais dos pacientes com doença de Hodgkin tratados com o protocolo DH-II-90

\begin{tabular}{lr}
\hline Variável & Total (\%) \\
\hline Sexo & \\
F & $20(29,4 \%)$ \\
M & $48(70,6 \%)$ \\
Idade (em anos) & \\
Média \pm DP & $9,22 \pm 4,19$ \\
Mediana (Mínimo - Máximo) & $9(3-21)$ \\
Faixa etária & \\
$\leq 5$ anos & $16(23,5 \%)$ \\
De 6 a 10 anos & $26(38,2 \%)$ \\
De 11 a 15 anos & $22(32,4 \%)$ \\
16 e mais anos & $4(5,9 \%)$ \\
Tempo de história (em meses) & \\
Média \pm DP & $6,4( \pm 7,5)$ \\
Mediana (Mínimo - Máximo) & $4(0-36,5)$ \\
Tempo de história (faixas) & \\
Até 1 mês & $10(15,4 \%)$ \\
1 a 3 meses & $18(27,7 \%)$ \\
4 a 6 meses & $20(30,8 \%)$ \\
$>6$ meses & $17(26,2 \%)$
\end{tabular}


Localização de gânglios

Cervical

$59(86,8 \%)$

Axilar

$10(14,7 \%)$

Inguinal

$7(10,3 \%)$

Supraclavicular

$33(48,5 \%)$

Mediastinal

$27(39,7 \%)$

Infra-diafragmáticos

$23(33,8 \%)$

Comprometimento de sítios extra-ganglionares

Pulmão

$4(5,9 \%)$

Fígado

$9(13,2 \%)$

Baço

$9(13,2 \%)$

Medula óssea

$2(2,9 \%)$

Número de cadeias ganglionares envolvidas

Uma cadeia ganglionar

$9(13,2 \%)$

Entre 2 e 3 cadeias ganglionares

$34(50 \%)$

Entre 4 e 5 cadeias ganglionares

$17(25 \%)$

6 ou mais cadeias ganglionares

$8(11,7 \%)$

HB (em mg/dl)

Média \pm DP

$11,53 \pm 1,75$

Mediana (Mínimo - Máximo)

$11,8(7,3-15,3)$

VHS (mm/hora)

Média \pm DP

$37,79 \pm 25,54$

Mediana (Mínimo - Máximo)

$33(5-116)$ 
DHL (em U/L)

Média \pm DP

$409,43 \pm 282,36$

Mediana (Mínimo - Máximo)

$337,5(0-1556)$

Histologia

Celularidade Mista

$39(57,4 \%)$

Esclerose Nodular

$18(26,5 \%)$

Depleção Linfocitária

$5(7,4 \%)$

Predominância Linfocitária

$4(5,9 \%)$

Não Classificado

$2(2,9 \%)$

Doença "bulky"

Não

$39(59,1 \%)$

Sim

$27(40,9 \%)$

Massa mediastinal

Não

$56(82,4 \%)$

Sim

$12(17,6 \%)$

\section{Sintomas B}

Ausente

$49(72,1 \%)$

Presente

$19(27,9 \%)$

\section{Estadiamento detalhado}

IA

$9(13,2 \%)$

IIA

$29(42,6 \%)$

IIB

$5(7,4 \%)$

IIIA

$9(13,2 \%)$

IIIB

$10(14,7 \%)$

IVA

$2(2,9 \%)$

IVB

$4(5,9 \%)$ 


\section{Estadiamento}

Baixo risco $38(55,9 \%)$

Alto risco $30(44,1 \%)$

RDT

Campo envolvido $28(41,2 \%)$

Campo estendido $40(58,8 \%)$

Dose Total RDT (em cGy)

Média \pm DP $2736,76 \pm 525,94$

Mediana (Mínimo - Máximo) $3000(2100-3720)$

Dose Total de RDT - faixa (em cGy)

Menor ou igual a 2100 $24(35,3 \%)$

Maior que 2100 $44(64,7 \%)$

FONTE: HC-FMUSP

NOTA: Dados colhidos nos prontuários dos pacientes com DH tratados entre 1990 e 2005

Foi possível recuperar o material de 37 pacientes para avaliação da associação com o vírus Epstein Barr (EBV) através da técnica de hibridização in situ. Destes, $28(75,7 \%)$ foram positivos. Entre os pacientes do sexo masculino, $25 / 30(83,3 \%)$ foram positivos, entre as meninas apenas $3 / 7$ (42,8\%). A idade média dos pacientes EBV positivos foi 7,5 anos, enquanto que os pacientes negativos tinham em média 10,9 anos. Todos os pacientes com cinco anos ou menos ao diagnóstico, que foram avaliados quanto à presença 
de EBV na amostra tumoral, foram positivos. Entre os pacientes com massa mediastinal, oito foram testados, sendo metade positiva e metade negativa para EBV. Entre aqueles que apresentaram doença "bulky", dezenove foram testados, a maioria positiva $(78,9 \%)$. Com relação ao estadiamento, os pacientes de baixo risco testados apresentaram uma positividade para EBV de $76,5 \%(13 / 17)$ e aqueles de alto risco de $75 \%$ (15/20).

Quanto ao tratamento quimioterápico, todos os pacientes receberam três ciclos de ABVD. Os pacientes de alto risco receberam quimioterapia complementar prevista no protocolo, sendo que em 18 pacientes $(60 \%)$ foi administrado MOP e em 12 pacientes (40\%), COP. Quanto à radioterapia, 28 pacientes $(41,2 \%)$ receberam irradiação em campo envolvido e $40(58,5 \%)$ em campo estendido, sendo a média da dose total utilizada de $2736 c G y$, com $64,7 \%$ utilizando doses maiores que $2100 \mathrm{cGy}$.

Quarenta e um pacientes $(61,2 \%)$ não apresentaram qualquer tipo de intercorrência aguda referente ao tratamento quimioterápico. Em 27 casos $(39,7 \%)$ houve algum tipo de toxicidade aguda relacionada ao tratamento. Destes, 13/68 (19,1\%) apresentaram infecção sem necessidade de internação, 10/68 (14,9\%) apresentaram infecção com necessidade de internação, em 1/68 $(1,5 \%)$ paciente ocorreu extravasamento de quimioterapia, em 1/68 $(1,5 \%)$ 
houve hiperbilirrubinemia e em 2/68 (3\%) houve necessidade de hemotransfusão. Não houve toxicidade aguda fatal relacionada ao tratamento. Entre os pacientes de baixo risco, quatorze pacientes apresentaram quadros infecciosos, em sua maior parte infecções corriqueiras sem necessidade de internação 10/14 (71,4\%), não havendo outros tipos de intercorrências neste grupo. No grupo de pacientes com alto risco, houve um predomínio de infecções que necessitavam internação 6/13 (46,1\%). O tempo de seguimento fora de terapia variou entre 22 e 207 meses, com uma média de 109,5 meses.

\section{REMISSÃO COMPLETA}

A taxa de remissão completa após a quimioterapia prevista pelo protocolo foi de $94,1 \%(64 / 68)$ para todo o grupo. Para os pacientes de baixo risco, os quais receberam três ciclos de $A B V D$, a taxa de remissão completa foi $97,3 \%(37 / 38)$ e para aqueles de alto risco, os quais receberam mais três ciclos de MOP ou COP, foi de $90 \%(27 / 30)$. Não houve falha indutória para pacientes com cinco anos de idade ou menos. 
Quatro pacientes apresentaram falha indutória. Um paciente era de baixo risco de estadiamento IIA, foi tratado com o protocolo para alto risco com mais três ciclos de MOP e radioterapia campo envolvido na dose de 3000 cGy, alcançando a remissão completa, e mantém-se sem sinais de recaída após mais de dez anos de seguimento. Três pacientes com falha indutória eram de alto risco. Entre eles, um paciente recebeu quimioterapia alternativa, entrou em remissão e a manteve após três anos de seguimento. Os outros dois pacientes mantiveram doença refratária e foram a óbito durante terapia de resgate.

A probabilidade de SLD para todo o grupo foi de $89,7 \% \pm 3,7$ (figura 1) após 5 anos e 10 anos, tendo o grupo de alto risco pior SLD (figura 2) quando comparada com o de baixo risco, $92,1 \% \pm 4,4$ e $86,5 \% \pm 6,3$ respectivamente, porém sem significado estatístico $(p: 0,468)$. A probabilidade de SLD em 10 anos foi de $96,4 \% \pm 3,5$ para pacientes EBV positivos e $77,8 \% \pm 13,8$ para aqueles negativos (figura 3), mas esta diferença também não foi significante ( $p$ : $0,063)$. 
Figura 1. Curva de estimativa de sobrevida livre de doença para todo o grupo de pacientes com doença de Hodgkin pelo método de Kaplan-Meier

Tempo de Sobrevida Livre de Doença

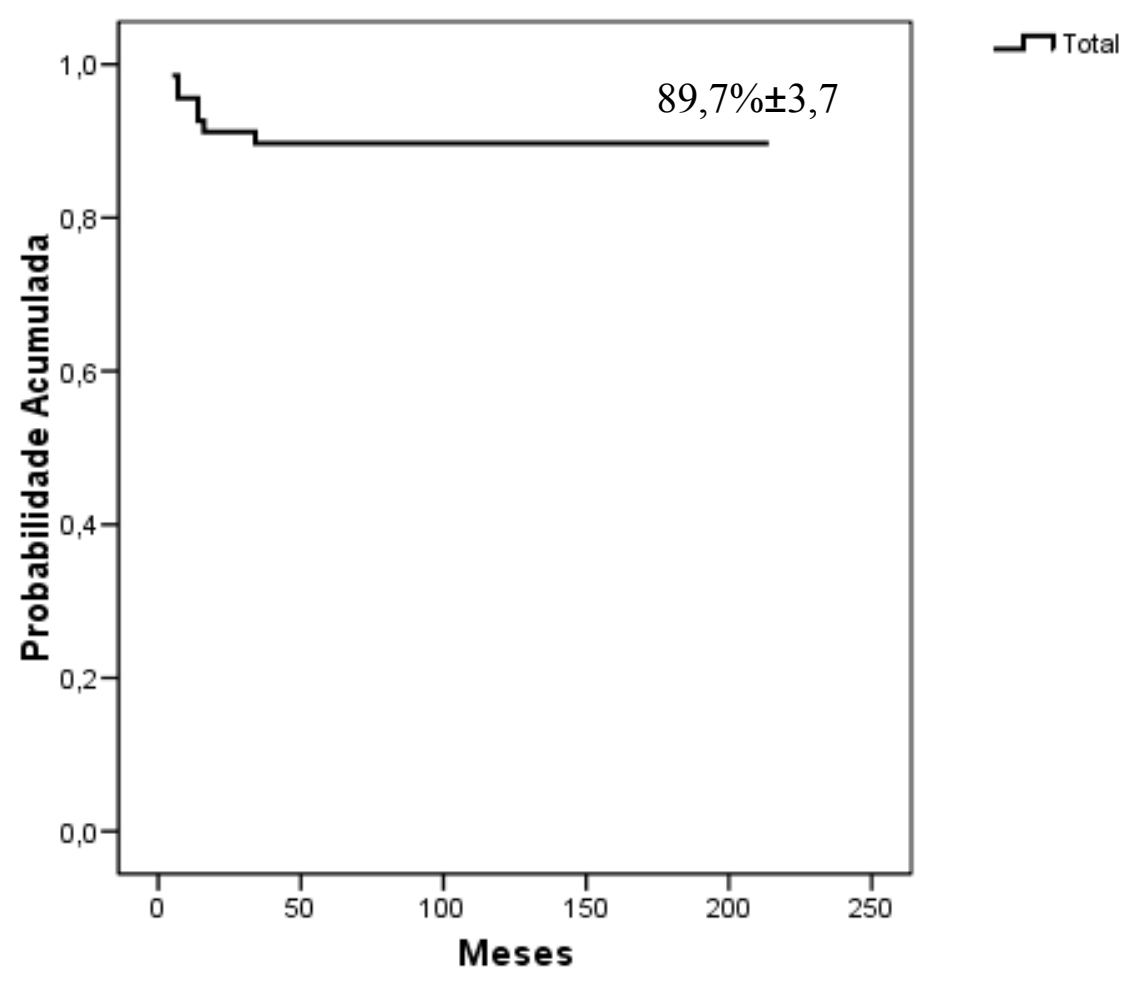


Figura 2. Curva de estimativa de sobrevida livre de doença para pacientes com doença de Hodgkin por estadiamento pelo método de Kaplan-Meier

\section{Tempo de Sobrevida Livre de Doença por Estadiamento}

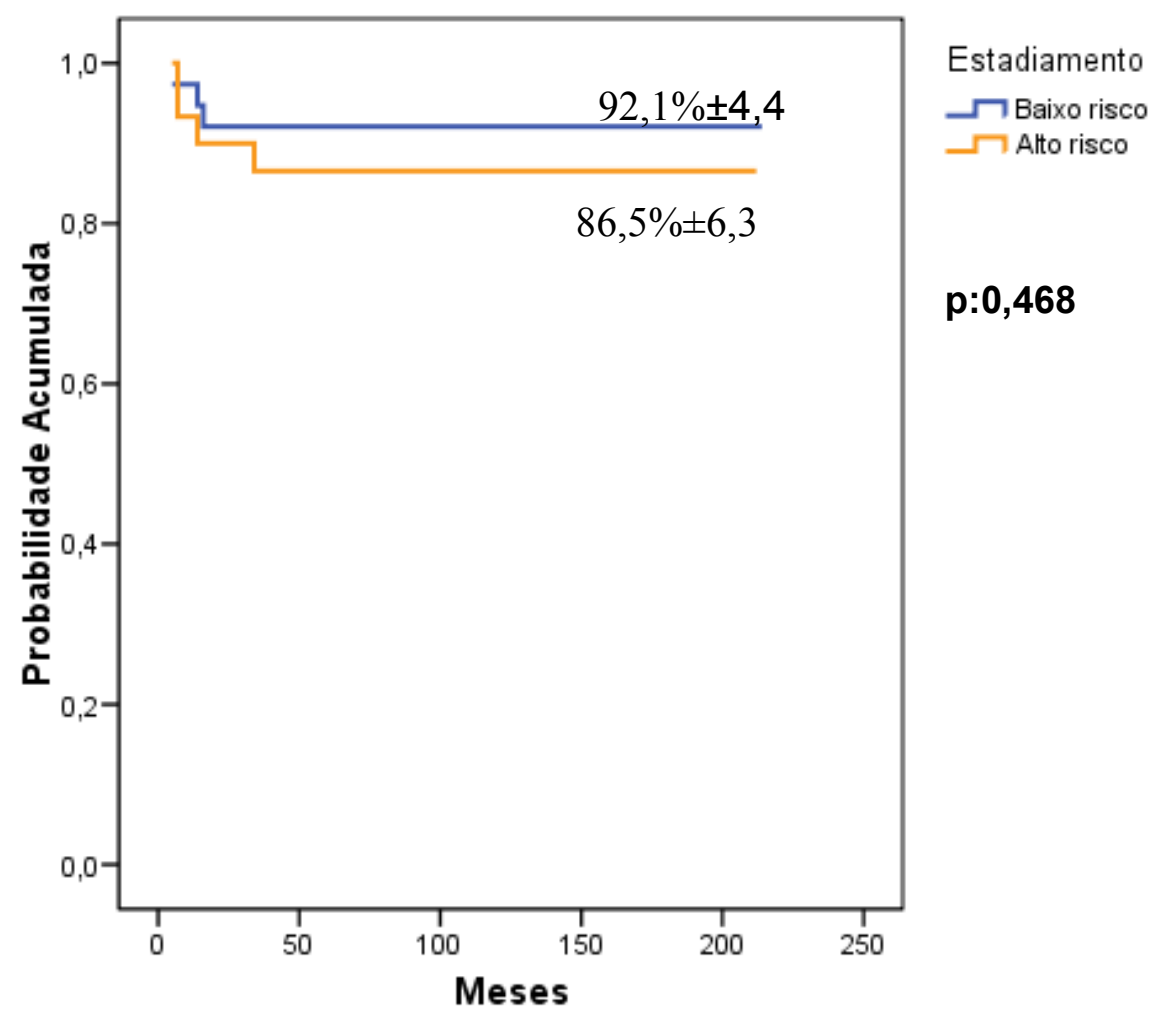


Figura 3. Curva de estimativa sobrevida de livre de doença pela positividade (1) ou não (2) ao EBV em pacientes com doença de Hodgkin pelo método de Kaplan-Meier

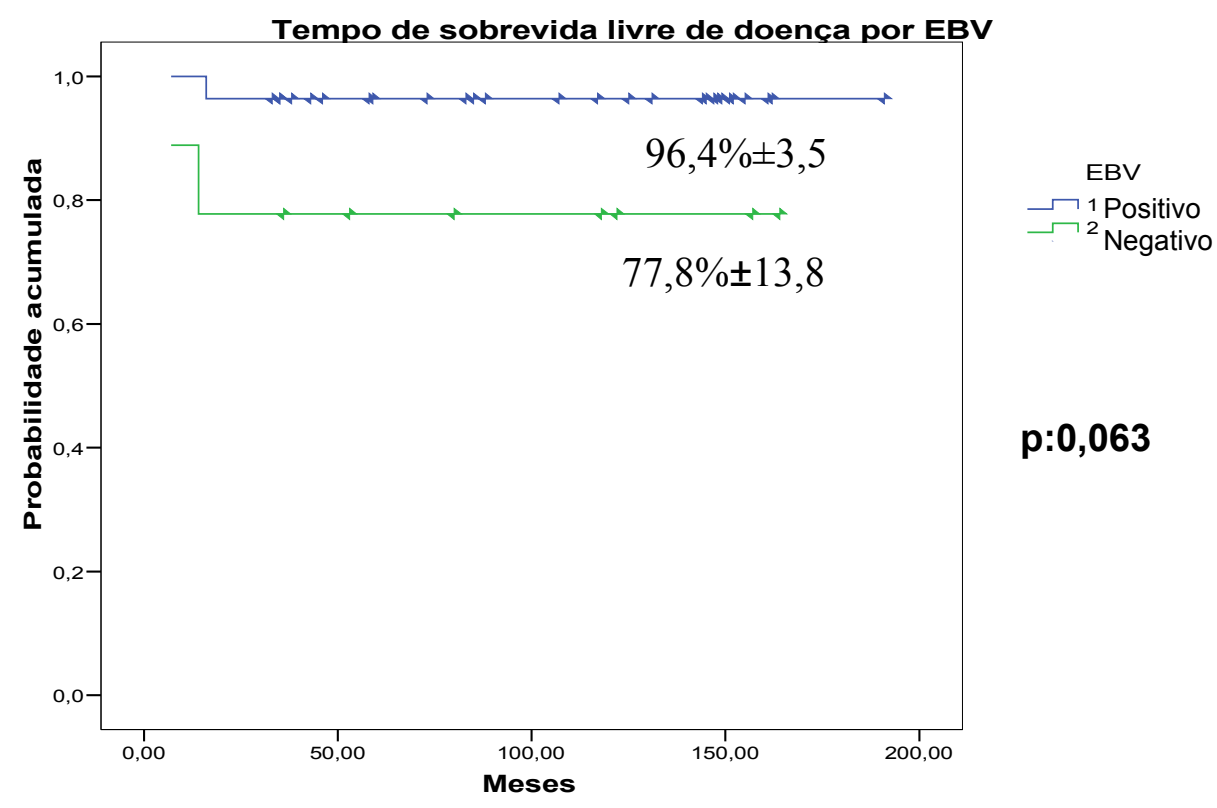




\section{EVENTOS}

A probabilidade de sobrevida livre de eventos foi de $89,7 \% \pm 3,7$ após 5 anos e $87,8 \% \pm 4,0$ após 10 anos para todo o grupo (figura 4). Pacientes de baixo risco apresentaram SLE (figura 5) melhor que os pacientes de alto risco em 5 anos $(92,1 \% \pm 4,4$ versus $86,5 \% \pm 6,3)$, porém semelhantes em 10 anos $(88,9 \% \pm 5,2$ versus $86,5 \% \pm 6,3)$ e esta diferença não foi estatisticamente significante (p: 0,969).

As figuras 6,7 e 8 evidenciam que também não foram estatisticamente diferentes a probabilidade de SLE quando comparadas por faixa etária $(p: 0,577)$, doença "bulky" ( $p: 0,341)$ ou por radioterapia campo envolvido versus campo estendido ( $\mathrm{p}: 0,733)$, respectivamente. 
Figura 4. Curva de estimativa de sobrevida livre de eventos para todo o grupo de pacientes com doença de Hodgkin pelo método de Kaplan-Meier

Tempo de Sobrevida Livre de Evento

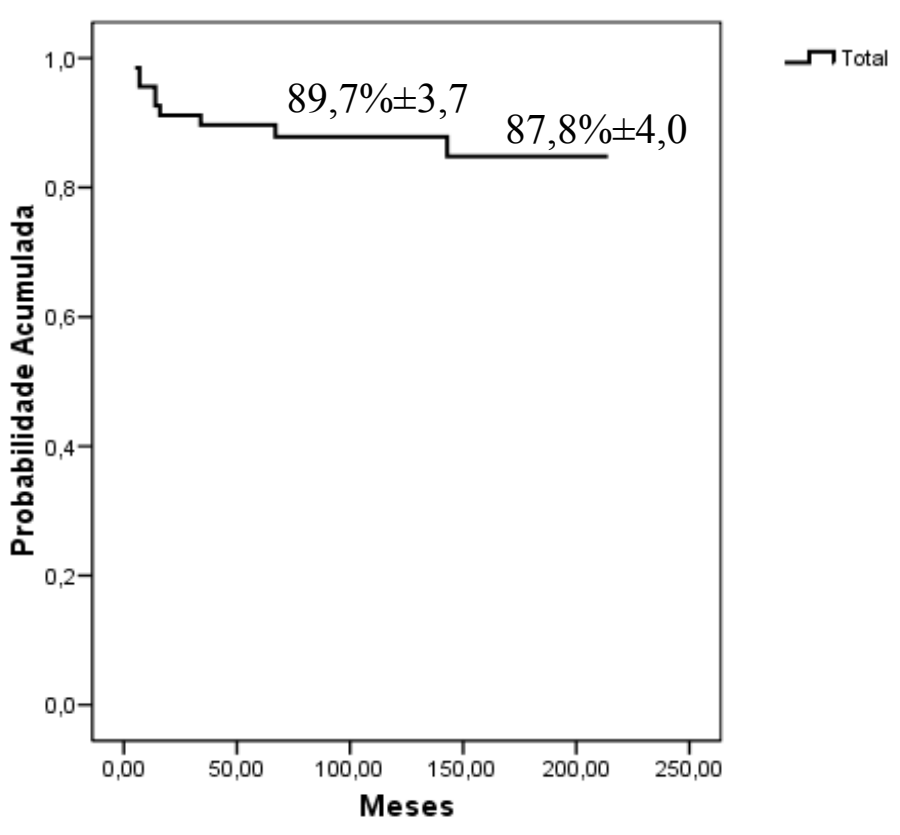


Figura 5. Curva de estimativa de sobrevida livre de eventos para pacientes com doença de Hodgkin por estadiamento pelo método de Kaplan-Meier

\section{Tempo de Sobrevida Livre de Evento por Estadiamento}

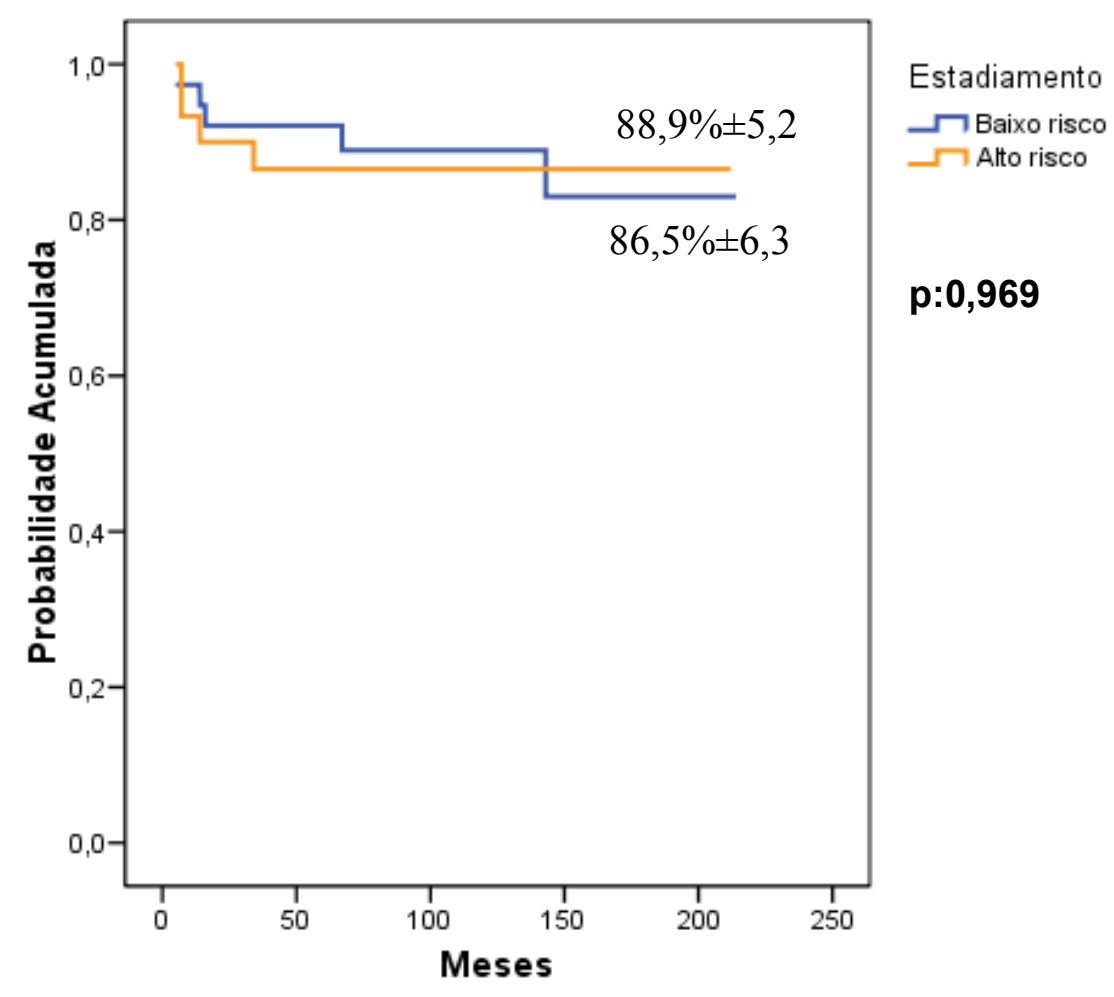


Figura 6. Curva de estimativa de sobrevida livre de eventos por faixa etária para pacientes com doença de Hodgkin pelo método de KaplanMeier

Tempo de Sobrevida Livre de Evento por Faixa Etária

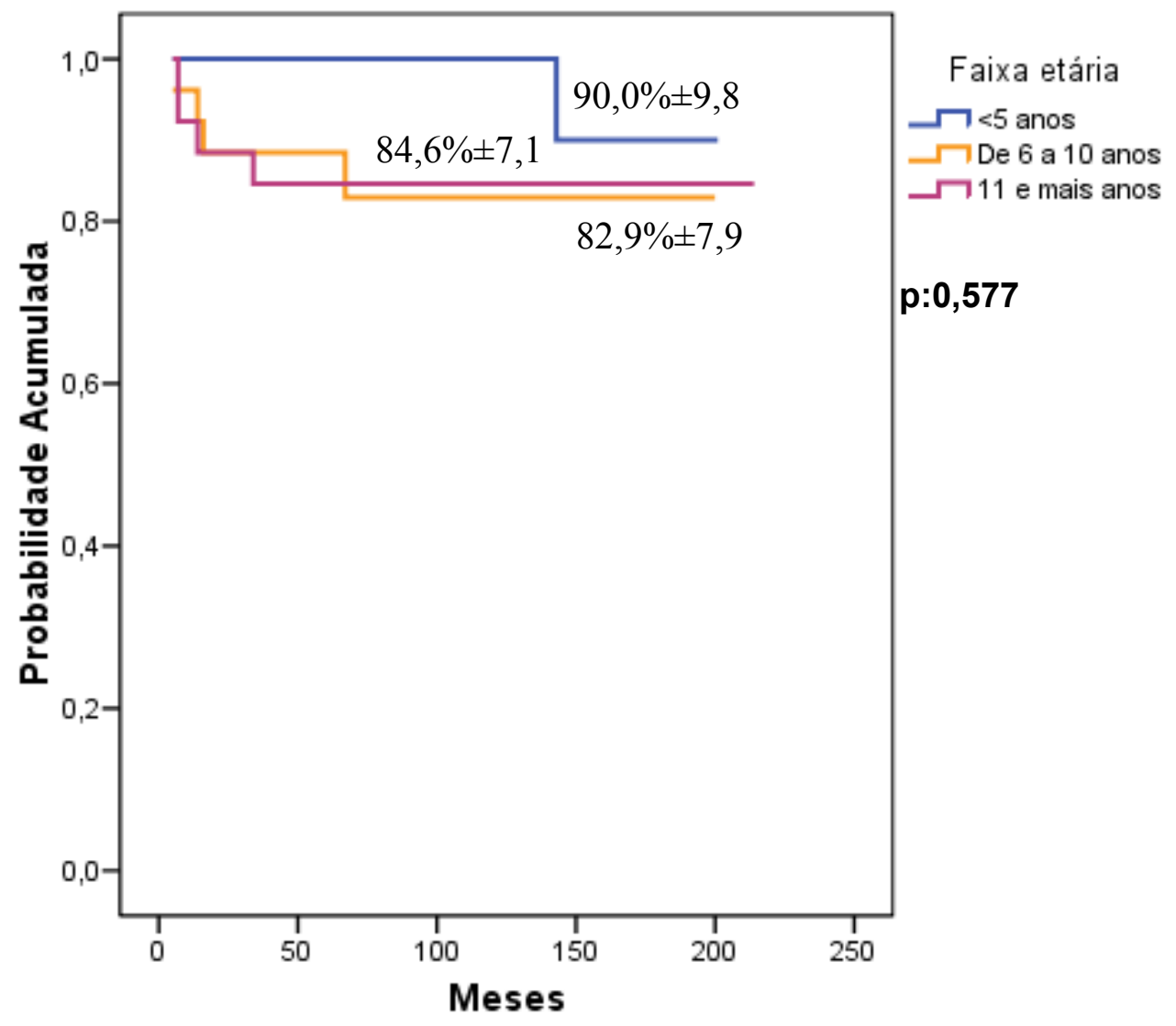


Figura 7. Curva de estimativa de sobrevida livre de eventos pela ausência (1) ou presença (2) de doença "bulky" em pacientes com doença de Hodgkin pelo método de Kaplan-Meier

Tempo de Sobrevida Livre de Evento por Bulky

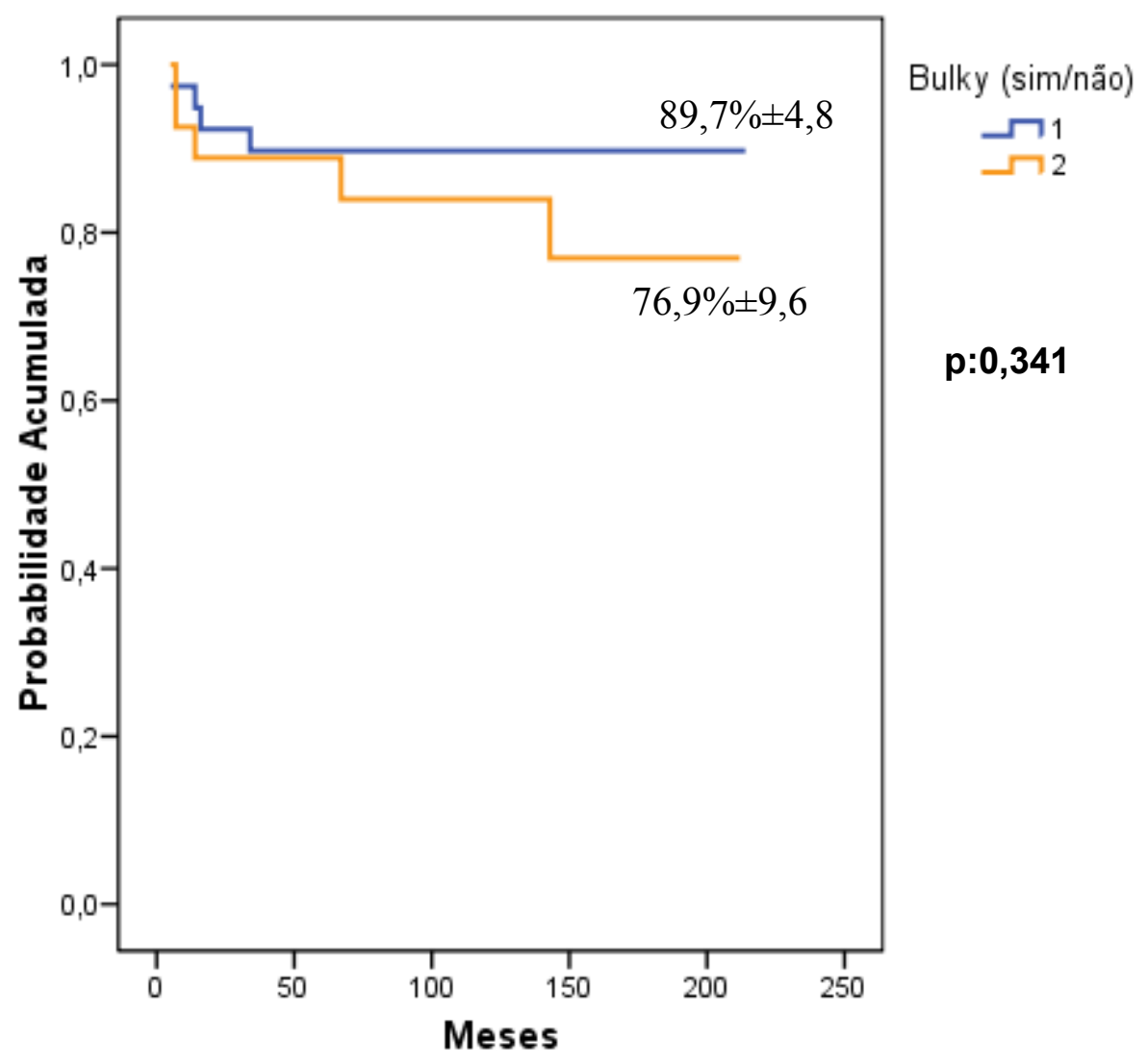


Figura 8. Curva de estimativa de sobrevida livre de eventos por tipo de radioterapia campo envolvido versus campo estendido para pacientes com doença de Hodgkin pelo método de Kaplan-Meier

\section{Tempo de Sobrevida Livre de Evento por RDT}

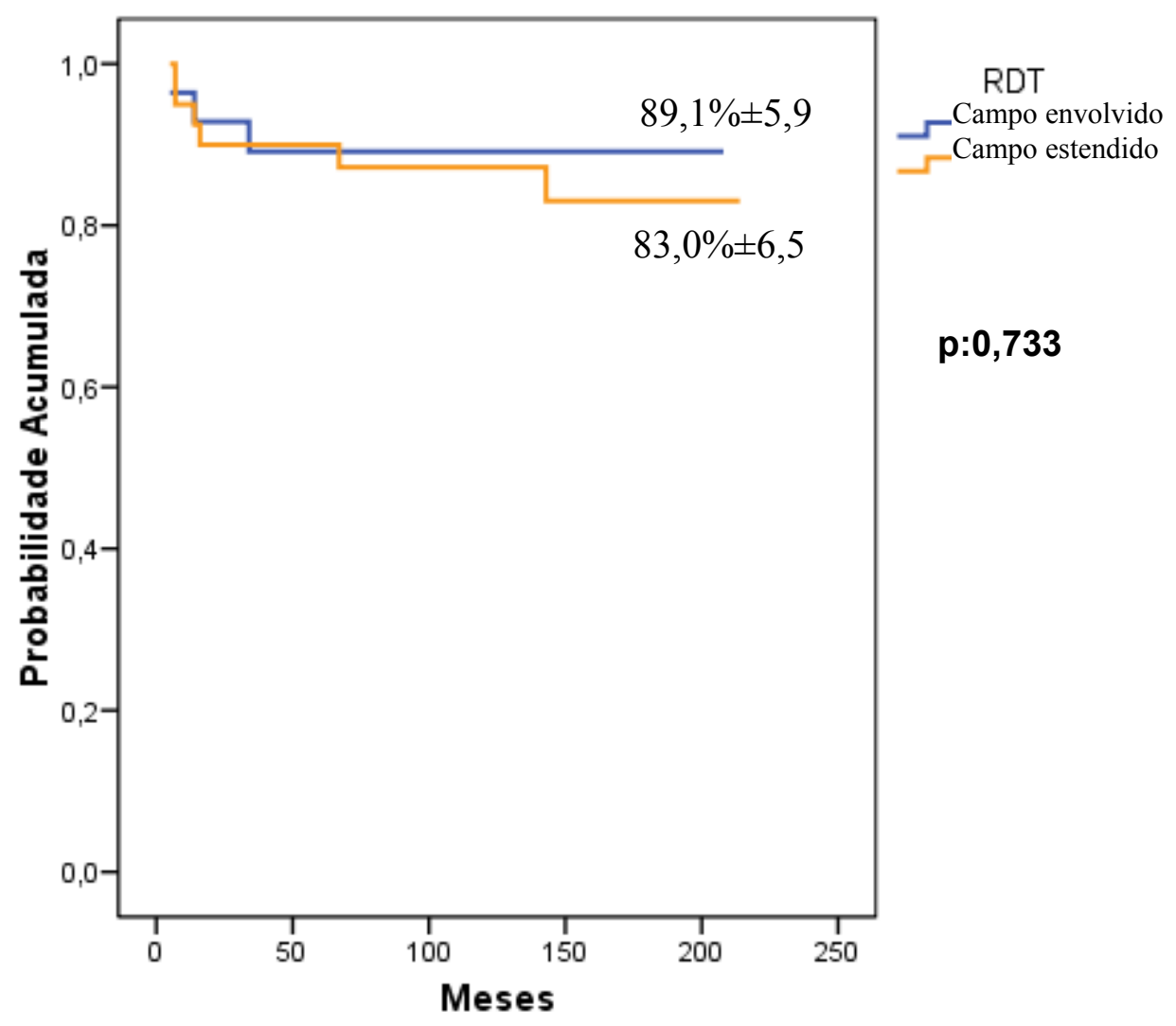


A probabilidade de SLE foi melhor para aqueles pacientes sem sintomas B (figura 9) nos primeiros 5 anos após o tratamento $(91,8 \% \pm 3,9$ versus $84,2 \%$ $\pm 8,4$ respectivamente, p: 0,014), porém as curvas se aproximam após 10 anos de observação $(89,2 \% \pm 4,6$ versus $84,2 \% \pm 8,4)$.

Diferença maior foi observada quando foram comparadas a presença ou ausência de massa mediastinal e a dose de radioterapia utilizada $(\leq 2100$ ou $>2100$ cGy). Pacientes com massa mediastinal apresentam SLE de 75,0 $\pm 12,5$ e $65,6 \% \pm 14,0$ e pacientes sem massa mediastinal apresentam SLE de 92,8 $\pm 3,4$ e $92,8 \% \pm 3,4$, respectivamente em 5 e 10 anos (figura 10, p: 0,020).

Pacientes que receberam radioterapia com baixas doses tiveram $100 \%$ de SLE e aqueles que receberam doses maiores que 2100 cGy tiveram $84,0 \%$ $\pm 5,5$ e $81,0 \% \pm 6,1$ de SLE respectivamente em 5 e 10 anos (figura 11, p: 0,014).

Foi observada ainda uma SLE estatisticamente melhor para pacientes EBV positivos $-96,4 \% \pm 3,5$ versus $62,2 \% \pm 17,8$ em 10 anos (figura 12, p: 0,029). 
Figura 9. Curva de estimativa de sobrevida livre de eventos para pacientes com doença de Hodgkin pela presença ou não de sintomas B pelo método de Kaplan-Meier

Tempo de Sobrevida Livre de Evento por Sintomas B

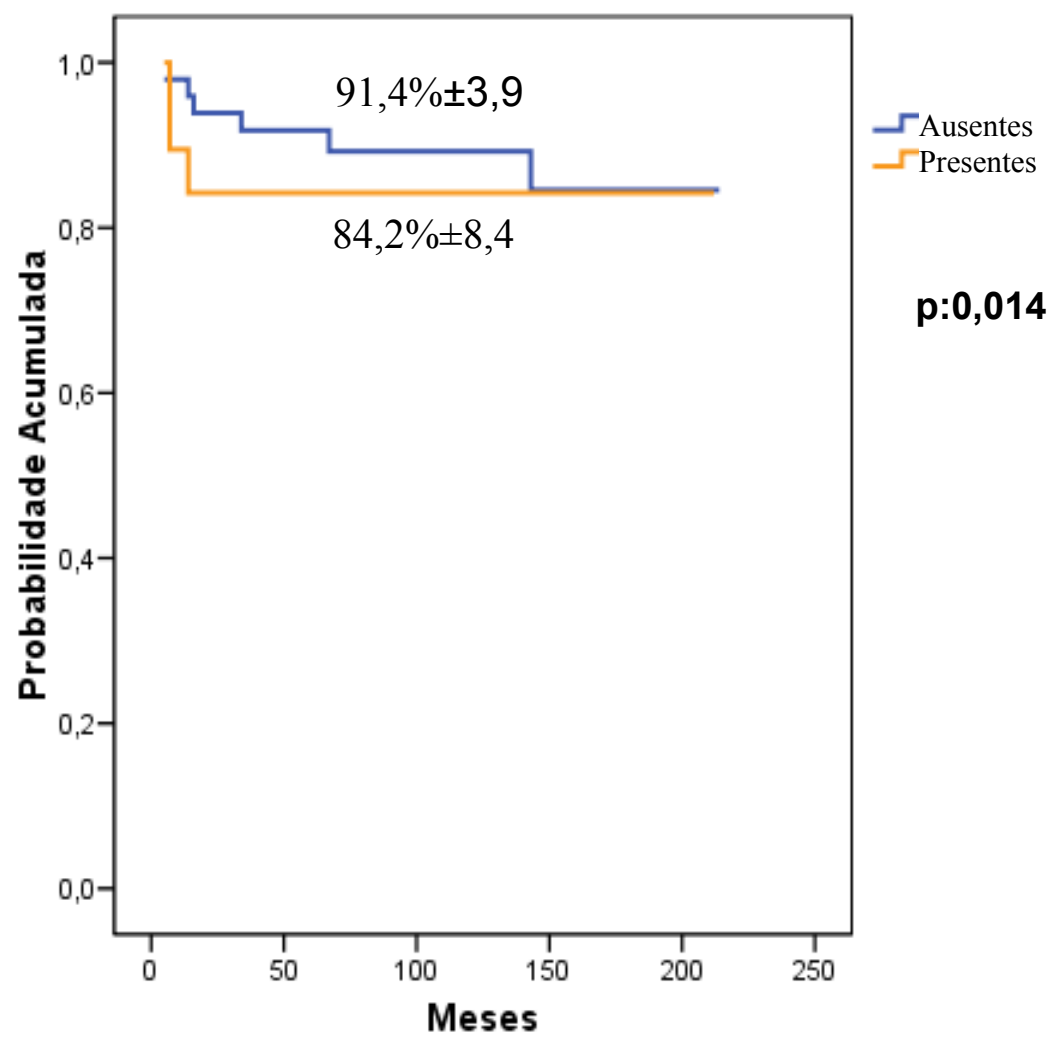


Figura 10. Curva de estimativa de sobrevida livre de eventos para pacientes com doença de Hodgkin pela presença ou ausência de massa mediastinal pelo método de Kaplan-Meier

Tempo de Sobrevida Livre de Evento por Massa Mediastinal

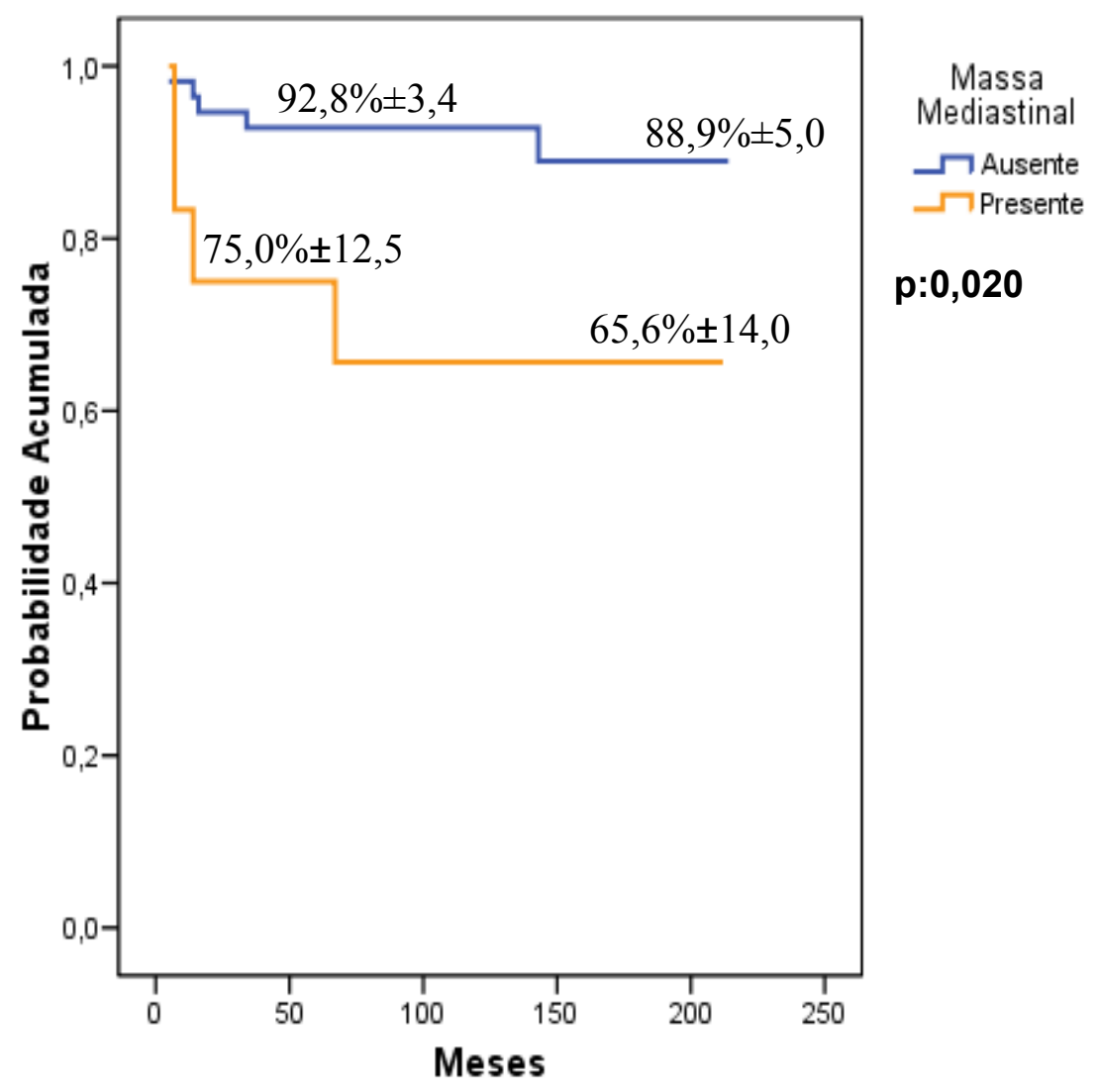


Figura 11. Curva de estimativa de sobrevida livre de eventos por dose total de radioterapia ( $\leq 2100$ versus $>2100$ cGy) para pacientes com doença de Hodgkin pelo método de Kaplan-Meier

\section{Tempo de Sobrevida Livre de Evento por Dose Total de Radioterapia}

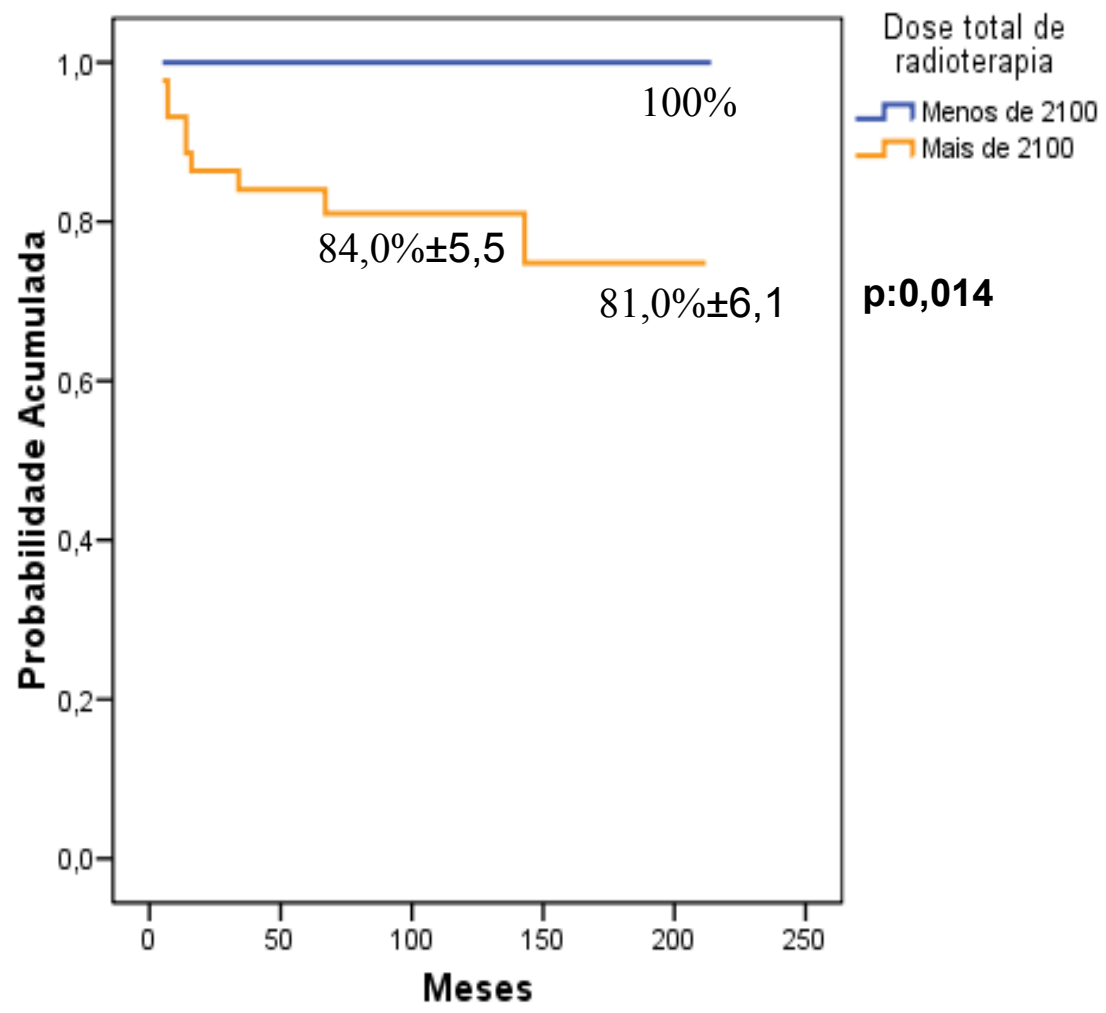


Figura 12. Curva de estimativa de sobrevida livre de eventos para pacientes com doença de Hodgkin pela positividade (1) ou não (2) ao EBV pelo método de Kaplan-Meier

Tempo de sobrevivência livre de evento por EBV

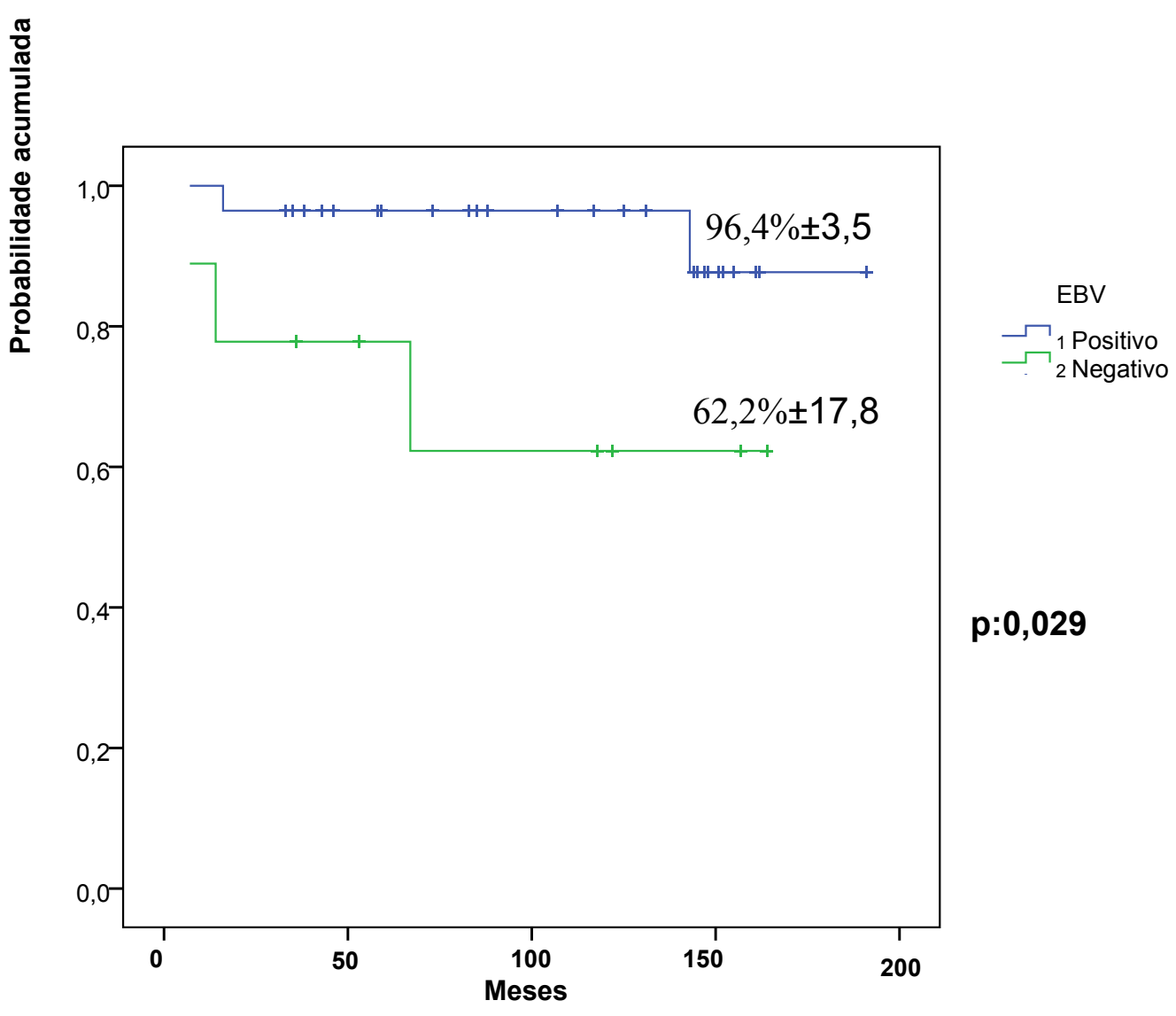


Houve três recaídas $(4,4 \%)$, dois pacientes de baixo risco e um de alto risco. Um dos casos de recaída do grupo de baixo risco foi submetido a várias tentativas de terapia de resgate, incluindo transplante autólogo e outro alogênico de medula óssea, porém faleceu por complicações deste último. Os outros dois casos, entraram em remissão após quimioterapia alternativa, porém ambos apresentam descrições de efeitos tardios do tratamento: alteração estrutural da glândula tireóide e espermograma alterado.

Houve três óbitos $(4,4 \%)$, dois por doença refratária e um por complicações de transplante alogênico de medula óssea. A probabilidade de sobrevida global foi de $97,0 \% \pm 2,0$ e $94,8 \% \pm 3,0$ em 5 e 10 anos respectivamente (figura 13), sendo $96,1 \% \pm 3,8$ para o grupo de baixo risco e $93,3 \% \pm 4,5$ para o alto risco em 10 anos (figura 14). Não houve óbitos no grupo de pacientes com pesquisa para EBV positiva, com uma probabilidade de SG de $100 \%$ e $71,1 \% \pm 18,0$ respectivamente em pacientes positivos e negativos (figura 15, p: 0,012 ). O tempo de seguimento médio dos pacientes foi de 125,2 meses (33 a 214 meses) com uma mediana de 129,5 meses. 
Figura 13. Curva de estimativa de sobrevida global para todo o grupo de pacientes com doença de Hodgkin pelo método de Kaplan-Meier.

Tempo de Sobrevida Global

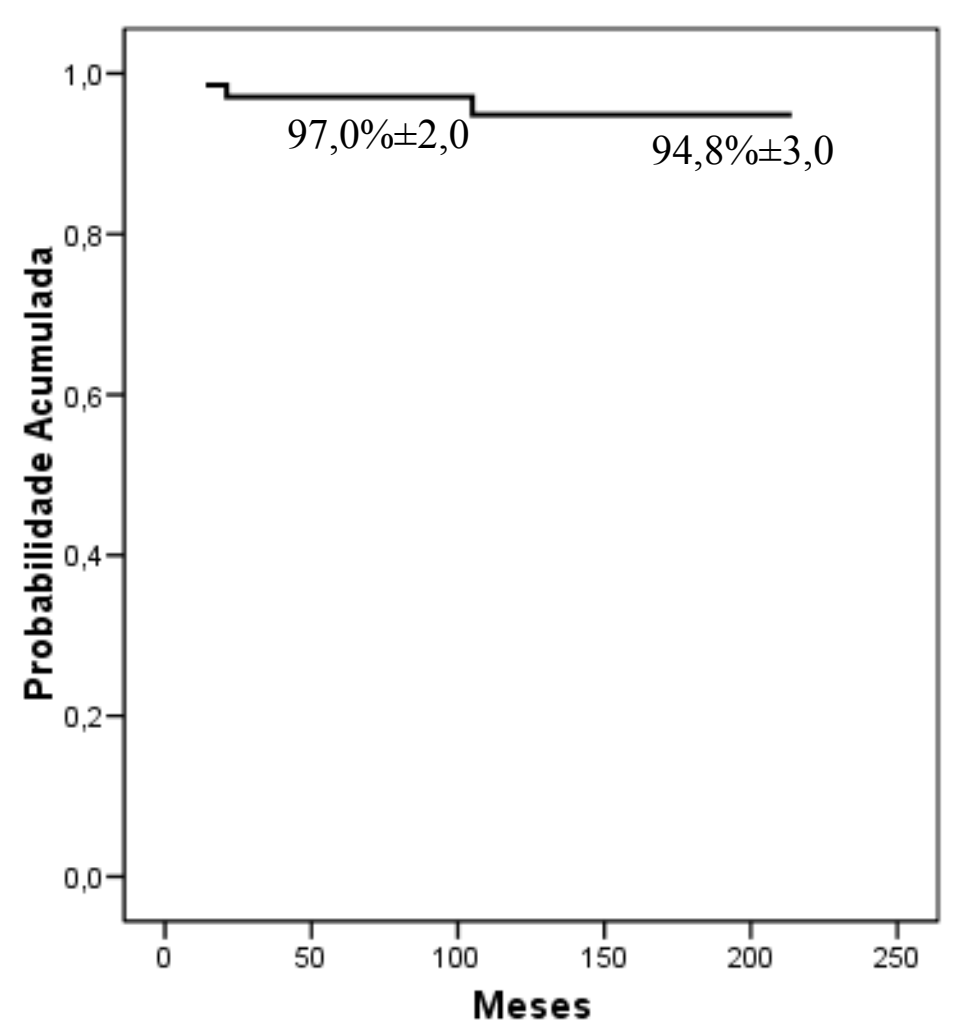

$\neg$ Total 
Figura 14. Curva de estimativa de sobrevida global para pacientes com doença de Hodgkin por estadiamento pelo método de Kaplan-Meier

Tempo de Sobrevida Global por Estadiameto

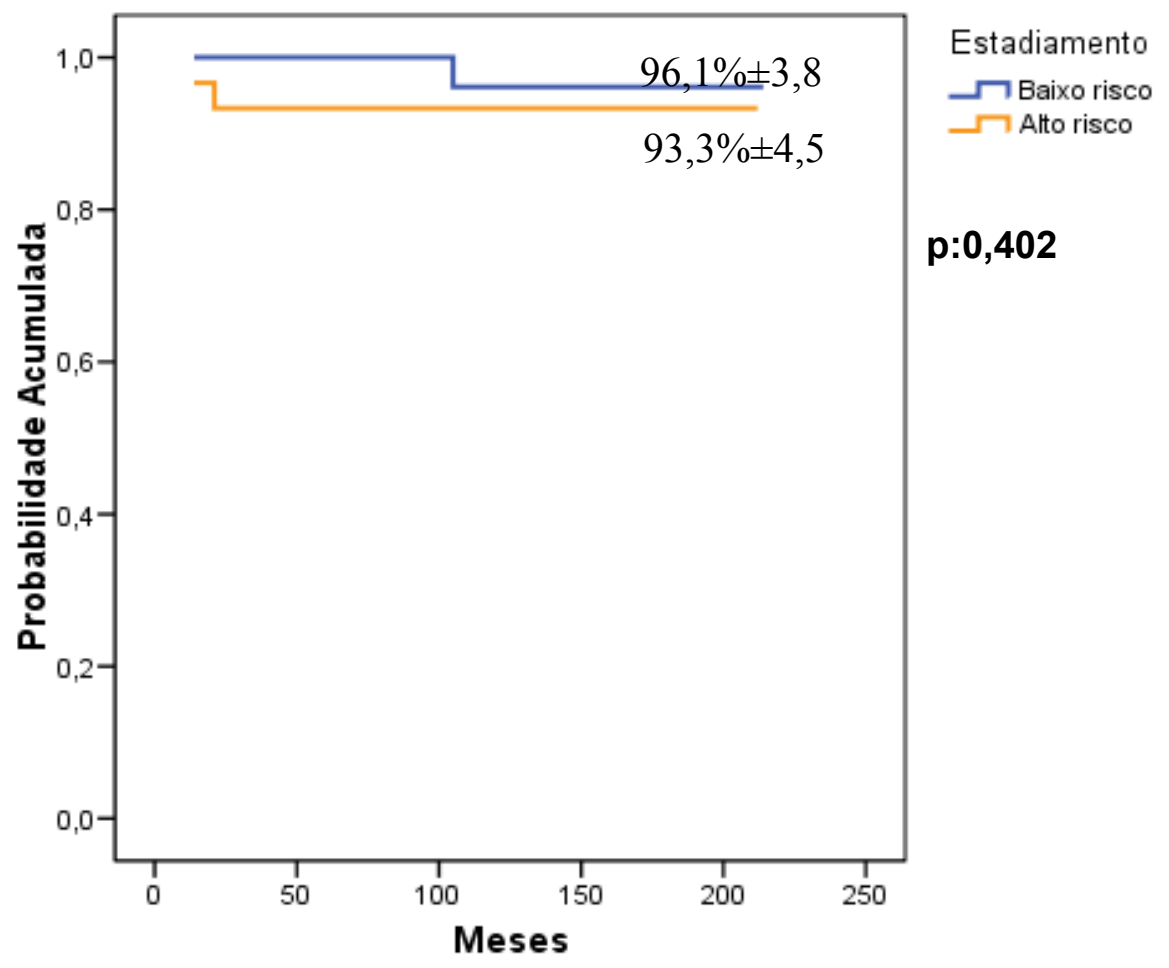


Figura 15. Curva de estimativa de sobrevida global para pacientes com doença de Hodgkin pela positividade (1) ou não (2) ao EBV pelo método de Kaplan-Meier

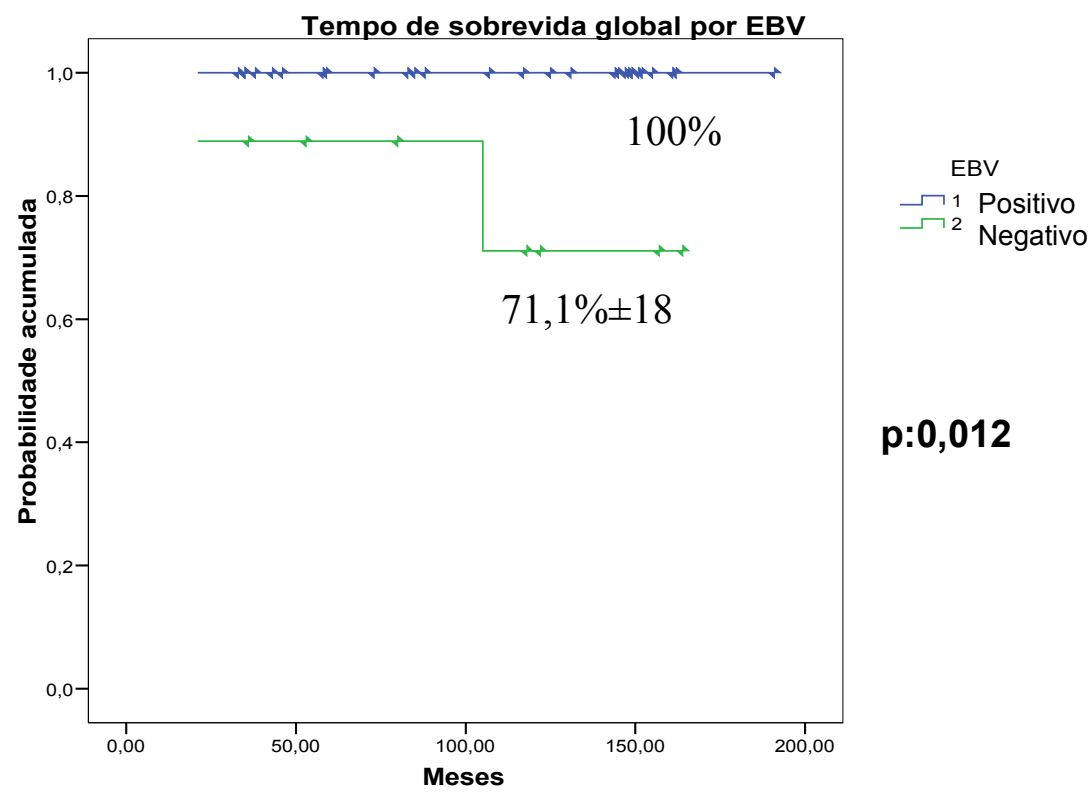


Ainda sobre os eventos ocorridos, entre os pacientes sobreviventes, foi observado que $35 / 65(53,8 \%)$ apresentavam algum tipo de toxicidade tardia. Dentre eles, 15 (42,9\%) apresentaram alguma disfunção da glândula tireóide. Seis pacientes tiveram disfunção funcional da tireóide: quatro com hipotireoidismo e quatro com hipertireoidismo. Nove pacientes apresentaram disfunção anatômica, destes, dois (2,9\% de toda a amostra) evoluíram com carcinoma de tireóide como segunda neoplasia, tendo sido irradiados com cinco e oito anos de idade com doses maiores que 2100 cGy. A tabela 5 descreve todos os efeitos tardios descritos em prontuário por paciente. 
Tabela 5 - Descrição de efeitos tardios do protocolo DH-II-90 descritos em prontuário, por paciente com doença de Hodgkin.

\begin{tabular}{ll}
\hline Paciente & \multicolumn{1}{c}{ Efeito tardio } \\
\hline VMCO & Disfunção anatômica da glândula tireóide - carcinoma de \\
& tireóide \\
AVS & Gastrite com H. pilori \\
CP & Psoríase \\
EMV & Baixa estatura e atraso puberal \\
KCF & Prolapso de válvula mitral e varizes \\
RSO & Amenorréia secundária \\
MDO & Pneumonias de repetição \\
MLB & Prolapso retal \\
EAS & Disfunção funcional da tireóide- hipertireoidismo \\
FSF & Asma, baixo rendimento escolar \\
GAL & Dilatação de ventrículo esquerdo \\
GCR & Disfunção funcional da tireóide- hipotireoidismo \\
ISA & Disfunção funcional da tireóide- hipotireoidismo \\
LHB & Baixa estatura \\
LOL & Disfunção anatômica da glândula tireóide \\
LMP & Sobrepeso \\
PMM & Hipoplasia mamária direita e disfunção funcional da tireóide- \\
& hipotireoidismo \\
PHSG & Disfunção anatômica da glândula tireóide \\
RFL & Obesidade \\
SASS & Parotidite \\
TSG & Disfunção funcional da tireóide- hipotireoidismo \\
VRL & Hipoplasia da cintura escapular, ginecomastia e disfunção \\
SRF & anatômica da glândula tireóide \\
LBSN & Púrpura trombocitopênica idiopática \\
MCASJ & Disfunção anatômica da glândula tireóide - carcinoma de \\
NMS & Direóide \\
FGRS & Disfunção função funcional da tireóide- hipertireoidismo da tireóide- hipertireoidismo \\
FFB & Dislipidemia \\
MAOJ & Instabilidade do joelho \\
& Asma e disfunção anatômica da glândula tireóide \\
&
\end{tabular}


GBF Proliferação miofibroblástica com atipia em couro cabeludo e nódulo ósseo em escápula

JSS Herpes Zoster

RM Espermograma alterado

$\mathrm{CL} \quad$ Espermograma alterado

PKZ Disfunção funcional da tireóide- hipertireoidismo

TSLI Disfunção anatômica da glândula tireóide e obesidade

FONTE: HCFMUSP

NOTA: Pacientes fora de terapia durante o período 1990 - 2008 
Foi realizada, ainda, a análise de sobrevida para os pacientes de alto risco comparando-se o uso de MOP e COP, porém não houve diferença estatisticamente significante para SG (p:0,821), SLD (figura 16, p:0,135) e SLE (figura 17, p:0,135).

$\mathrm{Na}$ análise multivariada para determinar um conjunto de fatores que causam maior impacto na ocorrência de falha indutória, recidiva, óbito ou segunda neoplasia, apenas massa mediastinal e estadiamento I foram selecionadas. A presença de massa mediastinal apresenta um risco de 2,78 vezes maior ( $p: 0,006)$ e o estadiamento I confere um risco de 2,69 vezes menor (p: 0,030) de ter algum destes eventos. 
Figura 16. Curva de estimativa de sobrevida livre de doença de pacientes com doença de Hodgkin pelo uso de MOP ou COP pelo método de Kaplan-Meier

Tempo de Sobrevida Livre de Doença por MOPICOP

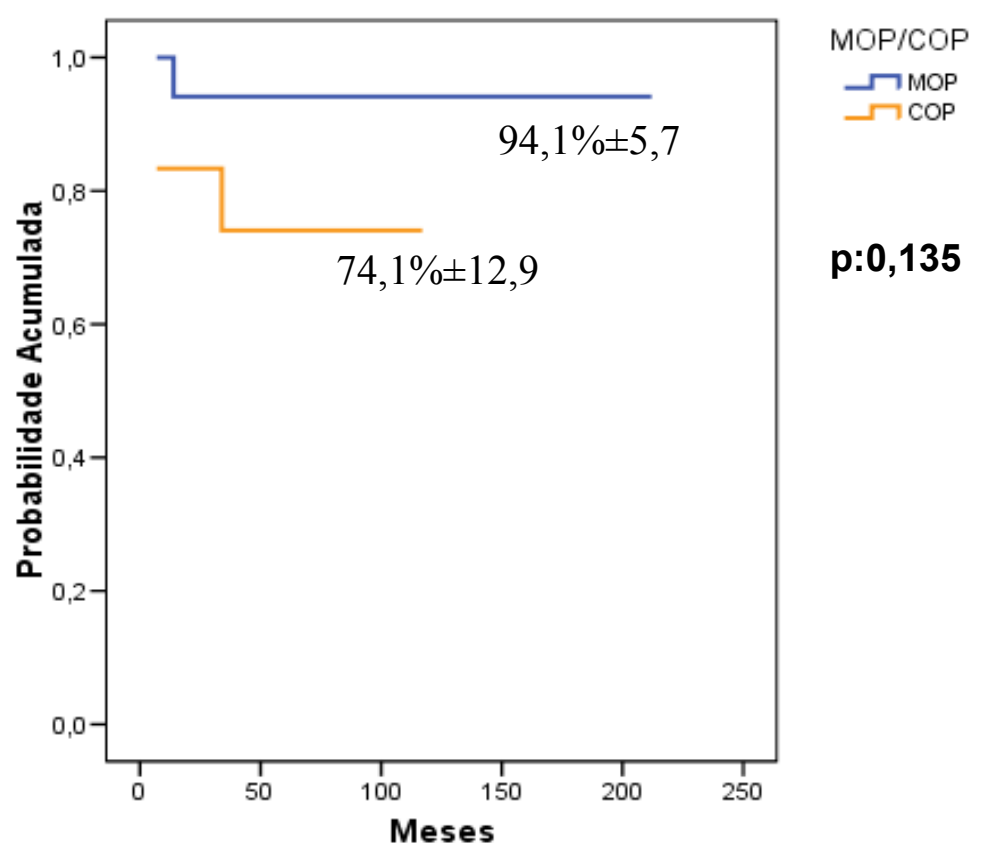


Figura 17. Curva de estimativa de sobrevida livre de eventos para pacientes com doença de Hodgkin pelo uso de MOP ou COP pelo método de Kaplan-Meier

Tempo de Sobrevida Livre de Evento por MOPICOP

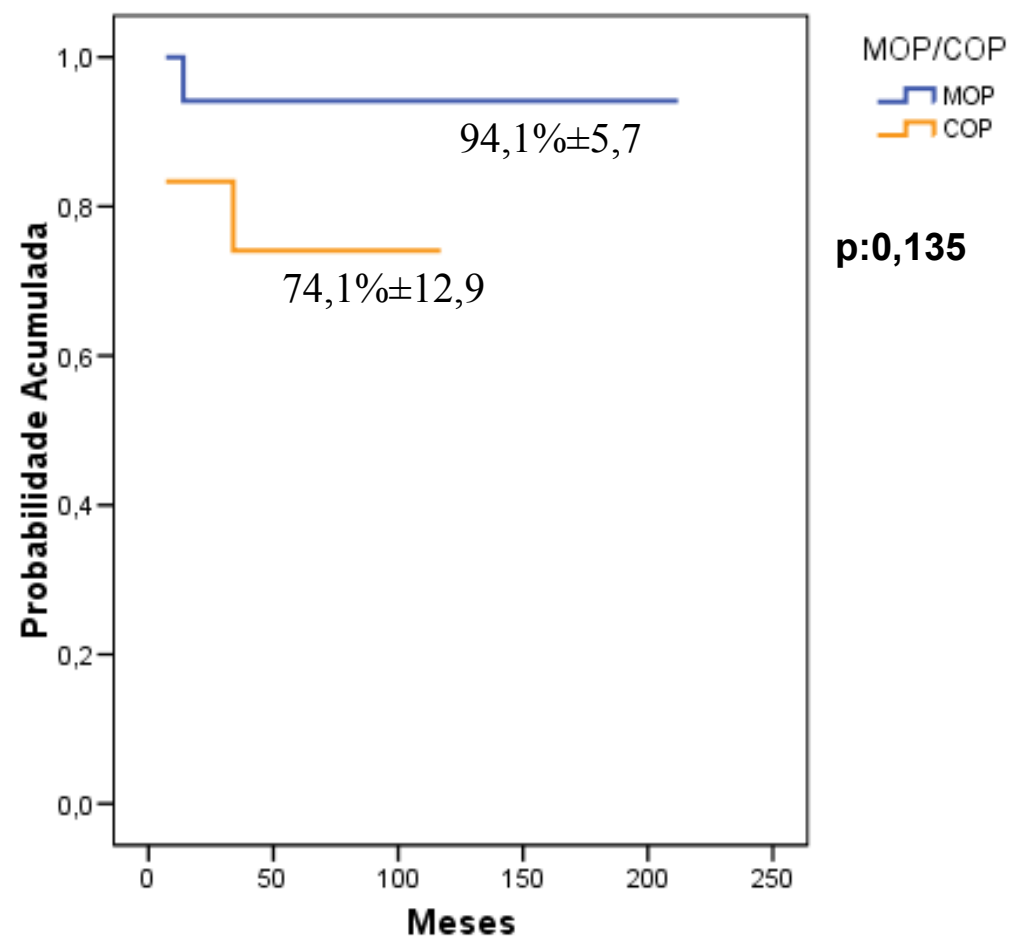




\section{DISCUSSÃO}

Considerando-se que o tratamento curativo para DH já é disponível há mais de trinta anos ${ }^{7,85,88,89,90,93}$, oncologistas que tratam crianças e adolescentes têm uma expectativa de sobrevida longa e cada vez mais há uma necessidade de fornecer a elas qualidade de vida. Com esta finalidade, o protocolo $\mathrm{DH}-\mathrm{I}-86$ foi introduzido e posteriormente modificado para o protocolo $\mathrm{DH}-\mathrm{II}-90$, o qual propunha uma redução na intensidade da quimioterapia e radioterapia.

Esta dissertação fez uma análise retrospectiva dos resultados de tratamento dos pacientes com $\mathrm{DH}$ que utilizaram o protocolo $\mathrm{DH}-\mathrm{II}-90$, avaliando o impacto do uso de menores doses de quimioterapia e radioterapia na sobrevida destes pacientes. Descreveu-se as características clínicas dos pacientes com $\mathrm{DH}$ sem tratamento prévio e que deram entrada no serviço de oncologia pediátrica do ICr-HC-FMUSP entre 1990 e 2005, e ainda relatou-se os possíveis efeitos tardios relacionados ao tratamento.

Foi observada maior ocorrência da $\mathrm{DH}$ em pacientes do sexo masculino o que é compatível com a literatura ${ }^{24,25,29,97}$. No entanto, este predomínio foi visto 
apenas no grupo com idade inferior a 10 anos, tornando a relação sexo feminino:sexo masculino equivalente entre os adolescentes (1:1). A maior freqüência do sexo masculino em pacientes de tenra idade foi inicialmente descrita por MacMahon ${ }^{25}$ em 1966 e posteriormente confirmada por outros autores $^{24,30,97}$. A predominância do sexo masculino parece ter mesmo menor relevância após os 10 anos de idade ${ }^{24,30}$.

Houve uma preponderância de pacientes com idade inferior a 10 anos, com cerca de um quarto da amostra com menos de cinco anos de idade, o que não é descrito por outros autores ${ }^{30,97}$. Há que se considerar que os pacientes admitidos ao serviço de oncologia pediátrica do ICr-HC-FMUSP são encaminhados em grande número pelo setor de emergência deste hospital e este tem um limite para atendimento da demanda externa em 14 anos. Logo, este serviço atende a uma faixa etária mais jovem, e proporcionalmente menor número de adolescentes, o que talvez justifique este achado. Weltman ${ }^{26}$ também observou um alto índice de pacientes com menos de quatro anos de idade $(18,4 \%)$ e com $51,5 \%$ da sua amostra entre cinco e nove anos, neste mesmo serviço.

Todavia, pode-se também supor que a incidência de crianças pequenas com DH seja realmente maior na população brasileira, como alguns autores 
têm relatado ocorrer em países em desenvolvimento ${ }^{24,30,98}$. Dados do INCA deixam a desejar quando se trata da população pediátrica, visto que a estimativa de incidência de câncer com base populacional no Brasil avalia tumores pediátricos como um grupo único de doenças, com poucas referências aos seus subtipos e faixas etárias pediátricas ${ }^{99}$. Isto dificulta uma avaliação objetiva da incidência da $\mathrm{DH}$ nesta população. Desta forma, dados epidemiológicos ainda são escassos em países em desenvolvimento e isto complica a inferência adequada do resultado da faixa etária deste estudo.

Quanto à variação histológica, observou-se que a maior parte da amostra apresentava histologia do subtipo celularidade mista $(57,4 \%)$, o que contrasta com dados americanos onde cerca de $70 \%$ dos casos são do subtipo esclerose nodular ${ }^{100}$. Estes dados, no entanto, são compatíveis com aqueles de países em desenvolvimento ${ }^{26,30}$. Estudos brasileiros demonstram achados controversos. Elgui de Oliveira et al $^{101}$ estudaram pacientes com $\mathrm{DH}$ em localizações distintas do país - Ceará e São Paulo, sendo a celularidade mista o subtipo histológico mais encontrado nos grupos pediátricos (65 e 68\% respectivamente) independentemente da procedência. Já o grupo de Vassallo et $a^{29}$ que realizou um estudo no estado de São Paulo com cinco grandes 
centros, reportou uma freqüência maior do subtipo esclerose nodular, mesmo para pacientes pediátricos, dados semelhantes aos norte-americanos ${ }^{100}$. Chabay e colaboladores ${ }^{28}$, ao descreverem pacientes pediátricos com $\mathrm{DH}$ na Argentina e no Brasil, também notaram um predomínio do subtipo esclerose nodular no Brasil, porém procedentes do Rio de Janeiro. Os relatos de Vassallo e Chabay talvez representem uma população do sudeste de nosso país, sabidamente região de maior desenvolvimento sócio-econômico, o que possa justificar estes achados semelhantes ao de países desenvolvidos. Estudos epidemiológicos que representem a diversidade da nossa população são escassos, o que dificulta a avaliação desta amostra. Apesar deste trabalho ter sido realizado no Hospital das Clínicas de São Paulo, esta amostra talvez possa representar esta diversidade, visto que pacientes de todo o país são diagnosticados e tratados neste hospital. Infelizmente, o esforço em tentar relacionar dados sócio-econômicos à $\mathrm{DH}$ neste estudo foi em vão devido à precariedade de informações deste aspecto descritas em prontuário.

É interessante o longo período de queixas antecedendo o diagnóstico de DH nestes pacientes, com quase $60 \%$ com mais de quatro meses de sintomas, porém este tempo chegou até três anos em alguns casos. Muitos destes doentes provavelmente demoraram a ter acesso a um centro de referência em 
câncer infantil, mesmo tendo assistência médica gratuita, através do sistema único de saúde. Isto pode refletir a existência de profissionais inadequadamente treinados para suspeitar da doença, ou ainda um fluxo de atendimento ineficaz entre a assistência primária e a terciária. A falta de recursos dos responsáveis pela criança também não pode ser descartada como causa da demora no diagnóstico. Dados sobre o intervalo de tempo de decorrido entre o início dos sintomas e o diagnóstico são escassos na literatura, mesmo em estudos internacionais ${ }^{29,30,101}$. Apesar da demora no diagnóstico, a maioria dos pacientes (55,9\%) apresentou-se com estadiamento de baixo risco (I A e II A). Isto pode sugerir que a população pediátrica tenha como característica evolução lenta da doença, com prognóstico favorável, mesmo sem um diagnóstico precoce.

A pesquisa de EBV nas amostras de tumor revelou uma positividade de $75,7 \%$ na população estudada. Sabe-se que a incidência de DH EBV positivo é influenciada pela procedência, idade, status sócio-econômico ${ }^{24}$. Loureiro et al detectaram o EBV em $75 \%$ dos pacientes abaixo de 18 anos em um estudo realizado no Rio de Janeiro ${ }^{102}$. Já Chabay et al, em um estudo em colaborativo entre brasileiros e argentinos, descreveram a positividade para o EBV em 52\% 
dos pacientes em sua amostra, sendo associado ao subtipo celularidade mista ${ }^{28}$. Neste mesmo estudo, houve maior positividade para EBV em menores que 10 anos apenas na população argentina e a infecção pelo EBV não influenciou o prognóstico. Claviez et al ${ }^{103}$ também afirmaram que com tratamento combinado adequado, a infecção latente pelo EBV não parece influenciar a SLD, mas pode estar associada a menor sobrevida global em pacientes de alto risco. Este assunto continua sendo discutido. Neste trabalho, observou-se uma probabilidade de SLE e SG melhores para pacientes EBV positivos, o que sugere um prognóstico melhor, apesar de não ser confirmado na análise multivariada.

Neste estudo, a taxa de remissão completa após a quimioterapia prevista pelo protocolo foi de $94,1 \%$. Para os pacientes de baixo risco, os quais receberam três ciclos de ABVD, a taxa de remissão completa foi $97,3 \%(37 / 38)$ e para aqueles de alto risco, os quais receberam ainda mais três ciclos de MOP ou COP foi de $90 \%$ (27/30). Entre os pacientes de baixo risco, maioria da amostra deste estudo, houve apenas uma falha indutória e duas recidivas tumorais. Por sua vez, apenas um destes casos apresentou doença refratária, indo a óbito após vários tratamentos alternativos, inclusive transplante de medula óssea, mais de oito anos após o seu diagnóstico. 
Observou-se uma probabilidade de sobrevida global de $97,0 \% \pm 2,0$ e $94,9 \% \pm 3,0$, sobrevida livre de doença de $89,7 \% \pm 3,7$ e $89,7 \% \pm 3,7$ e sobrevida livre de eventos de $89,7 \% \pm 3,7$ e $87,9 \% \pm 4,0$ respectivamente em 5 anos e 10 anos, para todo o grupo de pacientes. Estes resultados são semelhantes com os descritos na literatura ${ }^{6,104,105,106,107}$. As probabilidades de SG, SLD e SLE não foram estatisticamente distintas quando separadas por estadiamento de baixo ou alto risco ( $\mathrm{p}: 0,402 ; 0,468$ e 0,969 respectivamente). Talvez isto tenha ocorrido devido ao tamanho da amostra, além de que a dose de radioterapia teve pequenas variações de dose e campo, não sendo adequadamente uniformizada, o que pode ter interferido na avaliação da SLE.

Recentemente, vários protocolos de tratamento têm tentado reproduzir os excelentes resultados atingidos com o tratamento combinado, porém reduzindo o número de ciclos de quimioterapia e a dose e campo da radioterapia.

O grupo do Istittuto Nazionale Tumori ${ }^{74}$ relatou resultados a longo prazo equivalentes ao passado com um estudo randomizado com quatro ciclos de ABVD e radioterapia em campo envolvido $3000-4000$ cGy e comparando com ABVD e radioterapia em campo estendido. As probabilidades de sobrevida livre 
de doença e global foram de $93 \%$ e $96 \%$ para os pacientes que foram submetidos à radioterapia em campo estendido e $94 \%$ e $94 \%$ para campo envolvido, respectivamente. Com a exceção da toxicidade pulmonar, a combinação ABVD pareceu apresentar menor toxicidade que os regimes clássicos com alquilantes - mostarda nitrogenada e procarbazina.

Também o German Hodgkin Lymphoma Study Group (GHLSG) reportou o estudo $\mathrm{H} 10$, em que randomizava pacientes com linfoma de Hodgkin de estadiamento precoce para receberem dois ou quatro ciclos de ABVD, com uma segunda randomização na radioterapia em campo envolvido de 3000 ou 2000 cGy, resultando em uma sobrevida semelhante entre os grupos, porém com maior toxicidade entre os pacientes que faziam maior número de ciclos de quimioterapia e maior quantidade de radioterapia* apud Strauss ${ }^{93}$.

Donaldson et al testaram a combinação de vincristina, doxorrubicina, metotrexate e prednisona (VAMP) para tratar crianças e adolescentes com $\mathrm{DH}^{108}$. Após quatro ciclos da combinação e radioterapia em campo envolvido em baixas doses (1500 cGy para aqueles com resposta completa e 2500 cGy para aqueles com resposta parcial), os resultados foram eficazes para o grupo

\footnotetext{
* Engert et al. Combined modality treatment of two or four cycles of ABVD followed by involved field radiotherapy in the treatment of patients with early stage Hodgkin's lymphoma [Abstract]. Blood 2005; 160:750a.
} 
de estadiamento precoce de baixo risco, com probabilidade de SG e SLE de $99 \%$ e $93 \%$ respectivamente. A vantagem deste protocolo foi evitar o uso de agentes alquilantes, bleomicina, etoposido e radioterapia em altas doses ou em campo estendido.

Para os pacientes de alto risco, o $\mathrm{DH}-\mathrm{II}-90$, acrescentou três ciclos de MOP e posteriormente trocado para três ciclos de COP, devido à falta de oncocloramin no mercado. A avaliação das curvas de probabilidade de SG, SLD e SLE, quando separadas por COP e MOP, não foram estatisticamente diferentes ( $p: 0,821 ; 0,135$ e 0,135 , respectivamente). Apesar de não haver diferença estatística, a probabilidade de SLE foi pior quando utilizado COP como quimioterapia complementar ( $75 \%$ versus $94,4 \%$ ), com duas falhas indutórias e uma recaída no grupo que utilizou COP e apenas uma falha indutória para o grupo que usou MOP. Em cada grupo houve um óbito por doença refratária. $\mathrm{O}$ uso de $\mathrm{COP}$ com prednisona para o tratamento da $\mathrm{DH}$ ainda não foi descrito até a presente data que seja o conhecimento da autora desta dissertação. Hudson et al avaliaram o uso de COP com procarbazina em associação com VAMP para pacientes de alto risco, porém com resultados insatisfatórios ${ }^{104}$. 
Um outro esquema testado por Friedman et al ${ }^{109}$ foi o uso de VEPA (vimblastina, etoposido, prednisona e doxorrubicina) em combinação com radioterapia em campo envolvido para pacientes com doença avançada (estadiamento III ou IV) e aqueles com fatores de risco desfavoráveis com tumores "bulky". A probabilidade de SG e SLE em 5 anos foi de $81,9 \%$ e $67,8 \%$ respectivamente, porém com índices ainda mais baixos para os pacientes com doença avançada.

O estudo de Kelly et al investigou se resposta ao tratamento poderia ser melhorada com o uso de quimioterapia intensa com quatro ciclos de BEACOPP (bleomicina, etoposido, adriamicina, ciclofosfamida, vincristina, procarbazina e prednisona). Aqueles com resposta rápida deveriam receber um tratamento de consolidação com mais quatro ciclos de COPP/ABV no sexo feminino e ABVD em meninos, para tentar reduzir efeitos tardios sobre a fertilidade no sexo masculino ${ }^{110}$. O estudo tem seguimento muito curto, mas relata que $72 \%$ dos pacientes apresentaram resposta rápida e apenas um apresentou recaída em 6 meses de seguimento. O maior problema do uso do BEACOPP, sem dúvida, está relacionado aos efeitos tóxicos agudos sobre a medula óssea ${ }^{111}$. Além disto, há também maior toxicidade tardia, com risco de leucemia secundária, 
infertilidade e toxicidade cardíaca e pulmonar devido a maior dose cumulativa dos quimioterápicos ${ }^{112}$.

Estudo recente, realizado em adultos, comparou o uso de oito ciclos de COPP/ABVD, oito ciclos de BEACOPP e oito ciclos de BEACOPP escalonado com doses crescentes de quimioterápicos e redução do intervalo entre os ciclos com o uso de fatores de crescimento ${ }^{113}$. Com um seguimento de 10 anos, a probabilidade de sobrevida livre de recaídas foi de $64 \%, 70 \%$, e $82 \%$ com sobrevida global de $75 \%, 80 \%$ e $86 \%$ para pacientes tratados com COPPIABVD, BEACOPP e BEACOPP escalonado, respectivamente $(\mathrm{p}<$ 0,001). Contudo, o BEACOPP escalonado apresenta maior freqüência de leucemias secundárias $(0,4 \%, 1,5 \%$ e $3,0 \%)$, mas não de tumores sólidos $(2,7 \%, 3,4 \%$ e $1,9 \%$, respectivamente). Estes resultados desafiam o uso de ABVD no pequeno grupo de pacientes de alto risco, que anteriormente achavase que fossem resistentes à quimioterapia ${ }^{105}$. O tratamento da $\mathrm{DH}$ de estadiamento avançado continua em discussão, sendo o ABVD associado ou não ao MOPP ainda utilizado em muitos países ${ }^{114}$.

O DH-II-90 preconiza o uso de radioterapia em campo envolvido e em doses baixas para os pacientes de baixo estadiamento, e, para aqueles de 
estadiamento IV ou B, radioterapia estendida. A probabilidade de sobrevida livre de eventos foi estatisticamente maior com o uso de baixas doses de radioterapia (vide figura $13, \mathrm{p}: 0,014$ ), como já relatado na literatura por outros grupos $^{6}$. Também foi significantemente maior a probabilidade de SLE na ausência de massa mediastinal (vide figura 14, p:0,020), provavelmente por se tratar de menor campo irradiado, visto que nas apresentações mediastinais irradia-se o andar infra-diafragmático até a bifurcação da aorta, além de provável uso de maior dose de radioterapia.

O estudo do grupo Pierre-et-Marie-Curie ${ }^{90}$ mostrou que é possível substituir a irradiação clássica em manto por campos mais limitados aos locais anteriormente envolvidos pela doença - irradiação em campo envolvido, confiando que a quimioterapia irá tratar adequadamente doença microscópica de áreas não envolvidas macroscopicamente. Estes achados foram posteriormente confirmados por outros autores ${ }^{9,74,115,116}$, sendo a modalidade combinada de quimioterapia mais radioterapia em campo envolvido o tratamento padrão ouro para $\mathrm{DH}$ de baixo risco, mesmo para aqueles com fatores de risco desfavoráveis.

Alguns grupos ${ }^{36,75}$ passaram a defender o uso de quimioterapia isolada para o tratamento de $\mathrm{DH}$ principalmente para pacientes com doença localizada 
argumentando que: 1) o tratamento com esta modalidade pura pode ser utilizado em países em desenvolvimento, onde não há equipamentos e pessoal capacitado para uma irradiação adequada; 2) o estadiamento cirúrgico ou clínico preciso não seria essencial; 3) complicações tardias de crescimento ou segunda neoplasia associadas à radioterapia poderiam ser evitadas. Por outro lado, as desvantagens são a exposição a altas doses que agentes alquilantes e a morbidade relacionada à mielossupressão, infertilidade e leucemia secundária ${ }^{10}$. A avaliação de protocolos de tratamento de $\mathrm{DH}$ com quimioterapia isolada tem sido difícil, pois a maioria dos relatos descritos são de estudos de coorte, não randomizados, com número limitado de pacientes, amostras não controladas adequadamente, além de muitas vezes excluir aqueles com fatores de risco desfavoráveis ${ }^{10,117,118}$. Esta conduta não parece ser apropriada para casos de doença "bulky", além de que há pouca avaliação de toxicidade a longo prazo destes protocolos e em casos de recaída, a criança receberia ainda mais drogas e radioterapia, culminando em um aumento de toxicidade ${ }^{10,84}$.

Um estudo realizado na Índia por Laskar et al ${ }^{106}$ confirmou a necessidade do uso de radioterapia como tratamento de consolidação para $\mathrm{DH}$. Neste 
trabalho, pacientes com $\mathrm{DH}$ eram randomizados para receber seis ciclos de ABVD isolado ou associado à radioterapia. A probabilidade de SLE e SG em 8 anos de seguimento foi de $76 \%$ e $89 \%$ para o grupo que recebeu apenas quimioterapia e $88 \%$ e $100 \%$ para o grupo que recebeu tratamento combinado, respectivamente. Avaliando-se separadamente os pacientes menores que 15 anos, esta diferença era ainda maior (SLE em 8 anos de $53 \%$ para o braço de quimioterapia isolada e de $97 \%$ para a modalidade combinada, p: 0,02).

O "Children's Cancer Group" (CCG) também testou o uso de radioterapia como tratamento de consolidação para aqueles pacientes que atingiam remissão clínica completa após quimioterapia combinada, randomizando-os para receber radioterapia em baixas doses campo envolvido ou nenhum outro tratamento ${ }^{119}$. Este estudo precisou ser interrompido devido ao grande número de recaídas no grupo de quimioterapia isolada. As estimativas de sobrevida global para os grupos randomizados não são diferentes devido ao sucesso de tratamento de resgate, inclusive incluindo a radioterapia ${ }^{10,120}$.

O estudo alemão GPOH-HD-95 também avaliou a omissão de radioterapia para os pacientes que atingiam resposta completa à quimioterapia* apud Hudson et $\mathrm{al}^{10}$. A probabilidade de SLE em 5 anos para pacientes de

*Dorffel, W. Preliminary results of the multicenter trial GPOH-HD 95 for the treatment of Hodgkin's disease in children and adolescents: analysis and outlook. Klin Padiatr 2003;215:139-45 
baixo risco (estadiamento IA e IIA) foi de $97 \%$ e $94 \%$ respectivamente para aqueles tratados com quimioterapia isolada e em combinação com radioterapia. Porém, pacientes com risco intermediário e alto tiveram uma probabilidade de SLE significativamente menor quando não irradiados (79\% versus $91 \%$ ). Novamente aqui a probabilidade de sobrevida global não foi diferente, indicando que estes pacientes podem atingir segunda remissão com tratamento de resgate.

A lógica para o uso da modalidade combinada é que enquanto a quimioterapia cuida de doença subclínica disseminada, a radioterapia é necessária para o controle local de tumor persistente ${ }^{106}$. A combinação também permite a restrição da intensidade e duração da quimioterapia e da dose e volume de irradiação e, conseqüentemente, os efeitos tardios relacionados. $\mathrm{O}$ benefício da radioterapia no controle da doença, portanto, ainda parece ter maior valor que os efeitos adversos potenciais, sobretudo em pacientes com doença "bulky", de estadiamento avançado ou doença refratária ${ }^{10}$.

Os efeitos adversos agudos relacionados ao tratamento foram constatados em $39,7 \%$ dos casos, porém apenas $14,7 \%$ dos pacientes apresentaram necessidade de internação e não houve complicações fatais 
nesta amostra. Isto sugere que este é um tratamento seguro, predominantemente ambulatorial e com baixa taxa de complicações. Os pacientes que receberam quimioterapia complementar com MOP ou COP apresentaram maior índice de internação $(46,1 \%)$ quando comparados com o grupo que só usou ABVD (28,6\%), mas este achado já era esperado, visto que eles estavam expostos a maior número de ciclos de quimioterapia.

Uma outra vantagem importante do ABVD foi a baixa incidência de efeitos tóxicos tardios quando comparado com regimes contendo alquilantes ${ }^{76}$. O MOPP, por exemplo, induz infertilidade em quase todos os homens e em mulheres com mais de 30 anos por incluir a procarbazina ${ }^{6}$. A disfunção testicular é dose dependente ${ }^{121}$ e também é vista em pacientes tratados com o esquema OPPA ou OPPA/COPP ${ }^{24}$. Além disto, pacientes tratados com oncocloramin têm um risco de $3 \%$ de apresentar uma leucemia aguda durante toda a sua vida ${ }^{35}$. O ABVD apresenta poucos efeitos agudos e também um menor potencial de leucemogênese e infertilidade ${ }^{74,94,122}$. É associado, no entanto, a alto risco de cardiomiopatia crônica e disfunção pulmonar especialmente em crianças, porém a gravidade e a freqüência destes efeitos estão relacionadas à dose cumulativa, normalmente após seis a oito ciclos, e em parte à sua associação com radioterapia ${ }^{6,76}$. O ABVD é, portanto, aceito 
como padrão ouro para tratamento de $\mathrm{DH}$ em regimes com modalidade combinada em pacientes de baixo risco e deve ser testado com qualquer outra nova combinação de drogas ${ }^{105}$.

Ao aplicar apenas três ciclos de ABVD a estes pacientes, há uma redução significativa também dos efeitos tardios relacionados ao tratamento, restringindo a dose cumulativa e conseqüentemente com menor toxicidade cardíaca e pulmonar. A dose cumulativa de $150 \mathrm{mg} / \mathrm{m}^{2}$ de doxorrubicina é segura, sendo doses maiores que $300 \mathrm{mg} / \mathrm{m}^{2}$ associadas a maior incidência de insuficiência cardíaca congestiva ${ }^{123}$.

Infelizmente um estudo adequado dos efeitos tardios do protocolo proposto não foi possível nos moldes desta dissertação. Apesar disto, é possível uma descrição de efeitos tardios de maior relevância e pode-se retirar dela algumas considerações.

O protocolo DH-II-90 não utiliza a procarbazina, o que se traduz num menor índice de toxicidade a longo prazo, principalmente relacionada à fertilidade. Além disto, apesar do uso do oncocloramin em parte dos pacientes $(26,4 \%)$, posteriormente substituído por ciclofosfamida pela falta do primeiro no mercado brasileiro, não houve nenhum caso de leucemia secundária ou 
mielodisplasia, mesmo após longo período de seguimento (a média de seguimento entre os pacientes que receberam esta droga foi de 12,47 anos, sendo excluído um óbito após 14 meses por doença refratária). Ainda, a incidência de leucemia secundária parece também ter sido reduzida pelo abandono da esplenectomia, considerada por alguns autores como fator de risco independente ${ }^{6}$.

Os efeitos tardios da radioterapia costumam ser ainda mais freqüentes, como estenose de carótida, fibroses de válvulas miocárdicas, aumento em três vezes o risco de infarto, fibrose pulmonar ou pericárdica ${ }^{2,96}$. Num estudo cooperativo do "National Cancer Institute of Canada Clinical Trials" e do "Eastern Cooperative Oncology Group"118, observou-se maior índice de cardiotoxicidade para aqueles pacientes recebendo ABVD associado à radioterapia do que naqueles que receberam ABVD puro. Cardiotoxicidade parece estar associada à idade, estando as crianças sob maior risco ${ }^{24}$.

Os efeitos músculo-esqueléticos da radioterapia mais marcantes estão associados à idade menor que seis anos ou durante o estirão pubertário no momento do tratamento e dose de irradiação maior que 3500 cGy ${ }^{84}$. Por isto, a recomendação atual é usar radioterapia em baixas doses (menores que 2500 cGy) ${ }^{24}$. 
Seqüelas relacionadas à tireóide incluem hipotireoidismo, hipertireoidismo e nódulos tireoidianos benignos e malignos ${ }^{24}$. Um estudo multicêntrico retrospectivo do "Childhood Cancer Survival Study" reportou anormalidades tireoidianas em $34 \%$ de 1791 sobreviventes de $\mathrm{DH}^{124}$. Fatores de risco para hipotireoidismo incluem baixa idade durante o tratamento e doses altas de irradiação ${ }^{24}$. Constine et al observaram que $17 \%$ das crianças que receberam doses menores que 2600 cGy e $75 \%$ daquelas que receberam doses maiores que 2600 cGy desenvolveram hipotireoidismo ${ }^{125}$. Já Tucker et al descreveram uma associação entre doses de irradiação maiores que 2000cGy e um aumento de 13 vezes no risco de câncer de tireóide ${ }^{126}$. Apesar disto, mais de um terço dos pacientes com alteração do TSH apresentaram melhora espontânea. Os nódulos de tireóide ocorrem mais tardiamente, com uma média de 14 anos de seguimento ${ }^{24}$, sendo o risco de carcinoma 1,74 a 36,4 , maior que na população em geral ${ }^{127}$. No estudo do $\mathrm{DH}-\mathrm{II}-90,42,9 \%$ dos pacientes apresentaram alguma disfunção da glândula tireóide, com dois casos de carcinoma, ambos irradiados com doses maiores que 2100 cGy e idade menor que 10 anos de idade. 
A associação de câncer de mama com tratamento de DH na infância já é bem estabelecida, com um risco relativo entre 5,2 e 136, e sua incidência cumulativa aumenta com um maior seguimento a longo prazo ${ }^{2,10,127}$. A radioterapia está associada ao câncer de mama, mas também agentes alquilantes parecem ter um papel principalmente quando associados à radioterapia ${ }^{127,128}$. Não houve câncer de mama secundário nesta amostra no período de observação. Entretanto, este estudo tem um tempo de seguimento médio de 10,4 anos, o que é curto para avaliação desta toxicidade, já que o risco aumenta dramaticamente a partir dos 10 anos de seguimento, sendo a incidência cumulativa na idade de 40 anos de $12,9 \%{ }^{129}$.

Outras neoplasias secundárias têm sido descritas em associação com tratamento de $\mathrm{DH}$, principalmente em tecidos irradiados: osso, trato gastrointestinal, pulmão, entre outros ${ }^{2,127,128,130}$. Estas neoplasias ocorrem normalmente após 10 anos de seguimento e a incidência aumenta com o maior tempo de seguimento destes pacientes. Novamente, o trabalho aqui apresentado tem uma média de seguimento de pacientes fora de terapia curta para avaliação deste tipo de toxicidade. Se o $\mathrm{DH}-\mathrm{II}-90$ tem de fato incidência reduzida de neoplasia secundária pela redução de quimioterapia e radioterapia é uma 
questão a ser respondida no futuro, com maior prazo de seguimento destes pacientes.

Este continua sendo o desafio maior de quem cuida de pacientes com DH: manter as taxas de cura com mínima toxicidade. Nunca é demais lembrar que a preocupação em dar qualidade de vida para estes pacientes deve se iniciar com a escolha do tratamento a ser aplicado, e não somente da equipe que os ampara no ambulatório de pacientes fora de terapia. A interação entre oncologistas clínicos, patologistas, radiologistas e radioterapeutas é essencial para melhor atender a esta necessidade. 


\section{CONCLUSÕES}

1. Na casuística estudada, houve um predomínio de crianças com doença de Hodgkin estadiamento de baixo risco e do tipo histológico celularidade mista. A faixa etária de maior ocorrência foi entre 5 e 10 anos, porém com $23,5 \%$ da amostra com menos de 5 anos de idade.

2. As taxas de probabilidade de sobrevida global e livre de doença do protocolo DH-II-90 em 10 anos foram de $94,9 \pm 3,0$ e $89,7 \% \pm 3,7$ respectivamente. Elas são equivalentes àquelas de outros protocolos atuais utilizados em todo o mundo, com resultados excelentes do ponto de vista de eficácia terapêutica e com baixa morbidade aguda. Com base nos dados desta dissertação, é possível afirmar que ciclos restritos de $A B V D$ associados à radioterapia em campo envolvido em baixas doses foram suficientes para controle a longo prazo da $\mathrm{DH}$ em pacientes de baixo risco, com baixa morbidez inclusive tardia. Para os pacientes do grupo de alto risco, o $\mathrm{DH}-\mathrm{II}-90$ também foi eficaz, com maior toxicidade aguda e tardia. O uso de COP pareceu ser tão eficiente quanto o MOP, 
apesar do menor seguimento dos pacientes que usaram esta combinação.

3. A sobrevida livre de eventos em 5 anos foi de $92,1 \pm 4,4$ e $86,5 \% \pm 6,3$ para pacientes de baixo e alto risco, respectivamente. A presença de massa mediastinal e doses de radioterapia maiores que 2100 cGy apresentaram impacto negativo na sobrevida livre de eventos e estadiamento I confere um fator de proteção para sobrevida livre de eventos.

4. A presença do EBV foi detectada em $75,7 \%$ das amostras de tumor estudadas, sendo a sua positividade associada ao sexo masculino e idade precoce. A presença de EBV na amostra tumoral apresentou impacto positivo na sobrevida livre de eventos e sobrevida global, na análise univariada.

5. Anormalidades da tireóide foram as seqüelas mais freqüentes neste grupo de pacientes, com dois casos de carcinoma de tireóide. 
7. ANEXO:

FICHA PARA PESQUISA - DOENÇA DE HODGKIN

Nome:

Registro:

Data de nascimento:

Sexo: $\square$ Feminino $\square$ Masculino

Cor: $\square$ Branca $\square$ Parda $\square$ Negra $\square$ Amarela $\square$ Índio

Data do Anátomo-patológico: __________ Idade do diagnóstico:

Procedência: $\square$ Norte $\square$ Nordeste $\square$ Centro-Oeste $\square$ Sudeste $\square$ Sul

Nível sócio-econômico:

Renda familiar:

Quantas pessoas moram na mesma casa:

Renda familiar per capta:

Quantos cômodos tem a casa:

\section{Apresentação:}

Tempo de doença: Tamanho do gânglio:

\begin{tabular}{|c|c|c|c|}
\hline Gânglio $\square$ Cervical & $\square$ Occipital & $\square$ Pré-auricular & $\square$ Axilar \\
\hline$\square$ Poplitea & $\square$ Epitroclear & 口lnguinal & $\square$ Supraclavicular \\
\hline$\square$ Mediastinal & $\square$ Paraórtico & $\square$ Mesentérico & 口 llíaco \\
\hline$\square$ Outros & & adeia única & $\square$ Cadeia Múltipla \\
\hline
\end{tabular}

$\square$ Fígado $\square$ Esplenomegalia $\square$ Pulmão $\square$ Massa mediastinal $\square$ Sd. Veia Cava 
$\square$ Mesmo lado do diafragma

$\square$ Dos dois lados do diafragma

Sintomas B: $\square$ Febre $\square$ Emagrecimento $\square$ Sudorese $\square$ Prurido

Exames iniciais:

$\mathrm{Hb}$ :

$\mathrm{Ht}:$ Leuco:

Eos:

Plaq:

VHS:

DHL:

Ur:

Cr:

TGO:

TGP:

FA:

YGT:

TC tórax:

TC Abdome:

TC pescoço:

Biópsia de Medula: $\square$ positivo $\square$ negativo Mielograma: $\square$ positivo $\square$ negativo

Cintilografia Ga: $\square$ positivo $\square$ negativo

Cintilografia óssea: $\square$ positivo $\square$ negativo

Sorologia para EBV $\lg G \square$ positivo $\square$ negativo $\quad \lg \mathrm{M} \square$ positivo $\square$ negativo

Sorologia para CMV $\lg \square$ positivo $\square$ negativo $\quad \lg M \square$ positivo $\square$ negativo

Sorologia para Rúbeola $\lg G \square$ positivo $\square$ negativo $\lg M \square$ positivo $\square$ negativo

Sorologia para TOXO $\quad \lg G \square$ positivo $\square$ negativo $\quad \lg \mathrm{M} \square$ positivo $\square$ negativo

Sorologia para Hepatite $\mathbf{A} \lg \square \square$ positivo $\square$ negativo $\lg \mathrm{M} \square$ positivo $\square$ negativo

Sorologia para Hepatite $B \lg \square \square$ positivo $\square$ negativo $\lg M \square$ positivo $\square$ negativo Sorologia para Hepatite C $\square$ positivo $\square$ negativo 


\section{Sorologia para HIV $\quad \square$ positivo $\square$ negativo}

Outros:

Anátomo-Patológico: Data ___ _ _ L__ Local da biópsia:

$\square$ Clássico $\square$ Celularidade Mista $\square$ Esclerose Nodular $\square$ Depleção Linfocitária

$\square$ Rico em linfócitos $\quad \square$ Predominância Linfocitária $\square$ Não Classificado

Imunohistoquímica: $\square \mathrm{CD} 3 \square \mathrm{CD} 15 \square \mathrm{CD} 20 \quad \square \mathrm{CD} 30 \quad \square \mathrm{CD} 45$

Estadiamento: $\square$ I $\square$ II $\square$ III $\square$ IV $\quad \square$ A $\square$ B

\section{Tratamento Inicial:}

Quimioterapia- data de início: data de fim:

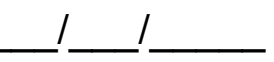

$\square$ ABVD $n^{\circ}$ de ciclos $\square \mathrm{MOP} \mathrm{n}^{\circ}$ de ciclos $\square \mathrm{COP} \mathrm{n}^{\circ}$ de ciclos

$\square$ Outros

Intercorrências:

Radioterapia- período: a 1

$\square$ pré-QT $\square$ pós-QT $\square$ inter-ciclos

Campo: Dose:

Campo: Dose:

\section{Desfecho}

Falha indutória: $\square$ Sim $\square$ Não

Recaída: $\square \operatorname{Sim} \square$ Não Data da 2a biópsia: 
Tratamento Alternativo:

Quimioterapia- data de início: ___ _ _ _ d data de fim: ___ _ _ _

$\square \mathrm{MOP} \mathrm{n}^{\circ}$ de ciclos __ $\quad \square$ CDDP/VP $\mathrm{n}^{\circ}$ de ciclos

$\square$ Outros

$\mathrm{TAMO} \square \operatorname{Sim} \square \mathrm{Não}$

Condicionamento

Óbito $\square \operatorname{Sim} \square$ Não

Motivo: $\square$ Doença refratária $\square$ TAMO $\square$ Infecção $\square$ Outros $\square$ Não relacionado Tempo fora de terapia:

Data da última consulta:

1

Seqüelas: 


\section{REFERÊNCIAS*:}

1. Hodgkin T. On some morbid appearances of the absorbent glands and spleen. In: Kelly EC. Medical Classics. Baltimore: Williams \& Wilkins;1937;1:741-70.

2. Hudson M, Donaldson S. Hodgkin's Disease. In: Pizzo PA, Poplack, DG, eds. Principles and Practice of Pediatric Oncology. 4a ed. Philadelphia: Lippincott Williams \& Wilkins; 2002:637-60.

3. Swerdlow SH, Campo E, Harris NL, Jaffe ES, Pireli SA, Stein H, Thiele J, Vardiman JW. WHO Classification of tumours of haematopoietic and lymphoid tissues. 4a ed. Lyon: IARC Press; 2008.

4. Harris NL, Jaffe ES, Stein H, Banks PM, Chan JKC, Cleary ML, Delsol G, Wolf-Peeters C, Falini B, Gatter KC, Grogan TM, Isaacson PG, Knowles DM, Mason DY, Mueller-Hermelink HK, Pireli SA, Piris MA, Ralfkaer E, Warnke RA. A revised European-American classification of Lymphoma

\footnotetext{
*De acordo com:

Adaptado de International Committee of Medical Journals Editors (Vancouver).

Universidade de São Paulo. Faculdade de Medicina. Serviço de Biblioteca e Documentação. Guia de apresentação de dissertações, teses e monografias da FMUSP. Elaborado por Anneliese Carneiro da Cunha, Maria Julia A.L. Freddi, Maria F. Crestana, Marinalva de S. Aragão, Suely C. Cardoso, Valéria Vilhena. 2a ed. São Paulo: Serviço de Biblioteca e Documentação; 2005.

Abreviaturas dos títulos dos periódicos de acordo com List of Journals Indexed in Index Medicus.
} 
Neoplasms: A proposal from the International Lymphoma Study Group. Blood. 1994;84:1361-92.

5. Weiss LM, Warnke RA, Hansmann ML, Chan JKC, Mueller-Hermelink HK, Harris NL, Stein H, Jaffe ES. Pathology of Hodgkin Lymphoma. In: Hoppe RT, Mauch PT, Armitage JO, Dihel V, Weiss LM. Hodgkin Lymphoma. 2a ed. Philadelphia: Lippincott Williams \& Wilkins; 2007:4371.

6. Schellong G, Pötter R, Brämswig J, Wagner W, Prott FJ, Dörffel W, Körholz D, Mann G, Rath B, Reiter A, Weissbach G, Riepenhausen M, Thiemann M, Schwarze EW. High cure rates and reduced long term toxicity in pediatric Hodgkin's disease: The German-Austrian multicenter trial DAL-HD-90. J Clin Oncol. 1999; 17:3736-44.

7. Hudson MM. Pediatric Hodgkin's Therapy: time for a paradigm Shift. $J$ Clin Oncol. 2002;20:3755-7.

8. Bartlett NL. Modern Treatment of Hodgkin Lymphoma. Curr Opin Hematol. 2008;15:408-14.

9. Noordijik EM, Carde P, Dupouy N, Hagenbeek A, Krol ADG, KluinNelemans JC, Tirelli U, Monconduit M, Thomas J, Eghbali H, Aleman 
BMP, Bosq J, Vovk M, Vesrchueren TAM, Pén AM, Girinsky T, Raemaekers JMM, Henry-Amar M. Combined-Modality Therapy for clinical stage I or II Hodgkin's Lymphoma: Long-term results of the European Organization for research and treatment of cancer $\mathrm{H} 7$ randomized controlled trials. J Clin Oncol. 2006;24:3128-35.

10. Hudson MM, Körholz D, Donaldson SS. Pediatric Hodgkin Lymphoma. In: Hoppe RT, Mauch PT, Armitage JO, Dihel V, Weiss LM. Hodgkin Lymphoma. 2a ed. Philadelphia: Lippincott Williams \& Wilkins; 2007:293317.

11. Weltman E. Tratamento da Moléstia de Hodgkin - Resultados do Protocolo DH-I-86 [dissertação]. São Paulo: Faculdade de Medicina, Universidade de São Paulo; 1991.

12. Weltman E, Takita C, Cristofani LM, Almeida MT, Britto JLBC, Maluf Jr. PT, Odone Filho V. Tratamento da moléstia de Hodgkin (MH) Resultados do protocolo de DH-I-86. In: X Congresso da Sociedade Latino-Americana de Oncologia Pediátrica, IV Congresso da Sociedade Brasileira de Oncologia Pediátrica e I Jornada de Enfermagem em Oncologia Pediátrica, Rio de Janeiro, Anais, 1993:n²1(resumo). 
13. Hellman S. Brief consideration of Thomas Hodgkin and his times. In: Hoppe RT, Mauch PT, Armitage JO, Dihel V, Weiss LM. Hodgkin Lymphoma. 2a ed. Philadelphia: Lippincott Williams \& Wilkins; 2007:3-6.

14. Dawson PJ, Path MC. The original illustrations of Hodgkin's Disease. Arch Intern Med. 1968;121:288-90.

15. Stone MJ. Thomas Hodgkin: medical immortal and uncompromising idealist. Proc (Bayl Univ Med Cent). 2005;18:368-75.

16. Jaffe ES, Harris NL, Stein H, Isaacson PG. Classification of Iymphoid neoplasms: the microscope as a tool for disease discovery. Blood. $2008 ; 112: 4384-99$.

17. Rosenfeld L. Thomas Hodgkin (1798-1866): morbid anatomist and social activist. Bull N Y Acad Med. 1986;62:193-205.

18. Rosenfeld L. Hodgkin's disease: origin of an eponym - and one that got away. Bull N Y Acad Med. 1989;65:618-32.

19. Küppers $R, \operatorname{Re} D$. Nature of Reed-Sternberg and L\&H cells, and their molecular biology in Hodgkin Lymphoma. In: Hoppe RT, Mauch PT, Armitage JO, Dihel V, Weiss LM. Hodgkin Lymphoma. 2a ed. Philadelphia: Lippincott Williams \& Wilkins; 2007:73-86. 
20. Dawson, PJ. Whatever happened to Dorothy Reed? Ann Diagn Pathol. 2003;7:195-203.

21. National Cancer Institute. SEER Cancer Statistics Review 1975-2006. Estimated New Cancer Cases and Deaths for 2009. Cancer.gov. [acessado em 11 de Agosto de 2009] Disponível em: http://seer.cancer.gov/csr/1975_2006/results_single/sect_01_table.01.pdf

22. Bigni R. Linfoma de Hodgkin. Inca.gov.br. [acessado em 26 de junho de 2009] Disponível em: http://www.inca.gov.br/conteudo_view.asp?id=458.

23. National Cancer Institute. SEER Stat Fact Sheets - Cancer: Hodgkin Lymphoma. Cancer.gov. [acessado em 26 de junho de 2009] Disponível em: http://www.seer.cancer.gov/statfacts/html/hodg.html.

24. Mueller NE, Grufferman S, Chang ET. The Epidemiology of Hodgkin Lymphoma. In: Hoppe RT, Mauch PT, Armitage JO, Dihel V, Weiss LM. Hodgkin Lymphoma. 2a ed. Philadelphia: Lippincott Williams \& Wilkins; 2007:7-23.

25. MacMahon B. Epidemiology of Hodgkin's disease. Cancer Res. 1966;26:1189-201. 
26. Solidoro A, Guzmán C, Chang A. Relative increased incidence of childhood Hodgkin's disease in Peru. Cancer Res. 1966;26:1204-8.

27. Weinreb M, Day PJR, Niggli F, et al. The role of Epstein-Barr virus in Hodgkin's disease from different geographical areas. Arch Dis Child. 1996;74:27-31.

28. Chabay P, Barros M, Hassan R. Pediatric Hodgkin's Lymphoma in 2 South American series: a distinctive epidemiologic pattern and lack of association of Epstein-Barr virus with clinical outcome. J Pediatr Hematol Oncol. 2008;30:285-91.

29. Vassallo J, Paes RP, Soares FA, Menezes Y, Aldred V, Ribeiro KCB, Alves AC. Histological classification of 1,025 cases of Hodgkin's lymphoma from the state of São Paulo, Brazil. São Paulo Med J. 2005;123:134-6.

30. Correa P, O'Conor GT. Epidemiologic patterns of Hodgkin's disease. Int J Cancer. 1971;8:192-201.

31. Westergaard T, Melbye M, Pedersen JB, Frisch M, Olsen JH, Andersen PK. Birth order, sibship size and risk of Hodgkin's disease in children and 
young adults: A population-based study of 31 million person-years. Int $J$ Cancer. 1997;72:977-81.

32. Dworsky RL, Henderson BE. Hodgkin's disease clustering in families and communities. Cancer Res. 1974;34:1161-3.

33. Hjalgrim H, Askling J, Rostgaard K, Dutoit SH, Frisch M, Zhang JS, Madsen M, Rosdahl N, Konradsen HB, Storm HH, Melbye M. Characteristic of Hodgkin's lymphoma after infectious mononucleosis. $N$ Engl J Med. 2003;349:1324-32.

34. Gulley ML, Glaser SL, Craig FE, Borowitz M, Mann RB, Shema SJ, Ambinder RF. Guidelines for interpreting EBER in situ hybridization and LMP1 immunohistochemical tests for detecting Epstein-Barr virus in Hodgkin Lymphoma. Am J Clin Pathol. 2002;117:259-67.

35. Cohen J. Epstein-Barr virus infection. N Engl J Med. 2000;343:481-92.

36. Robertson ST, Lowman JT, Grufferman S, Borowitz MJ, Bigner SH, Kostyu D, Van der Horst C, Matthews TJ. Familial Hodgkin's disease: a clinical and laboratory investigation. Cancer. 1987;59:1314-19.

37. Mack TM, Cosen W, Shibata DK, Weiss LM, Nathwani BN, Hernandez AM, Taylor CR, Hamilton AS, Deapen DM, Rappaport EB. Concordance 
for Hodgkin's disease in identical twins suggesting genetic susceptibility to the young-adult form of the disease. N Engl J Med. 1995;332:413-8.

38. Kanzler H, Kuppers R, Hansmann ML, Rajewsky K. Hodgkin and ReedSternberg cells in Hodgkin's disease represent the outgrowth of a dominant tumor clone derived from (crippled) germinal center B cells. $J$ Exp Med. 1996;184:1495-505.

39. Kuppers R, Rajewsky K, Zhao M, Simons G, Laumann R, Fisher R, Hansmann ML. Hodgkin disease: Hodgkin and Reed-Sternberg cells picked from histological sections show clonal immunoglobulin gene rearrangements and appear to be derived from B cells at various stages of development. Proc Natl Acad Sci U S A. 1994;91:10962-6

40. Thomas RK, Re D, Wolf J, Dihel V. Part I: Hodgkin's lymphoma molecular biology of Hodgkin and Reed-Sternberg cells. Lancet Oncol. 2004;5:11-8.

41. Re D, Kuppers R, Dihel V. Molecular Pathogenesis of Hodgkin's lymphoma. J Clin Oncol. 2005;23:6379-86. 
42. Stein $\mathrm{H}$, Gerdes $\mathrm{J}$, Schwab $\mathrm{U}$, et al. Identification of Hodgkin and Sternberg-Reed cells as a unique cell type derived from a newly-detected small-cell population. Int J Cancer. 1982;30:445-59.

43. Stein H, Manson DY, Gerdes J, O'Connor N, Wainscoat J, Pallesen G, Gatter K, Falini B, Delsol F, Lemke H, Schwarting R, Lennert K. The expression of the Hodgkin's disease associated antigen Ki-1 in reactive neoplastic lymphoid tissue: evidence that Reed-Sternberg cells and Histiocytic malignancies are derived from activated lymphoid cells. Blood. 1985;66:848-58.

44. Nogová L, Rudiger T, Engert A. Biology, clinical course and management of nodular lymphocyte-predominant Hodgkin lymphoma. Hematology. 2006;266-72.

45. Braeuninger A, Kuppers R, Strickler JG, Wacker HH, Rajewsky K, Hansmann ML. Hodgkin and Reed-Sternberg cells in lymphocyte predominant Hodgkin disease represent clonal populations of germinal center-derived tumor B cells. Proc Natl Acad Sci U S A. 1997;94:9337-42.

46. Marafioti T, Hummel M, Foss HD, et al. Hodgkin and reed-sternberg cells represent an expansion of a single clone originating from a germinal 
center B-cell with functional immunoglobulin gene rearrangements but defective immunoglobulin transcription. Blood. 2000;95:1443-50.

47. Marafioti T, Pozzobon M, Hanxmann ML, Delsol G, Pileri SA, Mason DY. Expression of intracellular signaling molecules in classical and lymphocyte predominance Hodgkin disease. Blood. 2004;103:188-93.

48. Stein H, Marafioti T, Foss HD, Laumen H, Hummel M, Anagnostopoulos I, Wirth I, Demel G, Falini B. Down-regulation of BOB.1/OBF.1 and Oct2 in classical Hodgkin disease but not in lymphocyte predominant Hodgkin disease correlates with immunoglobulin transcription. Blood. 2001;97:496-501.

49. Schwering I, Brauninger A, Klein U, Jungnickel B, Tinguely M, Diehl V, Hansmann ML, Dalla-Favera R, Rajewsky K, Kuppers R. Loss of the Blineage-specific gene expression program in Hodgkin and ReedSternberg cells of Hodgkin lymphoma. Blood. 2003;101:1505-12.

50. Marafioti T, Hummel M, Anagnostopoulos I, Foss HD, Huhn D, Stein H. Classical Hodgkin's Disease and Follicular Lymphoma Originating From the Same Germinal Center B Cell. J Clin Oncol. 1999;17:3804-9. 
51. Tzankov A, Bourgau C, Kaiser A, Zimpfer A, Maurer R, Pileri SA, Went P, Dirnhofer S. Rare expression of T cell marker in classical Hodgkin's Lymphoma. Mod Pathol. 2005;18:1542-9.

52. Müschen M, Rajewsky K, Braeuninger A, Baur AS, Oudejans JJ, Roers A, Hansmann ML, Kuppers R. Rare occurrence of classical Hodgkin's disease as T cell lymphoma. J Exp Med. 2000;191:387-94.

53. Seitz V, Hummel M, Marafioti T, Anagnostopoulos I, Assaf C, Stein H. Detection of clonal T-cell receptor gamma-chain gene rearrangements in Reed-Sternberg cells of classic Hodgkin disease. Blood. 2000; 95:30204.

54. Ambinder RF, Weiss LM. Association of Epstein-Barr virus with Hodgkin Lymphoma. In: Hodgkin Lymphoma. 2a ed. Philadelphia: Lippincott Williams \& Wilkins; 2007:25-39.

55. Bräuninger A, Schimitz R, Bechtel D, Renné C, Hansmann ML, Küppers R. Molecular biology of Hodgkin's and Reed/Sternberg cells in Hodgkin's Lymphoma. Int J Cancer. 2006;118:1853-61.

56. Jackson H, Parker F. Hodgkin's disease, II: pathology. N Engl J Med. $1944 ; 231: 35-44$ 
57. Lukes R, Butler J, Hicks E. Natural history of Hodgkin's disease as related to its pathological picture. Cancer. 1966;19:317-44.

58. Rosenberg SA, Kaplan HS. Evidence for an orderly progression in the spread of Hodgkin's Disease. Cancer Res. 1966;26:1225-31.

59. Lukes RJ, Craver LF, Hall TC, Rappaport H, Ruben P. Report on the nomenclature committee. Cancer Res. 1966;26:1311.

60. Harris NL, Jaffe ES, Diebold J, Flandrin G, Muller-Hermelink HK, Vardiman J, Lister A, Bloomfield CD. World Health Organization Classification of Neoplastic diseases of the hematopoietic and Lymphoid tissues: report of the clinical advisory committee meeting - Airlie Housse, Virginia, November 1997. J Clin Oncol. 1999;17:3835-49.

61. Mauch PM, Kalish LA, Kadin M, Coleman CN, Osteen R, Hellman S. Patterns of presentation of Hodgkin's disease. Cancer. 1992; 71:206271.

62. Hodgson DC, Gospodarowicz MK. Clinical Evaluation and staging of Hodgkin Lymphoma. In: Hoppe RT, Mauch PT, Armitage JO, Dihel V, Weiss LM. Hodgkin Lymphoma. 2a ed. Philadelphia: Lippincott Williams \& Wilkins; 2007:123-32. 
63. Kennedy BJ, Loeb Jr. V, Peterson VM, Donegan WL, Natarajan N, Mettlin C. National survey of patterns of care for Hodgkin's Disease. Cancer. 1985;56:2547-56.

64. Bierman PJ, Cavalli F, Armitage JO. Unusual syndormes in Hodgkin Disease. In: Hoppe RT, Mauch PT, Armitage JO, Dihel V, Weiss LM. Hodgkin Lymphoma. 2a ed. Philadelphia: Lippincott Williams \& Wilkins; 2007:411-8.

65. Carbone PP, Kaplan HS, Husshoff K, et al. Report of the committee on Hodgkin's disease staging classification. Cancer Res. 1971;31:1860-1.

66. Gobbi PG, Cavall C, Gendarini A, Crema A, Ricevuti G, Federico M, Prisco U, Ascari E. Reevaluation of prognostic significance of symptoms in Hodgkin's disease. Cancer. 1985;56:2874-80.

67. Abate G, Corazzelli G, Ciarmiello A, Monfardini S. Neurologic complications of Hodgkin's disease: a case history. Ann Oncol. 1997;8:593-600.

68. Hasenclever D, Diehl V. A Prognostic Score for Advanced Hodgkin's Disease. N Engl J Med. 1998;399:1506-14.

69. Brown RJK, Meynell MJ. Hemolytic Anemia associated with Hodgkin's Disease. Lancet. 1949;254:835-6. 
70. Rosenberg SA. Report of the committee on the staging of Hodgkin's disease. Cancer Res. 1966;26:1310.

71. Lister TA, Crowther D, Sutcliffe SB, Glatstein E, Canellos GP, Young RC, Rosenberg SA, Coltman CA, Tubiana M. Report of a committee convened to discuss the evaluation and staging of patients with Hodgkin 's disease: Cotswolds meeting. J Clin Oncol. 1989;7:1630-6.

72. Specht L, Hasenclever D. Prognostic factors in Hodgkin Lymphoma. In: Hodgkin Lymphoma. 2a ed. Philadelphia: Lippincott Williams \& Wilkins; 2007:157-74.

73. Schellong G. Pediatric Hodgkin's disease: Treatment in the late 1990's. Ann Oncol. 1998;9(suppl.5):S115-9.

74. Bonadonna G, Bonfante V, Viviani S, Di Russo A, Villani F, Valagussa P. ABVD plus subtotal nodal versus involved-field radiotherapy in earlystage Hodgkin's disease: long-term results. J Clin Oncol. 2004;22:283541.

75. Foltz L, Song K, Connors J. Hodgkin's Lymphoma in adolescents. J Clin Oncol. 2006,24:2520-5. 
76. Dihel V, Thomas RK, Re D. Part II: Hodgkin's lymphoma - diagnosis and treatment. Lancet Oncol. 2004;5:19-26.

77. Lee CKK, Bloomfield CD, Goldman AI, Levitt SH. Prognostic Significance of Mediastinal Involvement in Hodgkin's Disease Treated with Curative Radiotherapy. Cancer. 1980;46:2403-9.

78. Tubiana M, Henry-Amar M., Hayat M, Burgers M, Qasim M, Somers R, Sizoo W, Van der SchuerenE. Prognostic significance of the number of involved areas in the early stages of Hodgkin's disease. Cancer. 1984;54:885-94.

79. Gobbi PG, Ghiradelli ML, Salcia M, Giulio G, Merli F, Tavercchia L, Bertè R, Davini O, Levis A, Broglia C, Maffè GC, Ilariucci F, Dore R, Ascari E. Image-Aided estimate of tumor burden in Hodgkin's disease: evidence of its primary prognostic importance. J Clin Oncol. 2001;19:1388-94.

80. Smith RS, Chen Q, Hudson MM, Link MP, Kin L, Weinstein H, Billett A, Marcus KJ, Tarbell NJ, Donaldson SS. Prognostic factors for children with Hodgkin's disease treated with combined-modality therapy. J Clin Oncol. 2003;21:2026-33. 
81. Hudson MM, Constine LS. Hodgkin's Disease. In: Halperin EC, Constine LS, Tarbell NJ, Kun LE. Pediatric Radiation Oncology. 4a ed. Philadelphia: Lippincott Williams \& Wilkins; 2005: 223-59.

82. Yahalom J, Hoppe RT, Mauch PM. Principles and techniques of radiation therapy for Hodgkin Lymphoma. In: Hodgkin Lymphoma. 2a ed. Philadelphia: Lippincott Williams \& Wilkins; 2007:177-88.

83. Olson MR, Donaldson SS. Treatment of pediatric Hodgkin lymphoma. Curr Treat Options Oncol. 2008;9:81-94.

84. Donaldson SS, Kaplan HS. Complications of treatment of Hodgkin's disease in children. Cancer Treat Rep. 1982;66:977-89.

85. Mauch PM, Weinstein H, Botnick L, Belli J, Cassady JR. An evaluation of long-term survival and treatment complications in children with Hodgkin's disease. Cancer. 1983;51:925-32.

86. Hodgson DC, Hudson MM, Constine LS. Pediatric Hodgkin Lymphoma: Maximizing Efficacy and Minimizing Toxicity. Semin Radiat Oncol. 2007;17:230-42.

87. Goodman LS, Wintrobe MM, Dameshek W, Goodman MJ, Gilman MA, McLennan MT. Nitrogen mustard therapy: use of methyl-bis- 
(chloroethyl)amine hydrochloride for Hodgkin's disease, lymphosarcoma, leukemia and certain allied and miscellaneous disorders. JAMA. $1946 ; 132: 126-31$.

88. De Vita VTJ, Canellos G, Moxley J. A decade of combination chemotherapy of advanced Hodgkin's disease. Cancer. 1972;30:1495504.

89. Bonadonna G, Zucali R, Monfardini S, De Lena M, Uslenghi C. Combination chemotherapy of Hodgkin's disease with adriamycin, bleomycin, vinblastine and imidazole carboxamide versus MOPP. Cancer. 1975;36:252-9.

90. Zittoun R, Audebert A, Hoerni B, Bernadou A, Krulik M, Rojouan J, Eghbali H, Merle-Béral H, Parlier Y, Diebold J, Grellet J, Laugier A, Debray J. Extended versus involved fields irradiation combined with MOPP chemotherapy in early clinical stages of Hodgkin's disease. J Clin Oncol. 1985;3:207-14.

91. Lanzkowsky P, Shende A, Karayalcin G, Aral I. Staging laparotomy and splenectomy: Treatment and complications of hodgkin's disease in children. Am J Hematol. 1976,1:393-404. 
92. Donaldson SS, Glatstein E, Vosti KL. Bacterial infections in pediatric Hodgkin's disease. Cancer. 1978;41:1949-58.

93. Straus D. Treatment of early-stage nonbulky Hodgkin Lymphoma. Curr Opin Oncol. 2006;18:432-6.

94. Santoro VA, Bellani FF, Franchi F, Banfi A, Bonadonna G. Absence of treatment-induced second neoplasms after ABVD in Hodgkin's Disease. Blood. 1982;59:488-94.

95. Sleijfer S. Bleomycin-induced pneumonitis. Chest. 2001;120:617-24.

96. Hull MC, Morris CG, Pepine CJ, Mendenhall NP. Valvular dysfunction and carotid subclavian, and coronary artery disease in survivors of Hodgkin lymphoma treated with radiation therapy. JAMA. 2003;290:28317.

97. Kung FH. Hodgkin's disease in children 4 years of age or younger. Cancer. 1991;67:1428-30.

98. Thomas R, Re D, Zander T, Wolf J, Diehl V. Epidemiology and etiology of Hodgkin's lymphoma. Ann Oncol. 2002;13(suppl.4):147-52.

99. Cordeiro BPV, Felipe CFP, Noronha CP, Ramos DN, Cabral ESC, Ferreira JMO, Oliveira JFP, Santos MO, Costa MCE, Rebelo MS, Reis 
RS (editores). Estimativa 2010 - Incidência de câncer no Brasil - INCA. Instituto Nacional de Câncer/ Ministério da Saúde; 2009. Acessado em 07 de dezembro de 2009. Disponível em http://www1.inca.gov.br/estimativa/2010/.

100. Ries LAG, Smith MA, Gurney JG, Linet M, Tamra T, Young JL, Bunin GR (editores). Cancer incidence and survival among children and adolescents: United States SEER Program 1975-1995 [monograph on the internet]. Bethesda: National Cancer Institute; 1999. Acessado em 07 de dezembro de 2009. Disponível em: http://seer.cancer.gov/publications/ childhood/.

101. Elgui de Oliveira D, Bacchi MM, Abreu ES, Niero-Melo L, Bacchi CE. Hodgkin Disease in adult and juvenile groups from two different geographic regions in Brazil. Am J Clin Pathol. 2002;118:25-30.

102. Loureiro MM, Morais JC, Milito CB, Portugal RD, Pulcheri W, Spector N. Expression of Epstein-Barr virus in patients with Hodgkin's disease: report of 64 cases from Rio de Janeiro, Brazil. J Bras Pathol Med Lab. 2004;40:37-40.

103. Claviez A, Tiemann M, Lüders H, Krams M, Parwaresch R, Schellong G, Dörffel W. Impact of latent Epstein Barr Virus infection on outcome in 
children and adolescents with Hodgkin's Lymphoma. J Clin Oncol. 2005;23:4048-56.

104. Hudson MM, Krasin M, Link MP, Donaldson SS, Billups C, Merchant TE, Kun L, Billet AL, Kaste S, Tarbell NJ, Howard S, Friedmann AM, Hurwitz CA, Young JA, Marcus KC, Rai S, Cowan T, Weinstein HJ. Risk-adapted, combined-modality therapy with VAMP/COP and response-based, involved-field radiation for unfavorable pediatric Hodgkin's disease. J Clin Oncol. 2004;22:4541-50.

105. Dihel, V. Advanced Hodgkin's Disease: ABVD is better yet is not good enough! J Clin Oncol. 2003;21:583-5.

106. Laskar S, Gupta R, Vimal S, Muckaden MA, Saikia TK, Pai SK, Naresh $\mathrm{KN}$, Dubshaw KA. Consolidation radiation after complete remission in Hodgkin's disease following six cycles of doxorrubicin, bleomycin, vinblastine, and dacarbazine chemotherapy: is there a need? J Clin Oncol. 2004;22:62-8.

107. Meyer RM, Gospodarowicz MK, Connors JM, et al. Randomized comparison of ABVD chemotherapy with strategy that includes radiation therapy in patients with limited-stage Hodgkin's lymphoma: National 
Cancer Institute of Canada Clinical Trials Group and the Eastern Cooperative Oncology Group. J Clin Oncol. 2005;23:4634-42.

108. Donaldson S, Hudson M, Lamborn K. VAMP and low-dose involved-field radiation for children and adolescents with favorable, early-stage Hodgkin 's disease: results of a prospective clinical trial. $J$ Clin Oncol. 2002;20:3081-7.

109. Friedmann $A$, Hudson $M$, Weinstein $H$. Treatment of unfavorable childhood Hodgkin's disease with VEPA and low-dose, involved-field radiation. J Clin Oncol. 2002;20:3088-94.

110. Kelly KM, Hutchinson RJ, Weiner MA, Lones MA, Perkins SL, Massey V, Cohen R. Feasibility of upfront dose-intensive chemotherapy in children with advanced-stage Hodgkin's lymphoma: preliminary results from the Children's Cancer Group Study CCG-59704. Ann Oncol. 2002;13(Suppl1):107-11.

111. DiehI V, Franklin J, Pfreundschuh M, Lathan B, Paulus U, Hasenclever D, Tesch H, Herrmann R, Dörken B, Müller-Hermelink HK, Dühmke E, Loeffler M. Standard and increased-dose BEACOPP chemotherapy compared with COPP-ABVD for advanced Hodgkin's disease. $N$ Eng $J$ Med. 2003;348:2386-95. 
112. Horning SJ. Risk, cure and complications in advanced Hodgkin disease. Hematology. 2007;197-203.

113. Engert A, Diehl V, Franklin J, Lohri A, Dörken B, Ludwig VD, Koch P, Hänel M, Pfreundschuh M, Wilhelm M, Trümper L, Aulitzky WE, Bentz M, Rummel M, Sezer O, Müller-Hermelink HK, Hasenclever D, Löffler M. Escalated-Dose BEACOPP in the treatment of patients with advancedstage Hodgkin's Lymphoma: 10 years of follow-up of the GHSG HD9 study. J Clin Oncol. 2009;27:4548-54.

114. Engert A, Dreyling M. Hodgkin's lymphoma: ESMO Clinical Recommendations for diagnosis, treatment and follow-up. Ann Oncol. 2008;19(Suppl 2):ii65-6.

115. Engert A, Schiller $P$, Josting $A$, Herrmann $R$, Koch $P$, Sieber $M$, Boissevain F, De Wit M, Mezger J, Dühmke E, Willich N, Müller RP, Schmidt BF, Renner H, Müller-Hermelink HK, Pfistner B, Wolf J, Hasenclever D, Löffler M, Diehl V. Involved-field radiotherapy is equally effective and less toxic compared with extended-field radiotherapy after four cycles of Chemotherapy in patients with early-stage unfavorable 
Hodgkin's lymphoma: results of the HD8 trial of German Hodgkin's lymphoma study group. J Clin Oncol. 2003;19:3601-8.

116. Fermé C, Eghbali H, Meerwaldt JH, Rieux C, Bosq J, Berger F, Girinsky T, brice P, van't Veer MB, Walewski JA, Lederlin P, Tirelli U, Carde P, Neste EVD, Gyan E, Monconduit M, Diviné M, Raemaekers JMM, Salles G, Noordijk EM, Creemers GJ, Gabarre J, Hagenbeek A, Reman O, Blanc M, Thomas J, Vié B, Kluin-Nelemans JC, Viseu G, Baars JW, Poortmans P, Lugtenburg PJ, Carrie C, Jaubert J, Henry-Amar M. Chemotherapy plus involved-field radiation in early-stage Hodgkin's disease. N Engl J Med. 2007;357:1916-27.

117. Straus DJ, Portlock CS, Qin J, et al. Results of a prospective randomized clinical trial of doxorrubicin, bleomycin, vinblastine and dacarbazine (ABVD) followed by radiation therapy (RT) versus $A B V D$ alone for stages I, II, and III A nonbulky Hodgkin disease. Blood. 2004;104:3483-9.

118. Meyer RM, Gospodarowicz MK, Connors JM, et al. Randomized comparison of $A B V D$ chemotherapy with strategy that includes radiation therapy in patients with limited-stage Hodgkin's lymphoma: National Cancer Institute of Canada Clinical Trials Group and the Eastern Cooperative Oncology Group. J Clin Oncol. 2005;23:4634-42. 
119. Nachman J, Sposto R, Herzog P, et al. Randomized comparison of lowdose involved-field radiotherapy and no radiotherapy for children with Hodgkin's disease who achieve a complete response to chemotherapy. $J$ Clin Oncol. 2002;20:3765-71.

120. Josting A, Nogová L, Franklin J, Glossmann JP, Eich HT, Sieber M, Schober T, Boettcher HD, Schulz U, Müller RP, Diehl B, Engert A. Salvage radiotherapy in patients with relapsed and refractory Hodgkin's lymphoma: a retrospective analysis from the German Hodgkin Lymphoma Study Group. J Clin Oncol. 2005;23:1522-9.

121. Brämswig JH, Heimes U, Heiermann E, Schlegel W, Nieschlag E, Schellong G. The effects of different cumulative doses of chemotherapy on testicular function. Cancer. 1990;65:1298-302.

122. Duggan DB, Petroni GR, Johnson JL, Glick JH, Fisher RI, Connors JM, Canellos GP, Peterson BA. Randomized comparison of ABVD and MOPP/ABV hybrid for the treatment of advanced Hodgkin's disease: report of an intergroup trial. J Clin Oncol. 2003;21:607-14. 
123. Barry EV, Lipshultz SE, Sallan SE. Anthracycline-induced cardiotoxicity: Natural history, risk factors, and prevention. In: ASCO Spring Educational Book. U.S.A.: American Society of Clinical Oncology; 2008:448-53.

124. Sklar C, Whitton J, Mertens A, Stovall M, Green D, Marina N, Greffe B, Wolden S, Robison L. Abnormalities of the thyroid in survivors of Hodgkin's disease: data from the childhood cancer survivor study. J Clin Endocrinol Metab. 2000;85:3227-32.

125. Constine LS, Donaldson SS, McDougall R. Cox RS, Link MP, Kaplan HS. Thyroid dysfunction after radiotherapy in children with Hodgkin's disease. Cancer. 1984;53:878-83.

126. Tucker MA, Morris Jones PH, Boice Jr. JD, Robison LL, Stone BJ, Stovall M, Jenkin RDT, Lubin JH, Baum ES, Siegel SE, Meadows AT, Hoover $\mathrm{RN}$, Fraumeni JF. Therapeutic radiation at a young age is linked to secondary thyroid cancer. Cancer Res. 1991;51:2885-8.

127. Lin HMJ, Teitell MA. Second malignancy after treatment of pediatric Hodgkin disease. J Pediatr Hematol Oncol. 2005;27:28-36.

128. van Leeuwen FE, Klokman WJ, Veer MB, et al. Long-term risk of second malignancy in survivors of Hodgkin's disease treated during adolescence or young adulthood. J Clin Oncol. 2000;18:487-97. 
129. Kenney LB, Yasul Y, Inskip PD, Hammond S, Neglia JP, Mertens AC, Meadows AT, Friedman D, Robison LL, Diller L. Breast cancer after childhood cancer: a report from the Childhood Cancer Survivor Study. Ann Intern Med. 2004;141:590-7.

130. Metayer C, Lynch C, Clarke A. Second Cancer among long-term survivors of Hodgkin's disease diagnosed in childhood and adolescence. J Clin Oncol. 2000;18:2435-43. 